\title{
Interventions for sexual dysfunction following treatments for cancer in women (Review)
}

\author{
Candy B, Jones L, Vickerstaff V, Tookman A, King M
}

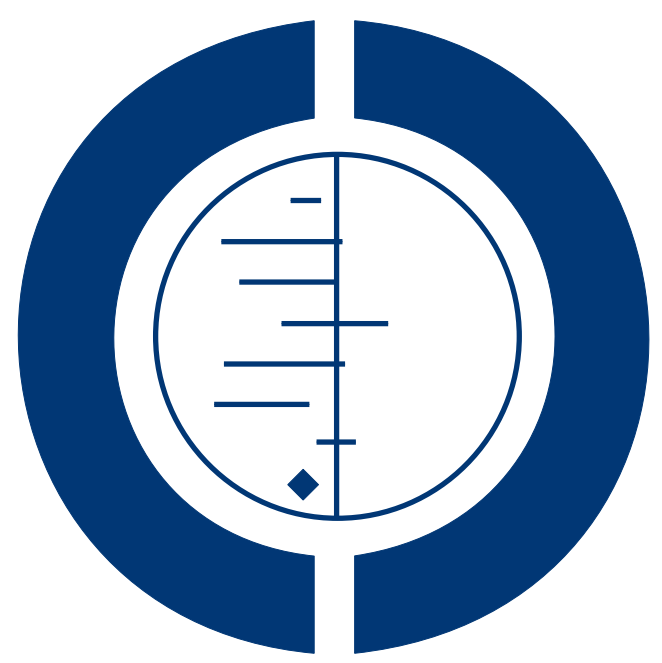

\section{THE COCHRANE COLLABORATION $^{\circledR}$}

This is a reprint of a Cochrane review, prepared and maintained by The Cochrane Collaboration and published in The Cochrane Library 2016, Issue 2

http://www.thecochranelibrary.com

\section{WILEY}

Interventions for sexual dysfunction following treatments for cancer in women (Review)

Copyright $\odot 2016$ The Cochrane Collaboration. Published by John Wiley \& Sons, Ltd. 
TABLE OF CONTENTS

HEADER . . . . . . . . . . . . . . . . . . . . . . . . . . . . . . . . . . . . . . . 1

ABSTRACT . . . . . . . . . . . . . . . . . . . . . . . . . . . . . . . . . . . . . . . . . . . . . . .

PLAIN LANGUAGE SUMMARY . . . . . . . . . . . . . . . . . . . . . . . . . . . . . . . . . . . 2

BACKGROUND . . . . . . . . . . . . . . . . . . . . . . . . . . . . . . . . . . . . . .

OBJECTIVES . . . . . . . . . . . . . . . . . . . . . . . . . . . . . . . . . . . . . . . . 44

METHODS . . . . . . . . . . . . . . . . . . . . . . . . . . . . . . . . . . . . . . . . .

RESULTS . . . . . . . . . . . . . . . . . . . . . . . . . . . . . . . . . . . . . . . 8

Figure 1. . . . . . . . . . . . . . . . . . . . . . . . . . . . . 9

Figure 2. . . . . . . . . . . . . . . . . . . . . . . . . . . . . . . . . . . . . . . . . . 11

Figure 3. . . . . . . . . . . . . . . . . . . . . . . . . . . . . . . . . . . . . . 12

DISCUSSION . . . . . . . . . . . . . . . . . . . . . . . . . . . . . . . . . . . . . 19

AUTHORS' CONCLUSIONS . . . . . . . . . . . . . . . . . . . . . . . . . . . . . . . . 21

ACKNOWLEDGEMENTS . . . . . . . . . . . . . . . . . . . . . . . . . . . . . . . . . . . . . .

REFERENCES . . . . . . . . . . . . . . . . . . . . . . . . . . . . . . . . . . . . . . . 21

CHARACTERISTICS OF STUDIES . . . . . . . . . . . . . . . . . . . . . . . . . . . . . . . . . . . . . . . .

DATA AND ANALYSES . . . . . . . . . . . . . . . . . . . . . . . . . . . . . . . . . . . 52

ADDITIONAL TABLES . . . . . . . . . . . . . . . . . . . . . . . . . . . . . . . . . . . 52

APPENDICES . . . . . . . . . . . . . . . . . . . . . . . . . . . . . . . . . . . 56

WHAT'S NEW . . . . . . . . . . . . . . . . . . . . . . . . . . . . . . . . . . . . . $\quad . \quad 72$

HISTORY . . . . . . . . . . . . . . . . . . . . . . . . . . . . . . . . . . . . . . . 72

CONTRIBUTIONS OF AUTHORS . . . . . . . . . . . . . . . . . . . . . . . . . . . . . . . 72

DECLARATIONS OF INTEREST . . . . . . . . . . . . . . . . . . . . . . . . . . . . . . . . 73

SOURCES OF SUPPORT . . . . . . . . . . . . . . . . . . . . . . . . . . . . . . . . . . 73

DIFFERENCES BETWEEN PROTOCOL AND REVIEW . . . . . . . . . . . . . . . . . . . . . . 73

INDEX TERMS . . . . . . . . . . . . . . . . . . . . . . . . . . . . . . . . . . . . . 73

Interventions for sexual dysfunction following treatments for cancer in women (Review)

Copyright $\odot 2016$ The Cochrane Collaboration. Published by John Wiley \& Sons, Ltd. 


\title{
[Intervention Review]
}

\section{Interventions for sexual dysfunction following treatments for cancer in women}

\author{
Bridget Candy ${ }^{1}$, Louise Jones ${ }^{1}$, Victoria Vickerstaff ${ }^{1}$, Adrian Tookman ${ }^{2}$, Michael King $^{3}$ \\ ${ }^{1}$ Marie Curie Palliative Care Research Department, UCL Division of Psychiatry, London, UK. ${ }^{2}$ Marie Curie Hospice, London, UK. \\ ${ }^{3}$ UCL Mental Health Sciences, University College Medical School, London, UK
}

Contact address: Bridget Candy, Marie Curie Palliative Care Research Department, UCL Division of Psychiatry, 6th Floor, Maple House, 149 Tottenham Court Road, London, W1T 7NF, UK. b.candy@ucl.ac.uk. bridget@metaclarity.com.

Editorial group: Cochrane Pain, Palliative and Supportive Care Group.

Publication status and date: New search for studies and content updated (conclusions changed), published in Issue 2, 2016.

Review content assessed as up-to-date: 8 September 2015.

Citation: Candy B, Jones L, Vickerstaff V, Tookman A, King M. Interventions for sexual dysfunction following treatments for cancer in women. Cochrane Database of Systematic Reviews 2016, Issue 2. Art. No.: CD005540. DOI: 10.1002/14651858.CD005540.pub3.

Copyright (C) 2016 The Cochrane Collaboration. Published by John Wiley \& Sons, Ltd.

\begin{abstract}
A B S T R A C T
Background

The proportion of people living with and surviving cancer is growing. This has led to increased awareness of the importance of quality of life, including sexual function, in those affected by cancer. Sexual dysfunction is a potential long-term complication of many cancer treatments. This includes treatments that have a direct impact on the pelvic area and genitals, and also treatments that have a more generalised (systemic) impact on sexual function.

This is an update of the original Cochrane review published in Issue 4, 2007, on interventions for treating sexual dysfunction following treatments for cancer for men and women. Since publication in 2007, there has been an increase in the number of trials for both men and women and this current review critiques only those for women. A review in press will present those for men.
\end{abstract}

Objectives

To evaluate the effectiveness of interventions for treating sexual dysfunction in women following treatments for cancer. To assess adverse events associated with interventions.

\section{Search methods}

We searched the Cochrane Central Register of Controlled Trials (CENTRAL 2015, Issue 9), MEDLINE, EMBASE, PsycINFO, AMED, CINAHL, Dissertation Abstracts and the NHS Research Register. The searches were originally run in January 2007 and we updated these to September 2015.

\section{Selection criteria}

We included randomised controlled trials (RCTs) that assessed the effectiveness of a treatment for sexual dysfunction. The trial participants were women who had developed sexual dysfunction as a consequence of a cancer treatment. We sought evaluations of interventions that were pharmaceutical, mechanical, psychotherapeutic, complementary or that involved physical exercise.

\section{Data collection and analysis}

Two review authors independently extracted the data and assessed trial quality. We considered meta-analysis for trials with comparable key characteristics.

Interventions for sexual dysfunction following treatments for cancer in women (Review)

Copyright () 2016 The Cochrane Collaboration. Published by John Wiley \& Sons, Ltd. 


\section{Main results}

Since the original version of this review we have identified 11 new studies in women. The one study identified in the earlier version of this review was excluded in this update as it did not meet our narrower inclusion criteria to include only interventions for the treatment, not prevention, of sexual dysfunction.

In total 1509 female participants were randomised across 11 trials. All trials explored interventions following treatment either for gynaecological or breast cancer. Eight trials evaluated a psychotherapeutic or psycho-educational intervention. Two trials evaluated a pharmaceutical intervention and one pelvic floor exercises. All involved heterosexual women. Eight studies were at a high risk of bias as they involved a sample of fewer than 50 participants per trial arm. The trials varied not only in intervention content but in outcome measurements, thereby restricting combined analysis. In the trials evaluating a psychotherapeutic intervention the effect on sexual dysfunction was mixed; in three trials benefit was found for some measures of sexual function and in five trials no benefit was found. Evidence from the other three trials, two on different pharmaceutical applications and one on exercise, differed and was limited by small sample sizes. Only the trial of a $\mathrm{pH}$-balanced vaginal gel found significant improvements in sexual function. The trials of pharmaceutical interventions measured harm: neither reported any. Only one psychological intervention trial reported that no harm occurred because of the intervention; the other trials of psychological support did not measure harm.

\section{Authors' conclusions}

Since the last version of this review, the new studies do not provide clear information on the impact of interventions for sexual dysfunction following treatments for cancer in women. The sexual dysfunction interventions in this review are not representative of the range that is available for women, or of the wider range of cancers in which treatments are known to increase the risk of sexual problems. Further evaluations are needed.

\section{PLAIN LANGUAGE SUMMARY}

\section{Interventions for sexual dysfunction following treatments for cancer \\ Background}

In women sexual dysfunction is a potential complication of many types of cancer treatments.

This review evaluated the effectiveness of treatments (interventions) of any kind, for example drugs or exercise, for treating sexual dysfunction in women following cancer treatment.

The review is an update of one published in 2007 that assessed the effectiveness of interventions for men and women. We decided to present this revised review separately for women because of the increase in the number of trials. Another review for men is underway.

\section{Study characteristics}

We identified 11 new trials on interventions for women in September 2015. We excluded one trial that was included in the earlier version of this review because it assessed treatment for preventing sexual dysfunction and was no longer relevant to this review. Interventions differed in their content and how the researchers measured benefit. Eight of the interventions involved psychological support such as counselling on sexual matters, or peer support. One of the others was of a testosterone cream, another tested a vaginal $\mathrm{pH}$-balanced gel and the other was of pelvic floor exercise. The findings from six of the trials are weak because they involved small numbers of women.

\section{Key results}

Across the trials the impact on sexual function was different. This makes it difficult to derive clear conclusions. For instance, in those that evaluated a psychological support treatment, four studies found that it improved some measures of sexual function but not others, but five found that it did not improve sexual function according to any of the measures used. For the other interventions tested, only the trial of the vaginal gel found improvements in sexual function and no side effects were reported. Only one of the psychological interventions reported that no harm occurred because of the intervention. The other trials of psychological support did not assess harm. This is an important gap as some women may find it distressing to discuss personal sexual problems as part of their treatment.

Further evaluations are needed for all interventions. Current studies have only explored effectiveness in women with gynaecological and breast cancers, but there is a risk of sexual problems after treatments for other cancers. New evaluations need to involve larger numbers of participants.

Interventions for sexual dysfunction following treatments for cancer in women (Review)

Copyright @ 2016 The Cochrane Collaboration. Published by John Wiley \& Sons, Ltd. 


\section{B A C K G R O U N D}

This review is an update of a previously published review in the Cochrane Database of Systematic Reviews (Issue 4, 2007) on 'Interventions for sexual dysfunction following treatments for cancer' (Miles 2007). This review presents the findings on the effectiveness and safety of interventions for sexual dysfunction in women following treatments for cancer. In its earlier version the review involved interventions for both men and women following treatments for cancer, and preventative treatments for sexual dysfunction. A separate review, in press, will report on interventions for men. Interventions for the prevention of sexual dysfunction are not included in either of these reviews.

\section{Description of the condition}

Sexual dysfunctions are characterised by a disturbance in sexual desire and in the psychological and physiological changes that characterise the sexual response (Diagnostic and Statistical Manual of Mental Disorders 5th edition (DSM-5) (DSM-5 2013)).

The DSM-5 recognises three sexual dysfunctions in women:

- sexual interest/arousal disorder;

- genitopelvic pain/penetration disorder;

- female orgasmic disorder.

Sexual dysfunction poses challenges to one's social, mental, emotional and physical wellbeing. In cancer, it is an important indicator of quality of life both in people undergoing treatments and in those surviving the disease (Ozyilkan 1995). It may occur as a result of the nature of a cancer, such as a cancer that affects the mechanics or hormonal pathways in sexual function, as a result of the treatment for cancer such as surgery, chemotherapy or radiotherapy that may have local or systemic and hormonal effects, and it may occur from the emotional trauma of receiving a diagnosis or indeed living with cancer for the patient as well as their sexual partner. The causes of sexual dysfunction following cancer treatments may be multi-factorial but it may often result from the direct effects of the treatment. A hysterectomy, for example, may disrupt the pelvic anatomy and the local nerve supplying the pelvic floor, which are part of the trunk stability mechanism involved in sexual arousal, and this may be accompanied by loss of vaginal lubrication and sensation (Jackson 2006). Other cancer treatments may affect sexual function, for example chemotherapy may induce the symptoms of menopause, in particular vaginal dryness. Sexual dysfunction following a cancer treatment may also relate to lowered physical fitness, symptoms of depression or anxiety, and changes to self esteem and feelings of sexuality (Greenwald 2008; Pignata 2001; Stead 2007; Tabano 2002; Wiggins 2008). Although some treatment-related sexual dysfunction effects are short-term, sexual dysfunction is one of the more prevalent long-term complications following many types of life-saving cancer treatment (Ananth 2003; Ganz 1998; Syrjala 1998).
Sexual dysfunction following cancer treatments is becoming an increasingly important issue to tackle. With an aging global population, improved diagnosis and better cancer treatments, more people are living with and surviving cancer. For example, the US Centers for Disease Control and Prevention estimated that the number of cancer survivors in the US increased from 3 million in 1971 to 11.6 million in 2007, and of those in 2007 the largest group of survivors in women was those with breast cancer (CDC 2011). Sexual dysfunction is a known problem for people receiving various cancer treatments, including those for cancer of the bladder (Bhatt 2006; Zippe 2004), head and neck (Low 2009; Singer 2008), and rectum (Hendren 2005; Ho 2011). However, much of the research to date on the prevalence and treatments for sexual dysfunction following cancer treatments has focused on cancer treatments that have a direct impact on the genitals or other areas of the body involved in sexual functioning. It has been estimated that $50 \%$ of women who undergo gynaecological cancer treatments suffer long-term sexual dysfunction as a result (National Cancer Institute 2012). There is also evidence for a high prevalence of sexual dysfunction following treatments for breast cancer, where in one survey it was found in $45 \%$ women (Kedde 2013), and in another survey $76 \%$ had sexual dysfunction (Goldfarb 2009). A review found that the incidence of sexual dysfunction in women following radical rectal cancer resection varied from $19 \%$ to $62 \%$ (Cowan 2013).

Despite recognition of the problem, sexual morbidity remains under-treated in this patient group (Hill 2011). This is, in part, because of the embarrassment associated with sexual dysfunction not only from the patient's point-of-view but from that of clinicians (Dening 2013). In addition, sexual interest/arousal disorders in general may be under-recognised (Montgomery 2008).

\section{Description of the intervention}

There are various types of interventions available for the treatment of sexual dysfunction in women, these include:

- complementary and alternative medicine interventions such as the herbal therapies ginkgo and ginseng;

- exercises to strengthen the pelvic floor;

- mechanical interventions such as lubricating gels and clitoral therapy devices;

- pharmacological interventions including hormonal therapies such as testosterone or oestrogen (these may be applied topically or taken orally);

- psychotherapeutic and psycho-educational interventions such as counselling or psychotherapy, which aim to reduce the sexual dysfunction as well as improve the patient's communication skills with their sexual partner. Psychotherapeutic interventions may be combined with education to facilitate an understanding of treatment and it effects. 
The range of interventions is in part explained by the range of causes of sexual dysfunction, but also because it is known that the appropriateness, effectiveness and suitability of each intervention vary between individual patients.

\section{How the intervention might work}

The various types of interventions work in different as well as complex ways, with some mechanisms of action poorly understood. We briefly consider the mechanisms of action according to the following groupings.

\section{Complementary and alternative medicine}

There are various complementary and alternative medicines that are used to try to enhance sexual function. Their mechanisms of action are often unknown. Maca is an Andean plant belonging to the mustard family and it has been used for centuries to enhance fertility (Shin 2010). Maca is also reported to improve sexual function in healthy human populations (Gonzales 2003). Ginkgo biloba has been evaluated for depression-induced sexual dysfunction (Cohen 1998).

\section{Exercises to strengthen the pelvic floor}

Pelvic floor muscles give structural support to the pelvic organs (urethra, vagina and rectum). Pelvic floor dysfunction may be a direct outcome of gynaecological cancers and various cancer treatments. For example, radical hysterectomy and radiotherapy of the pelvic area may disrupt the anatomy and the local nerve supply to the pelvic floor muscles (Jackson 2006). This disruption may lead to urinary continence and a lack of sexual arousal. Pelvic floor exercises may reduce these problems by increasing muscle tone.

\section{Mechanical}

There are various mechanical devices for sexual dysfunction. In women a clitoral therapy device such as a hand-held battery powered vacuum creates a gentle suction to engorge the clitoris blood flow and thereby increase sensation (Schroder 2005).

\section{Pharmacological}

The relationship between endogenous testosterone levels and sexual function in women has not been clearly established. However, testosterone therapy has been found to improve the signs and symptoms of hypoactive sexual desire (Hubayter 2008). Exogenous oestrogen will increase vaginal blood flow and lubrication, and oestrogen therapy has been shown to improve clitoral sensitivity and the ability to reach orgasm (Berman 1999).

\section{Psychotherapeutic and psycho-educational}

Although evidence for the effectiveness of psychotherapeutic interventions is limited, the role of psychological processes in sexual function is acknowledged (Kazdin 2009). Normal sexual function is a biopsychosocial process that relies on the co-ordination of not only endocrine, vascular and neurological factors but also psychological factors (Allahdadi 2009). Treatment of sexual dysfunction in women with a psychotherapeutic intervention is a common approach in clinical practice (Berner 2012). There are a number of psychotherapy approaches including cognitive behaviour therapy, counselling and relationship therapy. Some interventions may include educational aspects, such as a discussion on the value of intimate communication with sexual partner and advice on vaginal lubrication.

\section{Why it is important to do this review}

Trials evaluating the effectiveness of treatments for sexual dysfunction often exclude patients with other major health problems, such as cancer. As cancer and its treatments disrupt physiological and anatomical integrity, it is not possible to simply extrapolate the results of these trials into the cancer field.

With the world's aging population, and improved diagnosis and better cancer treatments, more people are living with and surviving cancer. It is recognised that sexual morbidity is a major cause of poor quality of life. A growing number of treatments are being developed and evaluated; it is important to review their efficacy, safety and acceptability. This review is an update of an earlier Cochrane review on interventions for sexual dysfunction following treatments for cancer in men and women (Miles 2007). Since its publication many more trials have been undertaken. In light of this growth we have split this review. In this current update we evaluate only interventions for women. The update on interventions for men will be reported elsewhere in a new review.

\section{O B J E C T I VES}

- To evaluate the effectiveness of interventions for treating sexual dysfunction in women following treatments for cancer.

- To assess adverse events associated with interventions.

\section{METHOD S}

\section{Criteria for considering studies for this review}

\section{Types of studies}


We only included randomised controlled trials (RCTs). Published trials that were provided in full rather than in abstract only (such as a conference abstract) were eligible. There was no language restriction. In the case of cross-over trials, we only reported the first period results (if available) in this review in order to exclude any carry-over effect. Trials undertaken in any care setting, including hospital and community, were eligible.

\section{Types of participants}

Trial participants were women (aged 16 years or over), receiving any active treatment for any cancer or who had previously received any treatment for cancer. Participants must have been functioning sexually with a partner prior to cancer treatment. Participants at the start of the trial needed to have experienced any type of sexual dysfunction (however identified) subsequent to cancer treatment. If participants were not required for trial inclusion to have sexual dysfunction subsequent to cancer treatment, we included the study if it reported:

- $50 \%$ or more having sexual dysfunction following treatment;

- subgroup analysis on those with documented sexual dysfunction subsequent to cancer treatment;

- mean/average score in both trial arms at early measurement post-treatment indicating a level of sexual dysfunction.

We did not use the DSM-5 criterion that the duration of the sexual dysfunction had to be at least six months. We felt that this may not be relevant in this patient group as a significant proportion may have advanced disease with a prognosis of less than six months.

\section{Types of interventions}

We included evaluations of any type of intervention for treating sexual dysfunction following a treatment for cancer. These included pharmacological, mechanical, psychotherapeutic and psycho-educational, complementary medicine or exercise. The intervention for sexual dysfunction could be compared with a placebo, usual care or another active treatment.

We did not include trials of preventative strategies to refine the cancer treatment, such as peritoneal vaginoplasty in combination with a radical hysterectomy.

For this update, we only included studies of interventions for the treatment of sexual dysfunction in women, not the prevention of sexual dysfunction.

\section{Types of outcome measures}

\section{Primary outcomes}

The primary outcomes of interest were efficacy in regards to improved sexual function, quality of life and safety. We evaluated efficacy using the following outcomes:
- the proportion of participants within each trial arm with improved sexual function;

- mean scores on standardised sexual function questionnaires; these included the Female Sexual Function Index (FSFI), which involves 19 items yielding an overall sexual function score in addition to subscale scores for sexual desire, arousal, lubrication, orgasm and satisfaction (Rosen 2000);

- mean scores on standardised quality of life measures including the Quality of Marriage Index, which involves six items of marital quality (Norton 1983).

We evaluated safety using the following outcomes:

- number and type of adverse effects;

- number of participants who dropped out due to adverse effects.

\section{Secondary outcomes}

The secondary outcomes of interest were efficacy in regards to psychological and physiological functioning, and symptoms of disease.

We reported measured outcomes on sexual dysfunction relating to the patient's sexual partner.

\section{Exclusion criteria}

We did not include data from observational cohort or cross-sectional studies, nor RCTs evaluating the effectiveness of preventative measures such as breast reconstruction, or avoidance of one particular therapy. We did not include studies comprising of healthy volunteers or patients who reported sexual dysfunction subsequent to non-cancer treatments.

\section{Search methods for identification of studies}

\section{Electronic searches}

In the original review we searched for interventions for both men and women (Miles 2007). In this review we also planned to review interventions for both men and women. It was the high number of relevant studies found from these update searches which led us, to permit timely completion, to split the review into one on interventions for sexual dysfunction following treatments for cancer in women, and one on interventions for sexual dysfunction following treatments for cancer in men.

We searched the following electronic databases irrespective of language and publication status for the 2015 update:

- Cochrane Central Register of Controlled Trials

(CENTRAL 2015, Issue 9);

- MEDLINE (1966 to August 2015);

- EMBASE (1980 to September 2015);

- PsycINFO (1966 to September 2015); 
- AMED (1985 to August 2015);

- CINAHL (1966 to September 2015);

- National Health Service Research Register (containing the Medical Research Council Directory) (1990 to January 2007);

- metaRegister of controlled trials ( $m$ RCT) (www.controlledtrials.com/mrct), ClinicalTrials.gov (www.clinicaltrials.gov) and the World Health Organization (WHO) International Clinical Trials Registry Platform (ICTRP) (http://apps.who.int/ trialsearch/) to September 2015.

Please see Appendix 1 for search strategies.

\section{Searching other resources}

We checked for further relevant trials via the reference lists and undertook forward citation tracking for included trials. We also checked for further relevant trials via the reference lists of any related reviews.

\section{Data collection and analysis}

Two authors (BC, LJ) screened the keywords and abstracts of electronic citations. Where they appeared to be relevant, we obtained the full texts.

\section{Selection of studies}

Following screening, two review authors (BC, LJ) assessed the full text of potentially eligible citations for inclusion. If differences of opinion had arisen we planned to discuss this with the other review authors (VV, MK and AT) and if resolution had been difficult, we planned to attempt to contact the study authors for clarification. We documented studies excluded after full-text assessment, giving reasons for exclusion.

\section{Data extraction and management}

We designed a data extraction form for this review. Where possible, we extracted the following information for each trial.

- Methods: trial design, duration, allocation method, masking and care setting.

- Aim and inclusion criteria.

- The number of patients eligible, the number randomised and reasons why any patients were not included in the trial.

- The number of participants evaluated at follow-up(s), reasons for loss to follow-up and how the trials, if stated, handled deviations from randomised allocation and missing response.

- Participant characteristics: their age, gender, cancer and treatment, and measure of sexual function at baseline.

- Content of the intervention including who delivered it, duration and number of sessions and the mode of delivery (including whether it was conducted with individuals or in a group setting). We also report whether the content of the intervention was standardised by the use of a manual.

- Comparison intervention including content, duration and mode of delivery.

- Outcome data at the end of treatment and at the end of follow-up, including how it was measured. We extracted details on all outcomes on which authors collected measurements but only provide details in our results of those relevant to this review, specifically on sexual function, quality of life and safety, and of psychological and physiological functioning and symptoms of disease. We extracted, as appropriate, all outcome data on our outcomes of interest if they were reported in the trial papers. These included baseline scores, change scores and scores at follow-up between the trial arms.

- We also planned to extract any qualitative evidence in the included studies, such as analysis of participants' views on the value of the intervention.

Where information was lacking, we attempted to contact the trial authors or trial sponsors.

Two review authors (BC/VV) independently extracted data. One author (BC) entered the extracted data into Review Manager 2014 and a second author checked the data; specifically LJ checked entries on trial description and VV checked entries on trial findings. If there had been any discrepancies, the other review authors would have been consulted and discrepancy resolved by consensus.

\section{Assessment of risk of bias in included studies}

Two authors independently assessed risk of bias for each study using the criteria outlined in the Cochrane Handbook for Systematic Reviews of Interventions, resolving any disagreements by discussion (Higgins 2011). We completed a 'Risk of bias' table for each included study. We assessed the following for each study.

- Random sequence generation (checking for possible selection bias). We assessed the method used to generate the allocation sequence as: low risk of bias (any truly random process: random number table; computer random number generator); and unclear risk of bias (method used to generate sequence not clearly stated). We excluded studies using a nonrandom process, which were therefore at high risk of bias (odd or even date of birth; hospital or clinic record number).

- Allocation concealment (checking for possible selection bias). The method used to conceal allocation to interventions before assignment determines whether the intervention allocation could have been foreseen in advance of, or during, recruitment, or changed after assignment. We assessed the methods as: low risk of bias (telephone or central randomisation; consecutively numbered, sealed, opaque envelopes); and unclear risk of bias if the method was not clearly stated. We excluded studies that did not conceal allocation, which were therefore at high risk of bias (open list). 
- Blinding of participants and personnel (performance bias). We assessed the methods used to blind study participants and outcome assessors from knowledge of which intervention a participant received. We assessed the methods as: low risk of bias if the study stated that it was blinded and described the method used to achieve blinding: identical tablets, matched in appearance and smell; and unclear risk of bias if the study stated that it was blinded but did not provide an adequate description of how blinding was achieved. We judged a study as high risk if there was no blinding or incomplete blinding, and the outcome was likely to have been influenced by lack of blinding. We also judged a study as high risk if blinding was attempted but it was likely that the blinding could have been broken and the outcome was likely to be influenced by lack of blinding.

- Incomplete outcome data (attrition bias). We assessed whether there was attrition bias due to the amount, nature or handling of incomplete outcome data. We judged the study as having low risk of attrition bias if there were no missing outcome data or the reasons for missing data were unlikely to be related to true outcome, or missing data and reasons for it were similar across trial arms, or the missing data had been imputed using appropriate methods. We judged the study as high risk if the reason for missing outcome data was likely to be related to the outcome, with either imbalance across trial arms in numbers of reasons for missing data and if an inappropriate application of simple imputation was potentially used. We judged the study as unclear risk if there was insufficient reporting of attrition to permit judgement of low or high risk.

- Sample size (checking for possible biases confounded by small size). Small studies have been shown to overestimate treatment effects, probably because the conduct of small studies is more likely to be less rigorous, allowing critical criteria to be compromised (Zhang 2013). We considered studies to be at low risk of bias if they had 200 participants or more, at unclear risk if they had 50 to 200 participants, and at high risk if they had fewer than 50 participants.

- Selective outcome reporting (checking if there was a selection of a subset of the original variables recorded on the basis of the results). We assessed selective outcome reporting, if a protocol was available, by comparing outcomes in the protocol and published report. If they were the same we assessed it as low risk in this domain, if they differed we considered it as high risk. If a protocol was not available, then we compared the outcomes listed in the methods section of an article with the outcomes for which results were reported. If they differed we considered the study as high risk. If a protocol was not available and even though the outcomes listed in the methods section and the results section were the same, we considered the study as having an unclear risk of bias in this domain.

We incorporated the results of the 'Risk of bias' assessment into the review through systematic narrative description and commentary about each item.

\section{Measures of treatment effect}

Treatment effects were measured using dichotomous data or ordinal rating scales.

\section{Dichotomous data}

Where dichotomous data were reported (if data were available) we planned to extract or generate odds ratios (ORs) and their 95\% confidence intervals (CIs) where appropriate.

\section{Continuous data}

We assessed effect measures for ordinal data as continuous data. Where continuous data were reported, we planned to extract or generate the mean difference (MD) from the means and standard deviations.

\section{Unit of analysis issues}

For any identified cluster-randomised controlled trials we planned to check for errors in the unit of analysis and, if errors were found and sufficient data were available, to recalculate the results using the appropriate unit of analysis (Higgins 2011). For data arising from RCTs with a cross-over design, if available, we planned to use in any combined analysis only data from the first comparative phase prior to cross-over. This decision was based on the possibility of a 'carry-over' of treatment effect from the experimental or comparative treatment.

\section{Dealing with missing data}

Missing studies can result from an inadequate search for data or from publication bias in that papers with negative findings are less likely to be published. How we dealt with this is detailed in Search methods for identification of studies and in Assessment of reporting biases.

We anticipated finding a significant amount of loss to follow-up in this review. This was due either to the patient's declining health and the caregiver's need for more time with their loved one, or because of the death of the patient. We report attrition rates, per trial, in the 'Risk of bias' tables (see Characteristics of included studies). This included, if available, per trial arm reasons for attrition, and whether the trial analysis entailed any re-inclusions. We did not undertake any imputation for missing participant data.

A common item missing in outcome data is the standard deviation for continuous outcomes. Where data were not reported, but might be available, we attempted to contact the study authors. We attempted contact with them up to two times. If contact with the author was not possible, we planned to calculate or impute this using relevant data, only if a minority of the trials (to be combined in a meta-analysis) had a missing standard deviation (Higgins 2008). If we had undertaken such imputation we planned to perform sensitivity analyses to assess its impact on combined analysis. 
We did not exclude trials on the basis of missing data. In the Discussion section we address the potential impact of missing data on the findings of the review.

\section{Assessment of heterogeneity}

If meta-analysis had been possible, we would have assessed statistical heterogeneity between trials using the $\mathrm{Chi}^{2}$ test and $\mathrm{I}^{2}$ statistic (a Chi ${ }^{2} \mathrm{P}$ value of less than 0.05 or an $\mathrm{I}^{2}$ value equal to or more than $50 \%$ is considered to indicate substantial heterogeneity). If substantial heterogeneity was identified, we planned to undertake subgroup analyses to investigate its possible sources.

\section{Assessment of reporting biases}

If meta-analysis had been possible we would have sought to explore publication bias visually using funnel plots. In our interpretation of the plots we planned to use the Cochrane Handbook for Systematic Reviews of Interventions (Higgins 2011).

\section{Data synthesis}

For any combined analysis that had been possible, as the patient populations were quite variable in age and treatments (as were the interventions), we would have employed random-effects metaanalyses.

\section{Subgroup analysis and investigation of heterogeneity}

Subgroup analysis explores whether the overall effect varies with different trial populations and with the nature and content of the interventions. In this update we planned the following subgroup analysis:

- trials of participants with severe sexual dysfunction;

- trials of participants with advanced cancer.

\section{Sensitivity analysis}

We planned to perform sensitivity analyses in order to explore (by excluding trials) the influence of the following factors:

- unpublished trials;

- trials with high risk of bias.

\section{RES U L T S}

\section{Description of studies}

\section{Results of the search}

In this 2015 update we searched for both interventions for men and women; two review authors independently screened $85 \%$ of 4218 citations identified. Thirty studies evaluating interventions for women appeared to be relevant at citation assessment. At full-text assessment, 11 studies were eligible (Aktas 2015; Barton 2007; Baucom 2009; Classen 2013; Lee 2011; Marcus 2010; Rowland 2009; Schover 2011; Schover 2013; Svensk 2009; Yang 2012). We found two further articles at full-text assessment that related to studies in progress (DuHamel 2013; Schofield 2013) (see Characteristics of ongoing studies) and we excluded seven further articles because they did not fulfil the inclusion criteria, as they did not report sexual outcomes or were not a RCT. Details of these studies and those excluded in the original review (and involving populations of women) are in the table Characteristics of excluded studies. We found seven studies that are awaiting classification (see Characteristics of studies awaiting classification). The interventions for men identified in this updated search are reviewed in another Cochrane review, which is in progress. The search process is documented in Figure 1. 
Figure I. Study flow diagram.

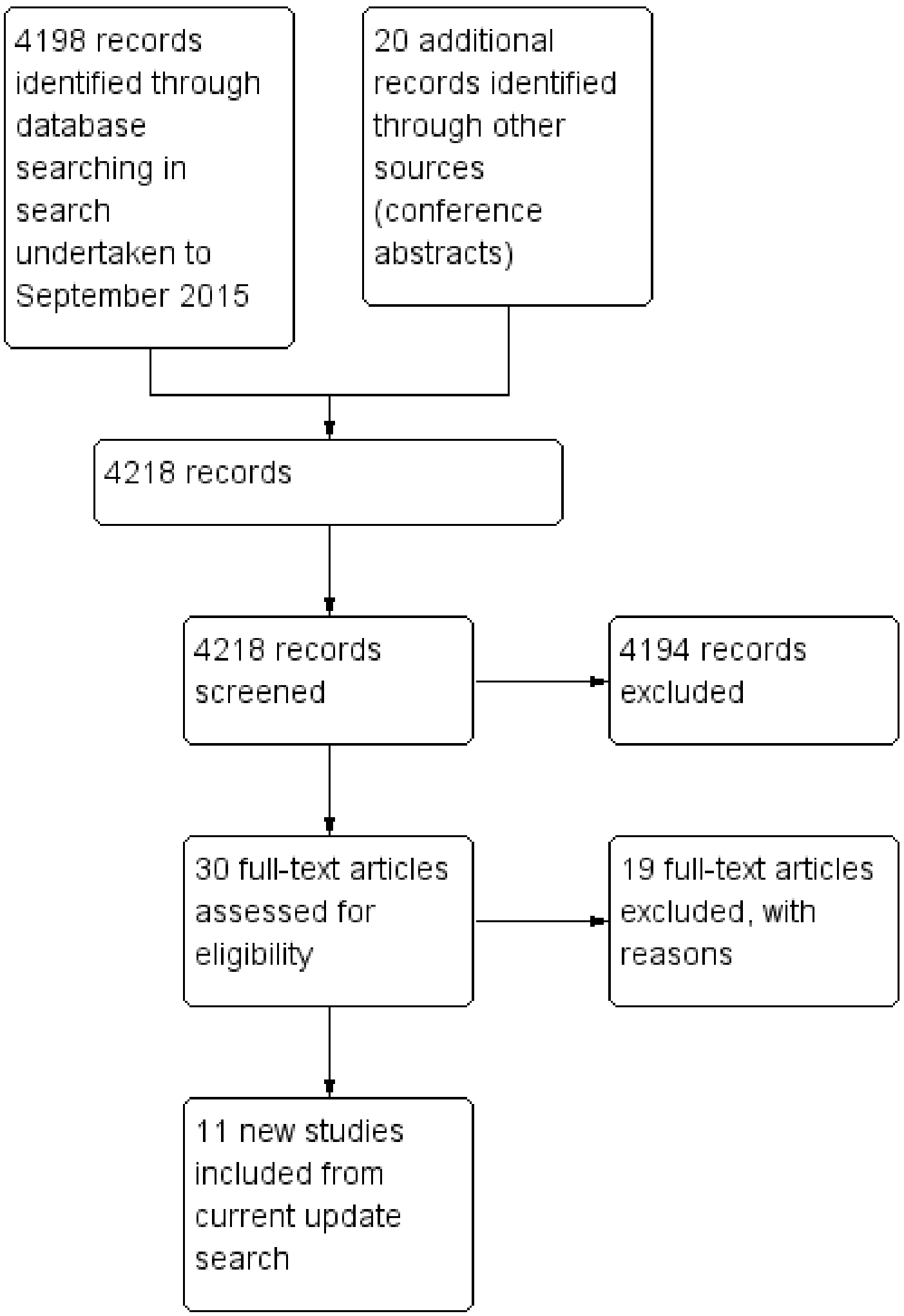


We excluded one RCT identified in the original review in this update as it no longer fitted our tighter inclusion criteria, as it is a preventative intervention (Pitkin 1971).

\section{Included studies}

The 11 completed trials randomised 1509 female participants (Aktas 2015; Barton 2007; Baucom 2009; Classen 2013; Lee 2011; Marcus 2010; Rowland 2009; Schover 2011; Schover 2013; Svensk 2009; Yang 2012).

The trials were undertaken in populations from four countries. Most were undertaken in US populations (Aktas 2015; Barton 2007; Baucom 2009; Marcus 2010; Rowland 2009; Schover 2011; Schover 2013). Others were undertaken in Canada (Classen 2013), South Korea (Lee 2011; Yang 2012), and Sweden (Svensk 2009).

One of the trials was of cross-over design (Barton 2007); the remainder were of parallel design. Three of the studies were feasibility or pilot trials (Baucom 2009; Classen 2013; Yang 2012). Two studies compared different forms of delivery of an intervention (Schover 2011; Schover 2013), and two used wait-list controls (Classen 2013; Schover 2011). Four trials involved samples of fewer than 50 participants (Baucom 2009; Classen 2013; Svensk 2009; Yang 2012). Four had samples of over 100 participants (Barton 2007; Marcus 2010; Rowland 2009; Schover 2011). None of the trials reported drug, staff or project pharmaceutical funding or affiliation.

All trials involved participants that had breast or gynaecological cancer. Where reported, the mean age of participants ranged across trials from 44 to 57 years. The treatments the participants underwent for cancer were surgery, radiation, endocrine therapy and/or chemotherapy.

As per the inclusion criteria participants in the majority of trials had documented poor sexual functioning following a cancer treatment (Barton 2007; Baucom 2009; Classen 2013; Lee 2011; Marcus 2010; Rowland 2009; Schover 2011; Schover 2013; Svensk 2009; Yang 2012). We included another trial as the authors were explicit in assuming that for a high proportion of the participants the cancer treatment would result in sexual dysfunction (Aktas 2015). Across the studies how sexual dysfunction was measured varied. This included self report and scales specifically developed for the project. Validated tools used included the Changes of Sexual Functioning Questionnaire (Clayton 1997), Derogatis Inventory of Sexual Functioning (Derogatis 1979), the Female Sexual Distress Revised Scale (Derogatis 2008), Female Sexual Function Index (Rosen 2000), and the sexual function subscale of the Australian Pelvic Floor Questionnaire (Baessler 2009). Only one trial specifically set out to only include those with severe sexual dysfunction (Classen 2013), although in two other trials the scores obtained on the scales used for sexual dysfunction suggested overall a significant problem (Lee 2011; Schover 2011). One trial evaluated sexual outcomes in both the women and their partners (Baucom 2009).

All involved participants were in a couple relationship, although only two of the trials documented that participants were sexually active prior to the cancer treatment (Aktas 2015; Classen 2013). In three trials the intervention was started during active treatment for cancer of surgery, radiography or chemotherapy (Aktas 2015; Baucom 2009; Svensk 2009); for one of these studies the treatment, radiology, was ongoing (Svensk 2009). In one other trial the intervention was started just after the treatment for cancer (Marcus 2010). In another the mean number of months since treatment for cancer ended was 24.3 in the intervention group and 31.3 in the control group (Classen 2013). In the remaining six trials time since cancer treatment was not reported (Barton 2007; Lee 2011; Rowland 2009; Schover 2011; Schover 2013; Yang 2012).

In three trials the effect of the intervention on sexual dysfunction was the primary focus (Aktas 2015; Barton 2007; Schover 2013). In five of the other trials there was no declared primary outcome; in four of these sexual dysfunction was one of several measures of wellbeing, including quality of life, mental health and distress, body image, spiritual wellbeing and personal growth (Baucom 2009; Marcus 2010; Schover 2011; Svensk 2009). In the fifth trial the other measures related to the impact of an exercise intervention on pelvic floor muscles (Yang 2012). In the other two included studies sexual dysfunction was a secondary outcome; in one the primary outcome was feasibility of the intervention (Classen 2013), and in the other mental health (Rowland 2009).

Further details on these trials are documented in the table Characteristics of included studies.

\section{Trial interventions}

The interventions evaluated were pharmacological, psychotherapeutic, psycho-educational or exercise. Most trials (8/11) evaluated an intervention involving psychotherapeutic techniques. Within these interventions there was heterogeneity in content.

\section{Pharmacological interventions}

Two types of pharmacological interventions were tested:

- Topical testosterone cream;

- Vaginal pH-balanced gel.

\section{Psychotherapeutic/psycho-educational}

The focus and delivery of the psychotherapeutic and psycho-educational interventions varied and included:

- Art therapy; 
- Counselling one to one, in group or by telephone. This included professional counselling or peer support. Topics included discussion of sexual matters, relationship functioning, quality of life and information on treatment;

- Relationship enhancement;

- Web-based support and information.

\section{Exercise}

- Pelvic floor exercises with and without biofeedback.

Further descriptions of the included trials can be found in the Characteristics of included studies table.

\section{Outcomes evaluated}

There was variation across the trials in how the effect of the intervention on sexual function was measured, as well as for other types of outcomes, including quality of life and psychological functioning. Where there was overlap, the trials differed in how they presented their results.

\section{Excluded studies}

We excluded 49 studies in the previous version of this review and 19 at this update.

The main reasons for exclusion of studies were that the report was a discussion paper, not a RCT, the study did not include cancer patients or that the evaluation had no sexual function outcomes. Reasons for exclusion for all excluded studies are listed in the Characteristics of excluded studies table.

\section{Ongoing studies}

There are seven relevant trials in progress (Davis 2015; DuHamel 2013; Gessler 2015; Hummel 2015; NCT00459134 2015; NCT02091765 2015; Schofield 2013). The trials vary. For example, one of the studies in progress is testing a psychotherapeutic intervention in female survivors of anal or rectal cancer (DuHamel 2013); another is testing a psychotherapeutic intervention in women following treatments for gynaecological cancer (Schofield 2013). Further details on these trials are documented in the table Characteristics of ongoing studies.

\section{Risk of bias in included studies}

All trials were vulnerable to a number of biases, most commonly selection bias. See Figure 2 and Figure 3.

Figure 2. 'Risk of bias' graph: review authors' judgements about each risk of bias item presented as percentages across all included studies.

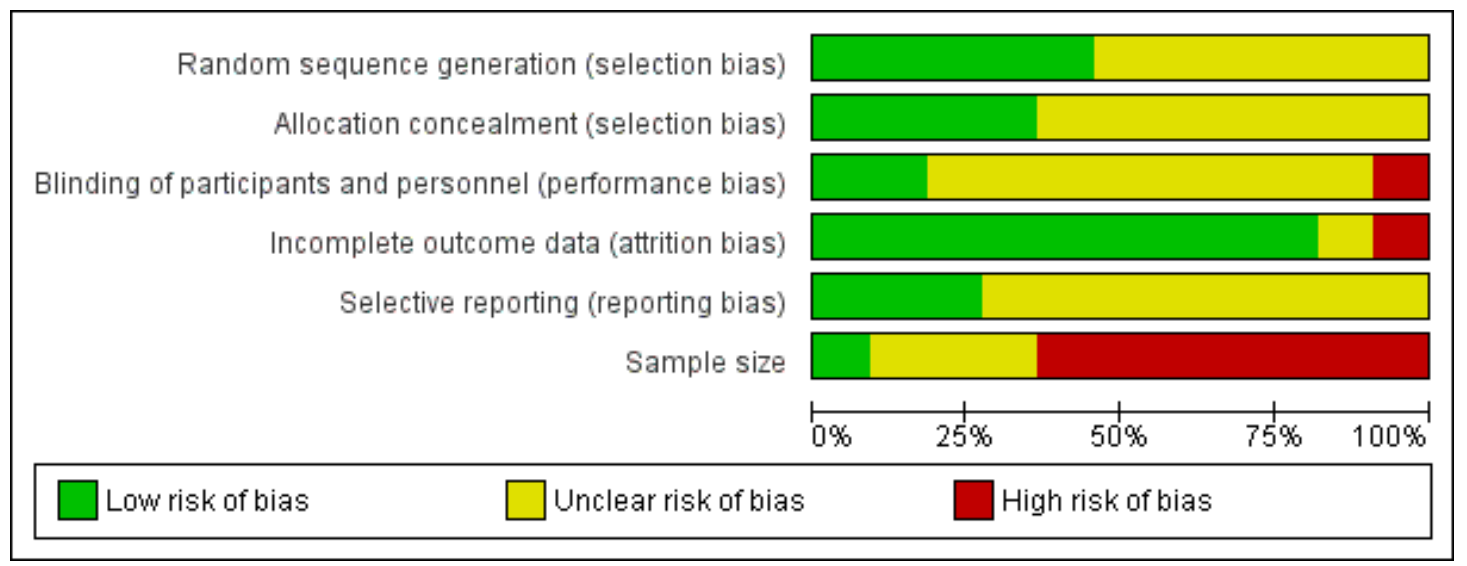

Interventions for sexual dysfunction following treatments for cancer in women (Review) 
Figure 3. 'Risk of bias' summary: review authors' judgements about each risk of bias item for each included study.

\begin{tabular}{|c|c|c|c|c|c|c|}
\hline & 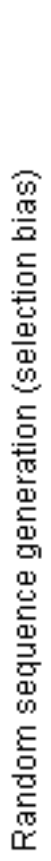 & 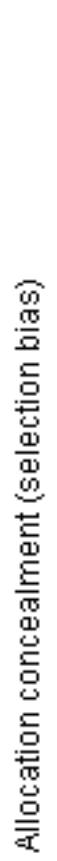 & 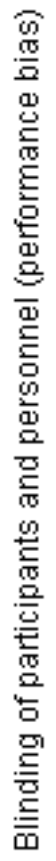 & 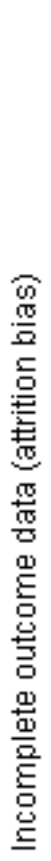 & 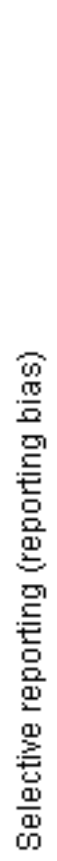 & 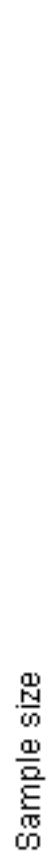 \\
\hline Aktas 2015 & $?$ & $?$ & $?$ & & $?$ & \\
\hline Barton 2007 & & + & & & + & $?$ \\
\hline Baucom 2009 & + & + & $?$ & & + & \\
\hline Classen 2013 & $?$ & $?$ & $?$ & & $?$ & \\
\hline Lee 2011 & + & + & & & + & \\
\hline Marcus 2010 & $?$ & $?$ & $?$ & & $?$ & $?$ \\
\hline Rowland 2009 & $?$ & $?$ & $?$ & & $?$ & \\
\hline Schover 2011 & $?$ & $?$ & $?$ & & $?$ & ? \\
\hline Schover 2013 & $?$ & $?$ & $?$ & $?$ & $?$ & \\
\hline Svensk 2009 & & + & & & $?$ & \\
\hline Yang 2012 & 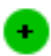 & $?$ & $?$ & & $?$ & \\
\hline
\end{tabular}




\section{Allocation}

Most trials $(\mathrm{n}=8)$ did not report the method of randomisation sequence generation (Aktas 2015; Barton 2007; Baucom 2009; Classen 2013; Marcus 2010; Rowland 2009; Schover 2011; Schover 2013). The method concealment of allocation was described adequately in three of the trials (Barton 2007; Baucom 2009; Svensk 2009).

\section{Blinding}

Two trials were at a low risk of performance bias (Barton 2007; Baucom 2009).

In the other trials the risk was either high, as the authors stated that the trial was single-blinded, or the risk was unclear as they provided no details.

\section{Incomplete outcome data}

The risk of attrition bias was low in most trials $(n=6)$ (Barton 2007; Baucom 2009; Classen 2013; Marcus 2010; Svensk 2009; Yang 2012).

\section{Selective reporting}

The risk of selective reporting was unclear in most studies ( $\mathrm{n}=$ 8) as they did not reference a protocol or clearly state primary outcomes.

\section{Other potential sources of bias}

Seven trials were at a high risk of bias as they involved fewer than 50 participants in each trial arm (Aktas 2015; Baucom 2009; Classen 2013; Lee 2011; Schover 2013; Svensk 2009; Yang 2012).

\section{Effects of interventions}

The effects of the interventions are reported as fully as possible. Some trials did not report for all outcomes assessed the actual scores for or number of participants experiencing an outcome.

\section{Pharmaceutical interventions}

Two trials evaluated a pharmaceutical intervention.

\section{Testosterone cream versus placebo}

One cross-over trial of 150 women with cancer evaluated the effect of testosterone 2\% in Vanicream versus plain Vanicream in the control group (Barton 2007). As per the inclusion criteria, at baseline all participants had a decrease in sexual desire. This was defined as a score of less than 8 on a 0 - to 10-point scale with 10 being highest interest (actual scores not provided). Participants were instructed to apply a spoonful of the cream (intervention treatment or control) onto a large area of their abdomen or thighs. The trial reported cross-over periods separately and so according to our protocol we only report the pre-cross-over results.

\section{Sexual function}

Outcomes for sexual desire/interest and frequency of desire were captured using the Changes in Sexual Functioning Questionnaire (CSFQ) (Clayton 1997). The overall score for the scale runs from 0 to 100 , with higher scores representing poorer outcome.

Using the CSFQ for the summed score of desire/interest and frequency of desire it was found that there was no significant difference in effect between the trial arms. The first cross-over mean score in the intervention group was 48.53 and in the control group it was 44.41 . The mean difference (MD) in change from baseline was 1.08 (95\% confidence interval (CI) -2.78 to 4.94$)$. Neither was there a significant difference in the CSFQ subscale on feelings of sexual pleasure (MD 4.67, 95\% CI -0.10 to 9.44) (see Table 1 for the actual scores).

\section{Quality of life}

Quality of life was not measured.

\section{Adverse effects}

The trial reported no significant difference between trial arms in adverse effects of acne, voice deepening, abnormal hair loss or growth, peripheral oedema or headache. The actual numbers of participants suffering these events were not reported.

\section{Secondary and other outcomes}

The Profile of Mood States (POMS) was used to measure psychological function. They also reported the findings of a subscale on vitality. There was no significant difference between trial arms for both outcomes (MD -3.37, 95\% CI -8.15 to 1.01; MD -2.20, 95\% CI -6.84 to 2.44 ) (see Table 1 for the actual scores). Impact on physical symptoms of cancer were not reported. 


\section{$\mathrm{pH}$-balanced vaginal gel versus placebo}

In one trial, 98 women with breast cancer were randomised to either apply three times a week a $\mathrm{pH}$-balanced vaginal gel or a placebo gel (Lee 2011). The women had experienced menopause after chemotherapy or endocrine therapy. In both trial arms, participants at baseline reported a high degree of dyspareunia. On a scale of 0 to 10 with 10 being the highest score for dyspareunia, the baseline mean in the intervention group was 8.23 (standard deviation (SD) 0.99) and in the control group 8.20 (SD 0.95). Likewise the score (using the same scoring system) for vaginal dryness with pain was high: in the intervention group it was 8.20 (SD 0.83 ) and in the control group 7.92 (SD 0.89).

\section{Sexual function}

Effectiveness of the gel was measured by whether it reduced dyspareunia and vaginal dryness. This was measured using a visual analogue scale of 0 to 10 with higher scores reflecting poorer function/more severe symptoms.

At 12 weeks of treatment there was a significant difference favouring those in the intervention group in reduced dyspareunia and other measures of vaginal health, including reduced vaginal dryness (mean dyspareunia 5.48 (SD 1.06) in the intervention group, mean dyspareunia 6.11 (SD 1.42) in the control group; MD $0.63,95 \%$ CI -1.13 to -0.13 ); mean vaginal dryness 4.23 (SD $1.40)$ in the intervention group and 6.51 (SD 1.51) in the control group; MD $-2.28,95 \% \mathrm{CI}-2.85$ to -1.71 ).

\section{Quality of life}

Quality of life was not measured.

\section{Adverse effects}

The most common adverse effect was the sensation of vaginal burning or irritation; there was no significant difference between the trial arms in the proportions of women experiencing this (18/ 49 in the intervention group versus $13 / 49$ in the control group; odds ratio (OR) $1.61,95 \%$ CI 0.68 to 3.80 ). There were no reported severe adverse effects.

\section{Secondary and other outcomes}

Impact on symptoms of cancer and psychological functioning were not reported.

\section{Psychotherapeutic and psycho-educational}

Eight trials assessed the effectiveness of a psychotherapeutic intervention or psycho-educational intervention (Aktas 2015; Baucom 2009; Classen 2013; Marcus 2010; Rowland 2009; Schover 2011; Schover 2013; Svensk 2009). The content of four interventions was specific to sexual matters (Aktas 2015; Baucom 2009; Classen 2013; Schover 2013). Three were broader in topic, covering in addition to sexual matters other quality of life issues such as physical, psychological, social and spiritual wellbeing (Marcus 2010; Rowland 2009; Schover 2011). The intervention in the other trial was art therapy and it did not explore sexual matters (Svensk 2009). Instead it provided participants with a medium for expression and reflection. It was included as sexual functioning was a specific outcome. The interventions not only varied in content, but in how they were delivered and in their comparison. In brief:

- Specialist nurse counselling on sexual matters (Aktas 2015). The comparison group received usual post-cancer treatment care;

- Face-to-face counselling on relationship enhancement compared with an active control of provision of a list of support services (Baucom 2009);

- Online support group to address the psychosexual impact of cancer compared with a wait-list control (Classen 2013);

- Telephone counselling on living with physical change, sexuality, relationships and economic change compared with an active control of a list of support services (Marcus 2010);

- Sexual relationship enhancement intervention compared to an active control of an educational leaflet (Rowland 2009);

- Peer counselling aiming to improve knowledge and reduce symptoms relating to sexual dysfunction compared to participant-initiated call to receive brief telephone counselling on sexual dysfunction (Schover 2011);

- Online intervention on sexual and fertility consequences of cancer and treatment (Schover 2013). Participants' use of the website was guided by a counsellor in one trial arm and not in the other arm;

- Art therapy intervention compared with a control group who had usual care (Svensk 2009).

Detailed information regarding treatment arms and outcomes is provided in the Characteristics of included studies.

This diversity and complexity of interventions precluded any taxonomy of simple labels that would accurately summarise efficacy per intervention type. It also precluded classification into general themes and groups. Moreover the trials varied in how they measured impact on sexual functioning, with five not reporting their findings in a way that was appropriate for combined analysis (Baucom 2009; Marcus 2010; Rowland 2009; Schover 2011; Schover 2013). Therefore for these reasons their results are presented individually.

\section{Results}


Three studies found that a psychotherapeutic or psycho-educational intervention had a beneficial effect on some measures of sexual function (Aktas 2015; Baucom 2009; Marcus 2010). In others the benefit of the intervention was either unclear (Rowland 2009; Schover 2013), or no difference was found in sexual function in comparison with the control intervention (Classen 2013; Schover 2011; Svensk 2009). Two trials reported a significant improvement in quality of life in the intervention group compared to the control group (Baucom 2009; Svensk 2009), but in another no difference was found (Schover 2011). Only one study specifically set out to measure adverse events (Baucom 2009). Four studies evaluated psychological health, such as symptoms of depression or anxiety (Baucom 2009; Marcus 2010; Rowland 2009; Schover 2011), and four evaluated physical functioning, impact on symptoms of cancer or impact of treatment on menopausal symptoms (Baucom 2009; Schover 2011; Schover 2013; Svensk 2009).

\section{Aktas 2014}

Aktas 2015 tested whether a specialist nurse counselling service compared to usual care would improve sexual satisfaction in 70 women following a hysterectomy for gynaecological cancer. Sexual dysfunction was not measured at baseline, however the authors assumed that most of the women would develop sexual problems because of their cancer treatments. The nurses visited the women in the intervention group three times a week until hospital discharge, and subsequently at home at one and 12 weeks. The nurse discussed sexual problems with the women including body image, self confidence, the fear of being rejected, loss of desire, sexual intercourse, vaginal sensitivity, vaginismus, dyspareunia, inability to reach orgasm, shortening of the vagina and incomplete penis penetration.

\section{Sexual function}

Sexual outcomes were measured using the Golombok Rusk Inventory of Sexual Satisfaction (GRISS), which involves 28 items graded on a Likert scale (Rust 1985). It provides a total score on satisfaction with sexual function and scores for 12 subscales of which seven were assessed in this study. The lower the scores the greater the sexual function.

At 12 weeks, using the total score for the GRISS, there was a statistically significant difference favouring the intervention group (mean 7.15 in the intervention group and 9.46 in the control group (MD $-1.40,95 \% \mathrm{CI}-2.27$ to -0.53 ).

There were mixed outcomes on the GRISS subscales. There was significantly more improvement in the intervention group in:

- sexual non-communication (MD -1.63, 95\% CI -2.52 to $0.74)$;

- anorgasmia (difficulty reaching orgasm) (MD -1.73, 95\%

CI -2.56 to -0.90$)$;

- avoidance (MD -2.11, 95\% CI -3.65 to -0.57);
- non-sensuality (MD -1.93, 95\% CI -3.45 to -0.41 ).

There was no significant difference between the trial arms in:

- frequency of sexual contact (MD - $0.11,95 \% \mathrm{CI}-1.01$ to $0.79)$;

- vaginismus (MD -1.27, 95\% CI -2.91 to 0.37);

- sexual dissatisfaction (MD 0.43, 95\% CI -0.66 to 1.52).

- the proportion of women who had resumed sexual relations by 12 weeks (7/35 in the intervention group and 10/35 in the control group; OR 2.36, 95\% CI 0.88 to 6.34).

Actual scores on the subscales are reported in Table 2.

\section{Quality of life and adverse effects}

Quality of life and adverse effects were not reported on.

\section{Secondary and other outcomes}

No other outcomes were reported.

\section{Baucom 2009}

Baucom 2009 conducted a pilot study of 14 couples, in which the wife had early-stage breast cancer. Mean baseline sexual functioning in both trial arms using the sexual drive and relationship subscale of the Derogatis Inventory of Sexual Functioning (DISFSR) suggested a level of sexual dysfunction. Higher scores suggested greater sexual function, drive and satisfaction, and better relationship. For both trials arms the score was below mid-score (16) on this subscale, with a mean score of 11.50 in the intervention group and a mean score of 10.33 in the comparison group. All women had received cancer treatment and in most cases it involved surgery. Couples were randomised to either counselling for relationship enhancement or an active control of provision of a list of community support services. The intervention used a cognitive behavioural approach and consisted of six sessions in which the therapist discussed with the couple how to share feelings and thoughts and to reach decisions jointly. The focus was on cancerrelated topics including fear, mortality, sexuality and body image. The small number of participants meant that inferential statistics were not used. Instead the researchers looked at between-group effect sizes, taking into account in their analysis the change scores for each participant. They reported that overall there was greater improvement in couples in the intervention group in all outcomes in relation to relationship and sexual functioning.

\section{Sexual function}

The outcomes were sexual functioning and drive using a four-item domain of the DISF-SR of which the mean in the intervention group 13.00 (SD 3.11) and in the control group 9.80 (SD 5.93); 


\section{Quality of life}

Relationship satisfaction was assessed using the Quality of Marriage Index (QMI), with higher scores indicating greater quality. QMI mean in the intervention group 39.71 (SD 3.45) and in the control group 40.20 (SD 5.07).

\section{Adverse effects}

No adverse effects were reported.

\section{Secondary and other outcomes}

They reported fewer overall physical symptoms secondary to cancer treatment, such as nausea and dizziness, in the intervention group compared to the control group. The study did not report any general measures of psychological functioning. See Table 3 for the actual scores for all outcomes reported.

\section{Classen 2013}

Classen 2013, in a feasibility study, included 27 women who were sexually distressed following gynaecological cancer treatment. In this trial they sought to identify women whose distress was "above and beyond what might ordinarily occur for women with gynaecologic cancer". This was defined as scoring at least 24 on the Female Sexual Distress Revised Scale. This is higher than the recommended cutoff of 11 for sexual distress. Actual baseline scores were not provided.

The women had received, on average two to three years earlier, surgery, chemotherapy or radiotherapy for gynaecological cancer and were randomised in the study to an online support group, GyneGals, or a wait-list control. The aim of the 12 -week online support group was to address the psychosexual impact of cancer and its treatments. It involved a closed group discussion forum moderated daily by two psychologists, who posted weekly a message on the forum to introduce discussion topics such as coping with emotional challenges or exploring sexuality. A dedicated website provided psycho-educational material to support the discussion.

\section{Quality of life and adverse effects}

Quality of life and adverse effects were not measured

\section{Secondary and other outcomes}

The main outcome of this study was feasibility and they found that the majority of women found the website content to be appropriate $(15 / 21)$ and felt comfortable about discussing their sexual concerns (14/21) in a forum. Using the Hospital Anxiety and Depression Scale (HADS) and the Illness Intrusion Rating Scale there was no significant difference in psychological functioning (for example, for HADS intention-to-treat analysis: MD 0.13, 95\% CI -2.44 to 2.70). See Table 4. Physiological functioning and impact on physical symptoms of disease were not reported.

\section{Marcus 2010}

Marcus 2010, in a multi-centre study, included 304 women who had just completed treatment for breast cancer, which in the majority of cases $(74 \%)$ involved chemotherapy. Sexual function was measured by using a 25 -item scale, which was composed of questions developed specifically for the project. Scores ranged from 0 to 100 with higher scores indicating greater sexual dysfunction. At baseline participants on average had a level of sexual dysfunction, as suggested by mean scores between 40 and 50 (actual scores not provided). The 152 participants randomised to the intervention received 16- to 45-minute telephone counselling sessions on topics regarding living with physical change, sexuality, relationships and economic change. Those randomised to the comparison group received a mailed booklet listing services in the community relevant to breast cancer.

Their findings were from a before and after comparison in each trial arm. They were not a direct comparison of effects between the trial arms.

Sexual function was measured at follow-up as it was for baseline. The Impact of Events Scale was used to measure cancer-specific distress and the Center for Epidemiologic Studies Depression Scale to measure depression.

\section{Sexual function}

Sexual function was measured using the Female Sexual Distress Scale (FSDS).

No significant difference was found on sexual distress using the FSDS between those who received psychosexual support compared to the wait-list control group in an intention-to-treat analysis or in an analysis of only those who actively used the forum (MD 2.28, 95\% CI -2.15 to 6.71 ; MD 3.56, 95\% CI -2.26 to 9.38, respectively). See Table 4 for the actual mean scores.

\section{Sexual function}

For sexual function they reported an overall significant improvement in the intervention group in mean changes scores from baseline at 12 and 18 months follow-up (at 18 months the effect size was 0.23 , P value $=0.04$ ), and likewise for "personal growth", described as deriving benefit from the cancer experience at 12 and 18 months (at 18 months the effect size was 0.22 , P value $=0.03$ ). The comparison group showed no change from baseline. The actual scores on these scales per trial arm were not reported. 


\section{Quality of life and adverse effects}

Adverse effects were not reported and neither were outcomes for quality of life.

\section{Secondary and other outcomes}

In both trial arms there was an improvement when comparing mean scores for cancer-specific distress and depression. Outcomes on symptoms of disease were not reported. The actual scores on these scales per trial arm were not reported.

\section{Rowland 2009}

Rowland 2009 studied 155 women treated for breast cancer who were randomised to either a psycho-educational programme or an active control involving an educational leaflet entitled 'Facing forward: a guide for cancer survivors'. All who were invited onto the trial had reported that they had problems with body image, sexuality and intimacy and/or communication with a partner. At baseline on a scale of 1 to 6 , with higher scores indicating a better outcome, pain with sex was 4.1 in the intervention group and 4.3 in the control group. The intervention consisted of six twohour weekly group meetings, which aimed to enhance participants' communication skills, reduce anxiety in intimate situations and provide information on sexual anatomy, menopause and sexual dysfunction.

\section{Sexual function}

The study's secondary outcomes were sexual function, via Likert scale (scores range from 1 to 6) items on satisfaction, pain and comfort, and relationship functioning using the Revised Dyadic Adjustment Scale (scores range from 0 to 69). For both outcomes the higher the scores the better the function. Baseline relationship functioning was 50.4 in the intervention group and 50.8 in the control group.

No significant differences were found in mean change scores from baseline to four-month follow-up between the trial arms in sexual satisfaction in regards to variety of sex and sexual relationship outcomes (MD 0.13, 95\% CI -0.24 to 0.50; MD 0.10, 95\% CI - 0.30 to 0.50 , respectively). Neither were there significant differences for most other outcomes relating to sex and relationships:

- pain interfering with pleasure (MD 0.30, 95\% CI -0.12 to $0.72)$;

- improved comfort with sexuality (MD 0.20, 95\% CI 0.00

to 0.40 );

- comfort about being touched (MD - $0.20,95 \%$ CI -0.23 to $0.63)$;

- comfort in undressing (MD 0.40, 95\% CI -0.21 to 1.01 );

- comfort in being nude (MD 0.40, 95\% CI -0.06 to 0.86);

- impact of cancer on sex (MD -0.10, 95\% CI -0.37 to 0.17).
However, in the case of pain during sexual activity, impact on relationship and communication there were significant differences favouring those in the intervention group (MD 0.80, 95\% CI 0.20 to 1.40 ; MD $2.40,95 \% \mathrm{CI} 1.02$ to 3.78 , MD $0.30,95 \% \mathrm{CI}$ 0.07 to 0.53 , respectively). See Table 5 for the actual mean scores.

\section{Qaulity of life and adverse effects}

Adverse events were not reported and neither were outcomes for quality of life.

\section{Secondary and other outcomes}

The study's primary outcome was mental health using the Mental Health Index-32. The index provides a total score with higher scores indicating better mental health. There was no significant difference in mean change in score from baseline to follow-up in those in the intervention group compared to those in the control group (MD 3.10, 95\% CI -0.18 to 6.38). See Table 5 for the actual mean scores.

Outcomes on impact on symptoms of disease were not reported.

\section{Schover 2011}

Schover 2011 randomised 300 African American women who were breast cancer survivors to either receiving a workbook and regular peer counselling or a workbook and participant-initiated telephone counselling. Participants at baseline had sexual dysfunction as defined on the Female Sexual Function Index (FSFI), with a mean score across the sample of 18.2 (the recommended score for indicating sexual dysfunction is less than 26.5 (Conaglen 2010)). The intervention workbook was designed specifically for African American women to improve knowledge and reduce symptoms relating to sexual dysfunction, menopause and distress about infertility. In the peer counsellor group participants met the counsellor individually three times a week for six weeks. Each session focused on a chapter of the workbook. The telephone counselling group were given the workbook and the counsellor's contact details and they were encouraged to call her.

The trial measured a range of outcomes at six and 12 months, which included spiritual wellbeing using the Functional Assessment of Cancer, relationship functioning using the Dyadic Adjustment Scale, emotional distress using the Brief Symptom Inventory (BSI), mental distress using the Global Severity Index and sexual function using the FSFI.

\section{Sexual function}

Using mixed model analysis they found overall no significant change across time in either group in sexual function. The exact scores for this outcome are not provided by the authors. 


\section{Quality of life and adverse events}

Adverse effects were not reported and neither were outcomes for quality of life.

\section{Secondary and other outcomes}

Using mixed model analysis they found overall no significant change across time in either group in relationship functioning, in total score for menopausal symptoms or childbearing distress. They found depression decreased after treatment in the peer-counselled group to less than 2.5 but increased in the telephone-counselled group to nearly 4 , but by 12 months depressive symptoms in the two groups were very similar, around a score of 3 . The exact scores for any of these outcomes are not provided by the authors. Outcomes on physiological functioning were not reported.

\section{Schover 2013}

Schover 2013 randomised 58 women with breast or gynaecological cancer to either receive counselling and use of a password-protected website or "self-help", which entailed access to the website without counselling support. All participants had some indication at baseline of sexual dysfunction using the FSFI as indicated by a score of less than 15 (scores for this scale ranged from 2 to 36, with the lower the score the poorer the sexual function). Actual scores for the participants were not provided. The intervention website provided information on the sexual and fertility consequences of their cancer and treatment, on management of vaginal dryness and pain, sexual issues and pelvic floor exercises. Those in the counselling group were given three sessions to guide them through the website and to discuss behavioural homework. At three and six months post-treatment sexual outcomes were measured using the FSFI and Menopausal Sexual Interest Questionnaire (MSIQ). Emotional distress was measured using the BSI and quality of life using the Quality of Life in Adult Cancer Survivors scale. The treatment effect was explored by using linear mixed models regression.

\section{Sexual function}

Based on the FSFI scale they found a significant treatment effect in improved sexual function in those who received counselling (mean change of 7.44 from baseline to post-treatment (no SD provided)). However, this was not apparent in a subgroup analysis of those who were sexually active; the authors did not provide actual data on this. Using the MSIQ scale there was also a significant effect in those in the counselling group (mean change score 13.22 from baseline to post-treatment, SD not provided), but this was only apparent to three months.

\section{Quality of life}

Quality of life was found to improve significantly in the self help group only. Full data on this outcome was not provided by the authors.

\section{Adverse effects}

Adverse effects were not reported.

\section{Secondary and other outcomes}

Emotional distress using the BSI at follow-up was reduced in the self help group by 3.73 , and in the counselled group by 2.63 , but this was not significant. Full data on this outcome was not provided by the authors.

Outcomes on physiological functioning and symptoms of disease were not reported.

\section{Svensk 2009}

Svensk 2009, in a trial of 41 women with breast cancer, tested the effect of five weeks of individual art therapy sessions compared with a control group who did not receive art therapy. Participants had a reduced level of sexual function and enjoyment at the first assessment following breast cancer treatments. This was indicated by the lower baseline scores for the European Organization for Research and Treatment of Cancer Quality of Life module (EORTC QLQ-BR23) subscale on sexual functioning at baseline in both trial arms (mean 25.44 in the intervention group and 25.00 in the control group, compared to 38.60 in the intervention group and 30.16 in the control group at first follow-up). The therapy, based on phenomenological methods, aimed to provide time and space for expression and reflection, to give support in the process of restoring body image and to act as a supporting agency.

\section{Sexual function}

The EORTC QLQ-BR23 instrument was used to measure sexual outcomes, and the impact of treatment and cancer on symptoms and body image. It is comprised of 23 items. A higher score for sexual functioning indicates a better level of functioning.

After radiation treatment there was no significant difference between trial arms in sexual function at two months (MD 8.44, 95\% CI-8.01 to 24.89) and at six months (MD 5.88, 95\% CI - 10.15 to 21.91). In the intervention group the baseline mean was 25.44 (SD 19.54) and at six months it was 43.21 (SD 24.52). In the control group the mean at baseline was 25.00 (SD 21.97) and at six months it was 28.33 (SD 26.55). 
There was no significant difference in sexual enjoyment at two months (MD 2.40, 95\% CI -16.61 to 21.41 ) or at six months (MD -3.17, 95\% CI -23.43 to 17.09 ). See Table 6.

\section{Quality of life}

Quality of life was measured using the Swedish version of the World Health Organization (WHO) instrument WHOQOLBREF. At two and six months there was a significant difference favouring the intervention in quality of life (MD 12.08, 95\% CI 0.39 to 23.77 ; MD $17.50,95 \%$ CI 7.14 to 27.86 , respectively).

\section{Adverse effects}

Adverse effects were not reported.

\section{Secondary and other outcomes}

Using the European Organization for Research and Treatment of Cancer (EORTC) QLQ-BR23 there was no significant difference between the trial arms at two and six months follow-up in body image, cancer therapy side effects, 'breast symptoms', 'arm symptoms', being upset by hair loss, physiological health, psychological heath and quality of social relationships. This is apart from being upset about hair loss at two months, where there was a significant difference favouring those in the intervention group. See Table 6. Physiological functioning were not reported.

\section{Exercise}

One trial of 28 women evaluated the effect of exercise on sexual function (Yang 2012). The women had pelvic floor dysfunction following a radical hysterectomy and pelvic lymph node dissection for gynaecological cancer. The trial compared four weeks of pelvic floor muscle training with a control group receiving no training. At the start of the intervention in both trial arms the overall mean for sexual function using the sexual function subscale of the Pelvic Floor Questionnaire indicated sexual dysfunction. Total scores on the scale ranged from 0 to 20 . Eight items on the scale covered sufficient lubrication, vaginismus, coital incontinence, vaginal laxity, dyspareunia and 'sexual bother'. A zero score meant that there was no problem in any of the items. In the intervention group the mean score was 6.02 and in the control group 4.62.

\section{Sexual function}

Sexual function was measured at four weeks via self report (yes or no), the Australian Pelvic Floor Questionnaire (APFQ) using a four-point scoring system $(0=$ no problem to $3=$ severe problem) and the cervical cancer-specific EORTC QLQ CX24, which assessed function using three items. Single-item measures on the EORTC QLQ CX24 were used in this study to assess sexual worry, activity and enjoyment. The trial had mixed outcomes for sexual function.

The trial reported no significant difference between trial arms in the number of participants at follow-up who were sexually functioning (8/12 in the intervention group compared with $5 / 12$ in the control group; OR 2.80, 95\% CI 0.53 to 14.74 ). In contrast, the mean score using the EORTC QLQ CX24 was significantly different between trial arms, favouring those who received the intervention (MD 10.30, 95\% CI 1.48 to 19.12), as was the mean change score from baseline to follow-up for sexual function using APFQ (MD -3.20, 95\% CI -5.55 to -0.85).

Using the EORTC QLQ CX24 the authors found no significant difference between trials arms in sexual worry or enjoyment but they found a difference in sexual activities favouring the intervention group (MD -10.00, 95\% CI -22.25 to 2.25; MD 2.70, 95\% CI -9.45 to 14.85 ; MD 18.40 , $95 \%$ CI 5.18 to 31.62 , respectively). Actual mean scores per trial arm were not reported.

\section{Quality of life}

Quality of life outcomes were not reported.

\section{Adverse effects}

The authors stated a physical therapist and a trained evaluator monitored adverse effects and any participants experiencing an aggravation of pelvic floor symptoms or difficulty in continuing the exercises was excluded from the final assessment. They did not provide the numbers of those excluded for these events.

\section{Secondary and other outcomes}

Psychological and physiological functioning, and symptoms of disease were not reported.

\section{DISCUSSIO N}

This is the first update of the 2007 Cochrane systematic review on interventions for sexual dysfunction following treatment for cancer in women (Miles 2007). The original publication included interventions for men and for women. It identified only one trial of an intervention for women. This trial was not included in this update as it no longer fitted the tighter inclusion criteria, which excluded trials on preventative treatments. Since the original review, as demonstrated in our identification of 11 new trials and two in progress, there has been much more research interest in 
interventions for women. Three-quarters of the trials evaluated interventions that involved a psychotherapeutic element; the others evaluated a pharmaceutical gel, testosterone cream and a pelvic floor exercise. The trials involved women with gynaecological or breast cancer. Overall, the trials were mostly not of high quality as they under-reported design features. Three were pilot or feasibility studies involving small samples and in which the primary aim was not to test effectiveness. We did not identify any randomised controlled trials (RCTs) that evaluated a complementary or alternative medicine intervention.

\section{Summary of main results}

The variation in interventions evaluated, including between those that involved a psychotherapeutic element, is the main reason why there is no combined analysis in this review. Psychotherapeutic interventions involved sexual counselling, art therapy, peer support or relationship therapy; overall they showed a mixed effect on sexual functioning. The evidence that testosterone cream, pH-balanced vaginal gel or pelvic floor exercise improves sexual function is weak. The evidence for each of these interventions is limited to one study and involved in three of the four studies fewer than 50 participants per arm. Evidence on potential harms was underreported in all studies. This is apart from the trial on a topical cream and the one on a $\mathrm{pH}$-balanced vaginal gel, which reported no significant increase in adverse effects in those in the intervention group compared to those allocated a placebo. Surprisingly few trials assessed quality of life, mental health or physiological functioning, therefore it is difficult to derive any conclusions on the effect of these interventions on these outcomes. The two trials of pharmaceutical interventions measured harm and neither reported any. Only one of the psychological intervention trials reported that no harm occurred because of the intervention; the other trials did not measure harm.

\section{Overall completeness and applicability of evidence}

We searched widely for evidence using 11 citation databases and using search terms to help identify as wide a range of interventions as possible. We found some notable gaps in the evidence. We did not identify any RCTs evaluating a complementary therapy or alternative medicine, despite trials of these interventions, such as Ginkgo biloba, being tested in other populations. However, a limitation is that we did not search foreign language databases, therefore we may have missed some studies, for example Chinese herbal medicines and acupuncture. In any further update we recommend that these need to be considered.

We also identified no completed trials of interventions that were evaluated in populations with cancers other than breast or gynaecological cancer. However, one of the trials in progress is assessing an intervention following treatment for rectal or anal cancer. This is an important omission as colorectal cancer is one of the most commonly diagnosed cancers and the treatment, such as surgery and radiation, is likely to affect sexual function (Donovan 2010). Moreover, it is known that head and neck cancer survivors struggle with disfigurement and changes in body image, and have increased social isolation, all of which may lead to sexual difficulties (Low 2009; Singer 2008). Another limitation is that all trials were undertaken in advanced western societies, with the majority being undertaken in US populations. Therefore our findings may not be applicable to other populations, in particular where cultural practices in regards to sexual matters may be different.

\section{Quality of the evidence}

We could not adequately assess risk of bias in that we found all trials to have at least one methodological item under-reported, including blinding or randomisation sequence generation. The quality of the evidence is also weakened as eight of the trials had samples of fewer than 50 participants per trial arm. Some of these were also pilot studies, the focus of which was on feasibility rather than effectiveness.

\section{Potential biases in the review process}

We undertook a comprehensive search of 11 databases; the last search was completed in September 2015. More recently published eligible studies will be captured at the next update. We identified seven potentially eligible studies in progress from trial registers and conference abstracts. In further updates of this review we recommend consideration of searching foreign language databases. At least two authors undertook all steps of this review. This limited the risk of errors in determining study eligibility, data extraction, 'Risk of bias' assessment and data synthesis.

\section{Agreements and disagreements with other studies or reviews}

There are two recent relevant systematic reviews of psychotherapy in general populations. Both are non-Cochrane reviews evaluating psychotherapeutic interventions in both men and women (Berner 2012; Fruhauf 2013). The review by Berner 2012 included 20 trials but only two of these included women with sexual dysfunction. They found no benefit of the interventions for women. The review by Fruhauf 2013 included 34 trials that compared the psychosocial intervention with a comparison group. They found in combined analysis of five trials an improvement in sexual function in those who received sexual skills training. However, it is important to note that these reviews were undertaken in non-cancer populations and therefore their findings are not necessarily transferable to the populations considered in our review. 


\section{AUTHORS' CONCLUSIONS}

\section{Implications for practice}

This update found insufficient evidence for the effectiveness of topical pharmacological treatments, psychotherapeutic interventions and pelvic floor exercises. Apart from the pharmacological treatment we found limited evaluations of any potential harms these interventions may incur.

\section{Implications for research}

Improved diagnosis and treatments for cancer mean that more people will be living with and surviving cancer, and of these a significant proportion may have sexual dysfunction. Further evidence is needed on treatments for sexual dysfunction from highquality trials with large samples that fully report key methodological characteristics and harms. It is difficult to suggest which interventions might be most useful for further evaluation, as the trials we evaluated were at risk of biased results. Across the trials there was also minimal overlap in how the intervention was evaluated. Future trials need to consider preparatory stages in intervention development, to increase appropriateness and need, such as in the case of psychotherapeutic interventions, for example those recommended in the Medical Research Council (MRC) guidelines on developing and evaluating complex interventions (Craig 2008). They also need to fully report details of the intervention. Consideration is also needed of the choice of outcome measures that are appropriate to the patient population and the nature of the intervention, such as measures of sexual function, quality of life and mental health.

The trials evaluated in this review varied in design; some included a comparative arm with no additional support for sexual dysfunction and others compared the intervention arm with an active control. Future research should consider the appropriateness of a control group that is given no support despite sexual dysfunction. Perhaps at the very least trialists should consider using a comparative arm for which the provision of usual care for sexual dysfunction is provided.

Sexual dysfunction is difficult to treat in this population as it may result from multiple causes, not all of which are a direct outcome of the cancer treatment. These causes include the emotional stress of having the diagnosis and its impact on daily living, as well as natural aging. Thus it may be a particularly difficult disorder to treat.

\section{ACKNOWLEDGEMENTS}

The authors wish to thank Phil Wiffen, Sylvia Bickley and Jessica Thomas from the Pain, Palliative and Supportive Care Review Group for their assistance given on the original review. We would also like to thank C Miles and Rachael Williams who were authors of the original review. In the 2015 update review we thank Anna Erskine and Jo Abbott from the Pain, Palliative and Supportive Care Review group for their support. We also thank the trial authors who responded to our request for further detail on their research: Lori Brotto, Deborah Bruner and Katherine DuHamel. We also thank Alvaro Diez Revuelta and Orii McDermott for translations of non-English papers. We thank Marie Curie Cancer care for core funding of some of the review authors (LJ, BC, VV). We also thank George Dowswell for his help in the early development of this 2015 update. Marie Curie Care funded both the 2007 and 2015 update of this review.

Cochrane Review Group funding acknowledgement: The National Institute for Health Research (NIHR) is the largest single funder of the Cochrane PaPaS Group. Disclaimer: The views and opinions expressed therein are those of the authors and do not necessarily reflect those of the NIHR, National Health Service (NHS) or the Department of Health.

\section{R E F E R E N C E S}

\section{References to studies included in this review}

Aktas 2015 \{published data only\}

Aktas D, Terzioglu F. Effect of home care service on the sexual satisfaction of patients with gynecologic cancer. Sexuality and Disability 2015;33(2):243-52. [10.1007/ s11195-014-9370-8]

Barton 2007 \{published data only\}

Barton DL, Wender DB, Sloan JA, Dalton RJ, Balcueva EP,

Atherton PJ, et al. Randomized controlled trial to evaluate transdermal testosterone in female cancer survivors with decreased libido; North Central Cancer Treatment Group Protocol N02C3. Journal of the National Cancer Institute 2007;99:672-9.
Baucom 2009 \{published data only\}

Baucom DH, Porter LS, Kirby JS, Gremore TM, Wiesenthal $\mathrm{N}$, Aldridge W, et al. A couple-based intervention for female breast cancer. Psycho-Oncology 2009;18:276-83.

Classen 2013 \{published data only\} Classen CC, Chivers ML, Urowitz S, Barbera L, Wiljer D, O'Rinn S, et al. Psychosexual distress in women with gynaecologic cancer: a feasibility study of an online support group. Psycho-Oncology 2013;22:930-5.

Lee 2011 \{published data only\} Lee YK, Chung HH, Kim JW, Park NH, Song YS, Kang $\mathrm{SB}$. Vaginal $\mathrm{pH}$-balanced gel for the control of atrophic 
vaginitis among breast cancer survivors: a randomised controlled trial. Obstetrics and Gynecology 2011;117:922-7.

Marcus 2010 \{published data only\}

Marcus AC, Garrett KM, Cella D, Wenzal L, Brady MJ, Fairclough D, et al. Randomized controlled trial of mindfulness-based stress reduction (MBSR) for survivors of breast cancer. Psycho-Oncology 2010;19:923-32.

Rowland 2009 \{published data only\}

Rowland JH, Meyerowitz BE, Crespi CM, Leedham B, Desmond K, Belin TR, et al. Addressing intimacy and partner communication after breast cancer: a randomised controlled group intervention. Breast Cancer Research and Treatment 2009;118:99-111.

Schover 2011 \{published data only\} Schover LR, Rhodes MM, Baum G, Harned Adams J, Jenkins R, Lewis P, et al. Sisters Peer Counseling in Reproductive Issues After Treatment (SPIRIT). Cancer 2011;117:4983-92.

Schover 2013 \{published data only\} Schover LR, Yuan Y, Fellman BM, Odensky E, Lewis PE, Marinetti P. Efficacy trial of an internet-based intervention for cancer-related female sexual dysfunction. Journal of the National Comprehensive Cancer Network 2013;11:1389-97.

Svensk 2009 \{published data only\}

O ster I, Tavelin B, Thyme KE, Magnusson E, Isaksson U, Lindh J, et al. Art therapy during radiotherapy - a five-year follow-up study with women diagnosed with breast cancer. The Arts in Psychotherapy 2014;41:36-40.

Svensk A-C, O־ ster I, Thyme KE, Magnusson E, Sjodin $\mathrm{M}$, Eisemann M, et al. Art therapy improves experienced quality of life among women undergoing treatment for breast cancer: a randomized controlled study. European Journal of Cancer Care 2009;18:69-77.

Yang 2012 \{published data only\}

Yang EJ, Lim JY, Rah UW, Kim YB. Effect of a pelvic floor muscle training program on gynaecologic cancer survivors with pelvic floor dysfunction: a randomized controlled trial. Gynecologic Oncology 2012;125:705-11.

\section{References to studies excluded from this review}

Badger 2005 \{published data only\}

Badger T, Segrin C, Meek P, Lopez AM, Bonham E, Sieger A. Telephone interpersonal counselling with women with breast cancer: symptom management and quality of life. Oncology Nursing Forum 2005;32:273-9.

Barber 2002 \{published data only\}

Barber MD, Visco AG, Wyman JF, Fantyl JA, Bump RC. Sexual function in women with urinary incontinence and pelvic organ prolapse. American College of Obstetrics and Gynecologists 2002;99:281-9.

Barrett-Connor 1996 \{published data only\} Barrett CE, Timmons C, Young R, Wiita B. Interim safety analysis of a two-year study comparing oral estrogenandrogen and conjugated estrogens in surgically menopausal women. Journal of Women's Health 1996;5:593-602.
Berman 2003 \{published data only\}

Berman JR, Berman LA, Toler SM, Gill J, Haughie S. Safety and efficacy of sildenafil citrate for the treatment of female sexual arousal disorder: a double-blind, placebo controlled study. Journal of Urology 2003;170:2333-8.

Boesen 2011 \{published data only\} Boesen EH, Karlsen R, Christensen J, Paaschburg B, Nielsen D, Bloch IS, et al. Psychosocial group intervention for patients with primary breast cancer: a randomised trial. European Journal of Cancer 2011;47:1363-72.

Brotto 2012 \{published data only\} Brotto LA, Erskine Y, Carey M, Ehlen T, Finlayson S, Heywood M, et al. A brief mindfulness-based cognitive behavioral intervention improves sexual functioning versus wait-list control in women treated for gynecologic cancer. Gynecologic Oncology 2012;125:320-5.

Burstein 1999 \{published data only\} Burstein HJ, Gelber S, Guadagnoli E, Weeks JC. Use of alternative medicine by women with early-stage breast cancer. New England Journal of Medicine 1999;340:1733-9.

Chow 2014 \{published data only\} Chow KM, Chan CWH, Chan JCCY, Choi KKC, Siu KY. A feasibility study of a psycho-educational intervention program for gynaecological cancer patients. European Journal of Oncology Nursing 2014;18:385-92.

Christensen 1983 \{published data only\} Christensen DN. Postmastectomy couple counselling: an outcome study of a structures treatment protocol. Journal of Sex \& Marital Therapy 1983;9:266-75.

Davis 2004 \{published data only\} Davis C. Psychosocial needs of women with breast cancer: how can social workers make a difference?. Health and Social Work 2004;29:330-4.

Decruze 1999 \{published data only\} Decruze SB, Gutherie D, Magnai R. Prevention of vaginal stenosis in patients following vaginal brachytherapy. Clinical Oncology 1999;11:46-8.

Dennerstein 1979 \{published data only\} Dennerstein L, Burrows GD, Hyman GJ, Sharpe K. Some clinical effects of oestrogen-progestogen therapy in surgically castrated women. Maturitas 1979;2:19-28.

Doorenbos 2006 \{published data only\} Doorenbos A, Given B, Given C, Verbitsky N. Effect of behavioural intervention for symptoms among individuals with cancer. Nursing Research 2006;55:161-71.

Floter 2002 \{published data only\} Floter A, Nathorst-Boos, Carlstrom K, von Schoultz. Addition of testosterone to estrogen replacement therapy in oophorectomized women: effects on sexuality and wellbeing. Climacteric 2002;5(4):357-65.

Ganz 2000 \{published data only\} Ganz PA, Greendale GA, Petersen L, Zibecchi L, Kahn B, Belin TR. Managing menopausal symptoms in breast cancer survivors: results of a randomized controlled trial. Journal of the National Cancer Institute 2000;92:1054-64. 
Given 2004 \{published data only\}

Given C, Given B, Rahbar M, Jeon S, McCorkle R, Cimprich B, et al. Effect of a cognitive behavioral intervention on reducing symptom severity during chemotherapy. Journal of Clinical Oncology 2004;22: 507-16.

\section{Goetsch 2014 \{published data only\}}

Goetsch MF, Lim JY, Caughey AB. Locating pain in breast cancer survivors experiencing dyspareunia: a randomized controlled trial. Obstetrics \& Gynecology 2014;123:1231-6.

Hasenbring 1999 \{published data only\}

Hasenbring M, Schulz KF, Hennings U, Florian M, Linhart $\mathrm{D}$, Ramm G, et al. The efficacy of relaxation/imagery, music therapy and psychological support for pain relief and quality of life: first results from a randomized controlled clinical trial [abstract]. Bone Marrow Transplant 1999;23: 166.

Huang 2013 \{published data only\}

Huang G, Basaria S, Travison TG, Ho MH, Davda M, Mazer NA, et al. Testosterone does-relationships in hysterectomised women with or without oopherctomy: effects on sexual function, body composition, muscle performance and physical function in a randomised trial. Journal of the North American Menopause Society 2013;21: $612-23$.

Izuo 1967 \{published data only\} Izuo M, Fujimori M. Studies on hormonal treatment for mastopathy, particularly its dose-response relationship. Endocrinologia Japonica 1967;14:27-33.

Jefferies 2006 \{published data only\} Jefferies SA, Robinson JW, Craighead PS, Keats M. An effective group psycho-educational intervention for improving compliance with vaginal dilation: a randomized controlled trial. International Journal of Radiation Oncology, Biology, Physics 2006;65:404-11.

\section{Jones 2006 \{published data only\}}

Jones RB, Pearson J, Cawsey AJ, Bental D, Barrett A, White J, et al. Effect of different forms of information produced for cancer patients on their use of the information, social support and anxiety: randomised trial. BMJ 2006;332: 942-8.

Jung Hoon 2006 \{published data only\}

Jong-Hoon K, Park CY, Sung-Jae L. Effects of Sun Ginseng on subjective quality of life in cancer patients: a doubleblind, placebo-controlled pilot trial. Journal of Clinical Pharmacy and Therapeutics 2006;31:331-4.

Juraskova 2013 \{published data only\}

Juraskova I, Jarvis S, Mok K, Peate M, Meiser B, Cheah $\mathrm{BC}$, et al. The acceptability, feasibility, and efficacy (phase I/II study) of the OVERcome (Olive Oil, Vaginal Exercise, and MoisturizeR) intervention to improve dyspareunia and alleviate sexual problems in women with breast cancer. International Society for Sexual Medicine 2013;10(10): 2549-58.
Kylstra 1999 \{published data only\}

Kylstra WA, Leenhouts GHMW, Everaerd W, Panneman MJM, Hahn DEE, Weijmar-Schultz WCM, et al. Sexual outcomes following treatment for early-stage gynaecological cancer: a prospective and cross-sectional multi-center study. International Journal of Gynecological Cancer 1999;9: 387-95.

Lengacher 2009 \{published data only\} Lengacher CA, Johnson-Mallard V, Post-White J, Moscoso MS, Jacobsen PB, Klein TW, et al. Randomized controlled trial of mindfulness-based stress reduction (MBSR) for survivors of breast cancer. Psycho-Oncology 2009;18: 1261-77.

Lepore 2015 \{published data only\}

Lepore SJ, Revenson TA. Randomised controlled trial of expressive writing and quality of life in men and women treated for colon or rectal cancer. Psychology and Health 2015;30:284-300.

Loprinzi 2011 \{published data only\} Loprinzi C, Balcueva EP, Liu H, Sloan JA, Kottschade LA, Stella PJ, et al. A phase III randomised, double blind, placebo-controlled study of pilocarpine for vaginal dryness: NCCTG study N04CA. Journal of Supportive Oncology 2011;9:105-12.

Marsden 2001 \{published data only\} Marsden J, Baum M, A'Hern R, West A, Fallowfield L, Whitehead $\mathrm{M}$, et al. The impact of hormone replacement therapy on breast cancer patients' quality of life and sexuality. Journal of the British Menopause 2001;7:85-91.

Moore 1999 \{published data only\} Moore RA. Livial: a review of clinical studies. British Journal of Obstetrics and Gynecology 1999;106:1-21.

Morales 2004 \{published data only\} Morales L, Neven P, Timmerman D, Christiaens MR, Vergote I, Van Limbergen E, et al. Acute effects of tamoxifen and third-generation aromatase inhibitors on menopausal symptoms of breast cancer patients. Clinical Report 2004;15:753-60.

Mulhall 2006 \{published data only\} Mulhall JP. Neuromodulatory drugs in a radical pelvic surgery patient. Journal of Sexual Medicine 2006;3:77-9.

Munarriz 2002 \{published data only\} Munarriz R, Talakoub L, Flaherty E, Gioia M, Hoag L, Kim NN, et al. Androgen replacement therapy with dehydroepiandrosterone for androgen insufficiency and female sexual dysfunction: androgen and questionnaire results. Journal of Sex and Marital Therapy 2002;28 Suppl 1:165-73.

Munstedt 1998 \{published data only\} Munstedt K, Milch W, Reimer C. Epicutaneous breast forms after mastectomy. Support Care Cancer 1998;6: 295-9.

Narvaez 2008 \{published data only\} Narvaez A, Rubinos C, Cortes-Funes F, Gomez R, Garcia A. Rating of the effectiveness of group therapy cognitive 
image in body, self-esteem, sexual distress, and anxiety and depression in breast cancer patients. [Spanish]. Psicooncologica 2008;5:93-102.

Nho 2013 \{published data only\}

Nho JH. Effect of PLISSIT model sexual health enhancement program for women with gynecologic cancer and their husbands. Journal of the Korean Academy of Nursing 2013;43(5):681-9.

Nieman 2003 \{published data only\}

Nieman LK. Management of surgically hypogonadal patients unable to take sex hormone replacement therapy. Endocrinology and Metabolism Clinics of North America 2003;32:325-36.

Nikander 2003 \{published data only\}

Nikander E, Kilkkinen A, Metsa HM, Adlercreutz H, Pietinen P, Tiitinen A, et al. A randomized placebocontrolled crossover trial with phytoestrogens in treatment of menopause in breast cancer patients. American College of Obstetricians and Gynecologists 2003;101:1213-20.

Northouse 2002 \{published data only\}

Northouse LL, Walker J, Schafenacker A, Mood D, Mellon S, Galvin E, et al. A family-based program of care for women with recurrent breast cancer and their family members. Oncology Nursing Forum 2002;29:1411-9.

Northouse 2013 \{published data only\}

Northouse LL, Mood DW, Schafenacker A, Kalemkerian G, Zalupski M, LoRussi P, et al. Randomised clinical trial of a brief and extensive dyadic intervention for advanced cancer patients and their family caregivers. Psycho-Oncology 2013; 22:555-63.

\section{Park 2015 \{published data only\}}

Park HY, Kim JH, Choi S, Kang E, Kim JY, Kim SW. Psychological effects of a cosmetic education programme in patients with breast cancer. European Journal of Cancer Care 2015;24:493-502.

Pietrzak 2007 \{published data only\}

Pietrzak L, Bujko K, Nowacki MP, Kepka L, Oledzki J, Rutkowski A, et al. Quality of life, anorectal and sexual functions after preoperative radiotherapy for rectal cancer: report of a randomised trial. Radiotherapy and Oncology 2007;84:217-25.

Pitkin 1971 \{published data only\}

Pitkin RM, VanVoorhis LW. Postirradiation vaginitis. Therapeutic Radiology 1971;99:417-21.

Ponzone 2005 \{published data only\}

Ponzone R, Biglia N, Jacomuzzi ME, Maggiorotto F, Mariani L, Sismondi P. Vaginal oestrogen therapy after breast cancer: is it safe?. European Journal of Cancer 2005; 41:2673-81.

Rawlins 1999 \{published data only\} Rawlins S, Burkman RT, Schwarz BE. The power of the pill: making evidence-based decisions. American Journal for Nurse Practitioners 2000;4:25-40.

Reese 2014 \{published data only\}

Reese JB, Porter LS, Regan KR, Keefe FJ, Azad NS, Diaz LA, et al. A randomized pilot trial of a telephone-based couples intervention for physical intimacy and sexual concerns in colorectal cancer. Psycho-Oncology 2014;23: 1005-13.

\section{Robinson 1999 \{published data only\}}

Robinson JW, Faris PD, Scott CB. Psychoeducational group increases vaginal dilation for younger women and reduces sexual fears for women of all ages with gynaecological carcinoma treated with radiotherapy. International Journal of Radiation Oncology, Biology, Physics 1999;44:497-506.

Schover 2006 \{published data only\} Schover LR, Jenkins R, Sui D, Adams JH, Marion MS, Jackson KE. Randomized trial of peer counseling on reproductive health in African American breast cancer survivors. Journal of Clinical Oncology 2006;24:1620-6.

\section{Schroder 2005 \{published data only\}}

Schroder M, Mell LK, Hurteau JA, Collins YC, Rotmensch J, Waggoner SE, et al. Clitoral therapy device for treatment of sexual dysfunction in irradiated cervical cancer patients. International Journal of Radiation Oncology, Biology, Physics 2005;61:1078-86.

Scott 2004 \{published data only\} Scott JL, Ward BG. United we stand? The effects of a couple-coping intervention on adjustment to early stage breast or gynecological cancer. Journal of Consulting and Clinical Psychology 2004;72:1122-35.

Seidman 2000 \{published data only\} Seidman SN. Hormonal aspects of sexual dysfunction: the therapeutic use of exogenous androgens in men and women. Current Psychiatry Reports 2000;2:215-22.

Serewel 1990 \{published data only\} Serewel A, Haggie JA, Cade D. A randomised controlled trial of medroxyprogesterone acetate in mastalgia. Annals of the Royal College of Surgeons of England 1990;72:273.

Shabani 2014 \{published data only\}

Shabani M, Moghimi M, Zamiri RE, Nazari F, Mousavinasab N, Shajari Z. Life skills training effectiveness on non-metastatic breat cancer mental health: a clinical trial. Iranian Red Crescent Medical Journal 2014;16:E8763.

Sherwin 1984 \{published data only\}

Sherwin BB, Gelfand MM. Effects of parenteral administration of estrogen and androgen on plasma hormone levels and hot flushes in the surgical menopause. American Journal of Obstetrics and Gynecology 1984;148: 552-7.

Sherwin 1985 \{published data only\}

Sherwin BB, Gelfand MM, Brender W. Androgen enhances sexual motivation in females: a prospective, crossover study of sex steroid administration in the surgical menopause. Psychosomatic Medicine 1985;4:339-51.

Shifren 2000a \{published data only\} Shifren JL, Braunstein GD, Simon JA, Casson PR, Buster JE, Redmond GP, et al. The efficacy of sildenafil citrate (Viagra) in clinical populations: an update. New England Journal of Medicine 2000;343:682-8. 
Suckling 2006 \{published data only\}

Suckling J, Lethaby A, Kennedy R. Local oestrogen for vaginal atrophy in postmenopausal women. Cochrane Database of Systematic Reviews 2006, Issue 4. [DOI: 10.1002/14651858.CD001500.pub2]

Sweeney 2002 \{published data only\} Sweeney C, Bruera E. Communication in cancer care: recent developments. Journal of Palliative Care 2002;18: 300-6.

Theobald 2002 \{published data only\} Theobald DE, Kirsh KL, Holtsclaw E, Donaghy K, Passik SD. An open-label, crossover trial of mirtazapine (15 and $30 \mathrm{mg}$ ) in cancer patients with pain and other distressing symptoms. Journal of Pain and Symptom Management 2002; 23:442-7.

Thompson 2003 \{published data only\}

Thompson EA, Reilly D. The homeopathic approach to the treatment of symptoms of oestrogen withdrawal in breast cancer patients. A prospective observational study. Homeopathy 2003;92:131-4.

van der Meulen 2014 \{published data only\}

van der Meulen IC, May AM, de Leeuw JR, Koole R, Ooserom M, Hordijk G-J, et al. Long-term effect of a nurse-led psychosocial intervention on health-related quality of life in patients with head and neck cancer: a randomised controlled trial. British Journal of Cancer 2014; 110:593-601.

Vos 2006 \{published data only\}

Vos JV, Visser AP, Garssen B, Duivenvoorden HJ, Hanneke CJM de Haes. Effects of delayed psychosocial interventions versus early psychosocial interventions for women with early stage breast cancer. Patient Education and Counseling 2006; 60:212-9.

Warkentin 2006 \{published data only\}

Warkentin KM, Gray RE, Wassersug RJ. Restoration of satisfying sex for a castrated cancer patient with complete impotence. Journal of Sex and Marital Therapy 2006;32: 398-9.

Watts 1995 \{published data only\}

* Watts NB, Morris N, Timmons CM, Allen Addison W, Wiita B, Downey LJ. Comparison of oral estrogens and estrogens plus androgen on bone mineral density, menopausal symptoms, and lipid-lipoprotein profiles in surgical menopause. Obstetrics and Gynecology 1995;85: 529-37.

Wei 2005 \{published data only\}

Wei W, Shuang L, Wu Guang-Jao, Li Li. Influence of perioperative supportive psychotherapy on the postoperative mental state and sexual life in patients with uterine cervix cancer. Chinese Journal of Clinical Rehabilitation 2005;9: $42-43$.

Wenzel 1999 \{published data only\}

Wenzel LB, Fairclough DL, Brady MJ, Cella D, Garrett KM, Kluhsman BC, et al. Age-related differences in the quality of life of breast carcinoma patients after treatment. American Cancer Society 1999;86:1768-74.
Wenzel 2015 \{published data only\}

Wenzel L, Osann K, Hsieh S, Tucker JA, Monk BJ, Nelson EL. Psychosocial telephone counseling for survivors of cervical cancer: results of a randomized biobehavioral trial. Journal of Clinical Oncology 2015;33:1171-9.

Wu 2014 \{published data only\}

Wu J-X, Chen Y. Effect of nursing intervention on mental and physical health in patients with rectal cancer after Miles operation. World Chinese Journal of Digestology 2014;22: $1460-4$.

\section{References to studies awaiting assessment}

Esplen 2014 \{published data only\}

Esplen MJ, Wong J, Warner E, Toner B. Can we fix what we've broken? Randomized controlled trial of a group therapy to address body image disturbance and sexuality following treatment with breast cancer. Canadian Association of Psychosocial Oncology Conference Proceedings. 2014:B-228.

Goetsch 2015 \{published data only\} Goetsch M, Lim JY, Caughey AB. A practical solution for dyspareunia in breast cancer survivors: a randomised controlled trial. Journal of Clinical Oncology 2015;33(30): 3394-400. [DOI: 10.1200/JCO.2014.60.7366]

Gremore 2014 \{published data only\} Gremore T, Horgan S. A couple-based intervention for patients with head and neck cancer and their partners. Psycho-Oncology 2014;23:42.

Hickey 2015 \{published data only\}

Hickey M, Allardice K. Silicone versus water-based lubricant for symptomatic vaginal dryness after breast cancer: preliminary findings from a randomized trial. Reproductive Sciences 2015;22:55A-390A.

Jensen 2014 \{published data only\} Jensen B, Jensen JB. Early rehabilitation can impact on health-related quality of life outcome in radical cystectomy: a randomised controlled trial. Supportive Care in Cancer 2014;22:s185.

Paterson 2015 \{published data only\} Paterson C, Lengacher C, Donovan K, Kip K, Tofthagen C. The effects of MBSR (BC) on sexual distress and body image disturbance in breast cancer survivors. Psychooncology 2015;24 Suppl 2:287.

Willems 2015 \{published data only\} Willems RA, Bolman CAW, Mesters I, Kanera IM, Beaulen AAJM, Lechner L. The Kanker Nazorg Wijzer (Cancer Aftercare Guide) protocol: the systematic development of a web-based computer tailored intervention providing psychosocial and lifestyle support for cancer survivors. BMC Cancer 2014;15:580.

\section{References to ongoing studies}

\section{Davis 2015 \{published data only\}}

The effect of $300 \mathrm{mcg}$ intravaginal testosterone therapy for the treatment of sexual dysfunction due to Genitourinary 
Syndrome of Menopause (GSM) in women with breast cancer being treated with an aromatase inhibitor (AI): a randomized placebo controlled trial over 26 weeks. http://apps.who.int/trialsearch/Trial2.aspx?TrialID= ACTRN12615000083594. [ACTRN12615000083594]

DuHamel 2013 \{published data only\}

DuHamel K, Temple L, Carter J, Schover L, Philip E, Jandorf $\mathrm{L}$, et al. Pilot randomized clinical trial to improve sexual health and quality of life in female rectal and anal cancer survivors. Psycho-Oncology 2013;22:35.

Gessler 2015 \{published data only\}

Gessler SF, Lanceley A. Developing a Stepped Approach to Improving Sexual Function aFteR Treatment fOr gyNaecological Cancer (SAFFRON). https://clinicaltrials.gov/ct2/show/NCT02458001. www.clinicaltrials.gov, 2015. [NCT02458001]

Hummel 2015 \{published data only\}

Hummel SB, Lankveld J. Internet-based cognitive behavioral therapy for sexual dysfunctions in women treated for breast cancer: design of a multicenter, randomized controlled trial. BMC Cancer 2015;15:321.

\section{NCT004591342015 \{published data only\}}

Greven K, Wake Forest NCORP Research Base. L-Arginine supplements in treating women who are cancer survivors. https://clinicaltrials.gov/ct2/show/NCT00459134 2007. [NCT00459134]

\section{NCT02091765 2015 \{published data only\}}

Aaronson NK, van Lankveld JJDM, Oldenburg HSA, Hahn D. KIS Study: a study evaluating the effectiveness of an internet-based therapy program for sexuality and intimacy problems in women treated for breast cancer. https://clinicaltrials.gov/ct2/show/NCT02091765 2014. [NCT02091765]

Schofield 2013 \{published data only\} Schofield P, Juraskova I, Bergin R, Gough K, Mileshkin L, Krishnasamy M, et al. A nurse- and peer-led support program to assist women in gynaecological oncology receiving curative radiotherapy, the PeNTAGOn study (peer and nurse support trial to assist women in gynaecological oncology): study protocol for a randomised controlled trial. Trials 2013;14:39.

\section{Additional references}

\section{Allahdadi 2009}

Allahdadi KJ, Tostes RCA, Webb RC. Female sexual dysfunction: therapeutic options and experimental challenges. Cardiovascular \& Hematological Agents in Medicinal Chemistry 2009;7:260-9.

Ananth 2003

Ananth H, Jones L, King M, Tookman A. The impact of cancer on sexual function: a controlled study. Palliative Medicine 2003;17(2):202-5.

\section{Baessler 2009}

Baessler K, O’Neill SM, Maher CF, Battistutta D. Australian pelvic floor questionnaire: a validated interviewer- administered pelvic floor questionnaire for routine clinic and research. International Urogynecology Journal and Pelvic Floor Dysfunction 2009;20:149-58.

\section{Berman 1999}

Berman JR, Berman LA, Werbin TJ, Flaherty EE, Leahy NM, Goldstein I. Clinical evaluation of female sexual function: effects of age and estrogen status on subjective and physiologic sexual responses. International Journal of Impotence Research 1999;11:31-8.

\section{Berner 2012}

Berner M, Gunzler C. Efficacy of psychosocial interventions in men and women with sexual dysfunctions-a systematic review of controlled clinical trials. Journal of Sexual Medicine 2012;9:3089-107.

\section{Bhatt 2006}

Bhatt A, Nandipati K, Dhar N, Ulchaker J, Jones S, Rackley R, et al. Neuro- vascular preservation in orthotopic cystectomy: impact on female sexual function. Urology 2006;67(4):742-5.

\section{CDC 2011}

Centers for Disease Control and Prevention. Cancer survivors - United States, 2007. Morbidity and Mortality Weekly Report. Surveillance Summaries: MMWR 2011;60: 269-72.

\section{Clayton 1997}

Clayton AH, McGarvey EL, Clavet GJ. The Changes in Sexual Functioning Questionnaire. Psychopharmacology Bulletin 1997;33:731-45.

\section{Cohen 1998}

Cohen AJ, Bartlik B. Ginkgo biloba for antidepressantinduced sexual dysfunction. Journal of Sex Marital Therapy 1998;24:139-43.

\section{Conaglen 2010}

HM Conaglen, O'Connor EJ, McCabe MP, Conaglen JV. An investigation of sexual dysfunction in female partners of men with erectile dysfunction: how interviews expand on questionnaire responses. International Journal of Impotence Research 2010;22:355-62.

\section{Cowan 2013}

Cowan ML, Krane MK. Sexual function after radical surgery for rectal cancer. Seminars in Colon and Rectal Surgery 2013;24:164-7.

\section{Craig 2008}

Craig P, Dieppe P, Macintyre S, Michie S, Nazareth I, Petticrew M. Developing and evaluating complex interventions: the new Medical Research Council guidance. BMJ 2008;337:A1655.

Dening 2013

Dening T, Thomas A. Oxford Textbook of Old Age Psychiatry. Second Edition. Oxford, 2013.

\section{Derogatis 1979}

Derogatis LR, Melisaratos N. The DSFI: a multidimensional measure of sexual functioning. Journal of Sex and Marital Therapy 1979;5:244-81. 


\section{Derogatis 2008}

Derogatis L, Clayton A, Lewis-D'Agostino D, Wunderlich G, Fu Y. Validation of the female sexual distress scale-revised for assessing distress in women with hypoactive sexual desire disorder. Journal of Sexual Medicine 2008;5:357-64.

\section{Donovan 2010}

Donovan KA, Thompson LMA, Hoffe SE. Sexual function in colorectal cancer survivors. Cancer Control 2010;17: $44-51$.

\section{DSM-5 2013}

American Psychiatric Association (editors). Diagnostic and Statistical Manual of Mental Disorders. Fifth. American Psychiatric Publishing, 2013.

\section{Fruhauf 2013}

Fruhauf S, Gerger H, Schmidt HM, Munder T, Barth J. Efficacy of psychological interventions for sexual dysfunction: a systematic review and meta-analysis. Archives of Sexual Behavior 2013;42:915-33.

\section{Ganz 1998}

Ganz PA, Rowland JH, Desmond K, Meyerowitz BE, Wyatt GE. Life after breast cancer: understanding women's healthrelated quality of life and sexual functioning. Journal of Clinical Oncology 1998;16(2):501-14.

\section{Goldfarb 2009}

Goldfarb SB, Dickler M, Sit L, Fruscione M, Barz T, Atkinson T, et al. Sexual dysfunction in women with breast cancer: prevalence and severity. Journal of Clinical Oncology 2009;15S:9558.

\section{Gonzales 2003}

Gonzales GF, Cordova A, Vega K, Chung A, Vilena A, Gonez C. Effect of Lepidium meyenii (Maca), a root with aphtodisiac and fertility-enhancing properties, on serum reproductive hormone levels in adult healthy men. Journal of Endocrinology 2003;176:163-8.

\section{Greenwald 2008}

Greenwald HP, McCorkle R. Sexuality and sexual function in long-term survivors of cervical cancer. Journal of Women's Health 2008;17:955-63.

\section{Hendren 2005}

Hendren SK, O'Connor BL, Liu M, Asano T, Cohen Z, Swallow CJ, et al. Prevalence of male and female sexual dysfunction is high following surgery for rectal cancer. Annals of Surgery 2005;242:212-23.

\section{Higgins 2011}

Higgins JPT, Green S (editors). Cochrane Handbook for Systematic Reviews of Interventions Version 5.1.0 [updated March 2011]. The Cochrane Collaboration, 2011. Available from www.cochrane-handbook.org.

\section{Hill 2011}

Hill EK, Sandbo S, Abramsohn E, Makelarski J, Wroblewski $\mathrm{K}$, Wenrich ER, et al. Assessing gynaecologic and breast cancer survivors' sexual health care needs. Cancer 2011;12: 2643-51.

\section{Ho 2011}

Ho VP, Lee Y, Stein SL, Temple LK. Sexual function after treatment for rectal cancer: a review. Diseases of the Colon and Rectum 2011;54:113-25.

\section{Hubayter 2008}

Hubayter Z, Simon JA. Testosterone therapy for sexual dysfunction in postmenopausal women. Climacteric 2008; 11:181-91.

\section{Jackson 2006}

Jackson KS, Naik R. Pelvic floor dysfunction and radical hysterectomy. International Journal of Gynecological Cancer 2006;16:354-63.

\section{Kazdin 2009}

Kazdin AE. Understanding how and why psychotherapy leads to change. Psychotherapy Research 2009;19:418-28.

\section{Kedde 2013}

Kedde H, van de Wiel HB, Weijmar Schultz WC, Wijsen C. Sexual dysfunction in young women with breast cancer. Support Care Cancer 2013;21:271-80.

Low 2009

Low C, Fullarton M, Parkinson E. Issues of intimacy and sexual dysfunction following major head and neck cancer treatment. Oral Oncology 2009;45:898-903.

\section{Montgomery 2008}

Montgomery KA. Sexual desire disorders. Psychiatry 2008; 5:50-5.

\section{National Cancer Institute 2012}

National Cancer Institute. Sexuality and reproductive issues. http://www.cancer.gov/cancertopics/pdq/supportivecare/ sexuality/healthprofessional 2012.

\section{Norton 1983}

Norton R. Measuring marital quality: a critical look at the dependent variable. Journal of Marriage and the Family 1983;45:141-51.

\section{Ozyilkan 1995}

Ozyilkan O, Karaagaoglu E, Topeli A, Kars A, Baltali E, Tekuzman G, et al. A questionnaire for the assessment of quality of life in cancer patients in Turkey. Materia Medica Polona 1995;27(4):153-6.

\section{Pignata 2001}

Pignata S, Ballatori E, Favalli G, Scambia G. Quality of life: gynaecological cancers. Annals of Oncology 2001;12(Suppl 3):S37-S42.

\section{Review Manager 2014 [Computer program]}

The Nordic Cochrane Centre, The Cochrane Collaboration. Review Manager (RevMan). Version 5.3. Copenhagen: The Nordic Cochrane Centre, The Cochrane Collaboration, 2014.

Rosen 2000

Rosen R, Brown C, Heiman J. The Female Sexual Function Index: a multidimensional self-report instrument for the assessment of female sexual function. Journal of Sex and Marital Therapy 2000;26:191-208. 


\section{Rust 1985}

Rust J, Golombok S. The Golombok-Rust Inventory of Sexual Satisfaction. British Journal of Clinical Psychology 1985;24:63-4.

Shin 2010

Shin BC, Lee MS, Yang EJ, Lim HS, Ernst E. Maca (L.meyenii) for improving sexual function: a systematic review. BMC Complementary and Alternative Medicine 2010;10:44.

Singer 2008

Singer S, Danker H, Dietz A. Sexual problems after total or partial laryngectomy. Laryngoscope 2008;118:2218-24.

\section{Stead 2007}

Stead ML, Fallowfield P, Selby P, Brown JM. Psychosexual function and impact of gynaecological cancer. Best Practice and Research Clinical Obstetrics and Gynaecology 2007;21: $309-20$.

Syrjala 1998

Syrjala KL, Roth Roemer SL, Abrams JR, Scanlan JM, Chapko MK, Visser $S$, et al. Prevalence and predictors of sexual dysfunction in long-term survivors of marrow transplantation. Blood 1998;16(9):3148-57.

Tabano 2002

Tabano M, Condosta D, Coons M. Symptoms affecting quality of life in women with gynaecologic cancer. Seminars in Oncology Nursing 2002;18(3):223-30.
Wiggins 2008

Wiggins DL, Dizon DS. Dyspareunia and vaginal dryness after breast cancer treatment. Sexuality Reproduction and Menopause 2008;6:18-22.

Zhang 2013

Zhang Z, Xu X, Ni H. Small studies may overestimate the effect sizes in critical care meta-analyses: a metaepidemiological study. Critical Care 2013;17:R2.

\section{Zippe 2004}

Zippe CD, Raina R, Shah AD, Massanyi EZ, Agarwal A, Ulchaker J, et al. Female sexual dysfunction after radical cystectomy: a new outcome measure. Urology 2004;63: 1153-7.

\section{References to other published versions of this review}

\section{Miles 2005}

Miles CL, Jones L, Tookman A, King M. Interventions for sexual dysfunction following treatments for cancer. (Protocol). Cochrane Database of Systematic Reviews 2005, Issue 4. [DOI: 10.1002/14651858.CD005540]

\section{Miles 2007}

Miles C, Candy B, Jones L, Williams R, Tookman A, King M. Interventions for sexual dysfunction following treatments for cancer. Cochrane Database of Systematic Reviews 2007, Issue 4. [DOI: 10.1002/14651858.CD005540.pub2]

* Indicates the major publication for the study 


\section{CHARACTERISTICS OF STUDIES}

\section{Characteristics of included studies [ordered by study ID]}

\section{Aktas 2015}

Methods

Randomised, controlled, single-centre trial

Participants

Entered trial: 70 US women with gynaecological (42\% ovarian and 42\% endometrial) cancer who underwent surgery, chemotherapy or radiotherapy for their cancer. Most $(62 \%)$ had a hysterectomy and chemotherapy. Highest disease stage was 3, at baseline $45 \%$ had reached this stage. All were sexually active before treatment. SD was not measured early in the trial, however the authors assumed that most of the women would developed sexual problems because of the cancer treatment. 14\% in both trial arms had a higher education. The average age was 49.3 years. They were required to abstain from sex for the first 8 weeks following surgery

Interventions

Nursing care service to discuss sexual issues

Aim: to investigate the effect of a nurse care service on the sexual satisfaction of patients with gynaecologic cancer

Interventionist: nurse

Intervention: nursing counselling service involving additional specialist nursing care and consultancy at hospital and at home. Nurse discussed sexual issues including loss of the body part, body image, fear of being rejected, loss of reproductive function, loss of desire, decrease in vaginal sensitivity, decrease in sexual intercourse, decrease in vaginal sensitivity, vaginismus, dyspareunia, inability to reach orgasm, shortening of the vagina and incomplete penis penetration

Comparison: usual care following hospital protocols

Time since cancer treatment: at the start of the intervention patients were undergoing cancer treatment

Intensity of intervention: nurse visits 3 times a week whilst in hospital and twice at home at 1 and 12 weeks

Time length of intervention: not clear

Outcomes

An Interview Questionnaire, Home Visit Monitoring Questionnaire and Golombok Rust Inventory of Sexual Satisfaction (GRISS), which contains 28 items and 7 subscales on vaginismus, anorgasmia, infrequency, non-communication, dissatisfaction, non-sensuality and avoidance

Notes

Risk of bias

\begin{tabular}{lll}
\hline Bias & Authors' judgement & Support for judgement \\
\hline $\begin{array}{l}\text { Random sequence generation (selection } \\
\text { bias) }\end{array}$ & Unclear risk & No details provided \\
\hline Allocation concealment (selection bias) & Unclear risk & No details provided
\end{tabular}

Interventions for sexual dysfunction following treatments for cancer in women (Review) 


\section{Aktas 2015 (Continued)}

\begin{tabular}{|c|c|c|}
\hline $\begin{array}{l}\text { Blinding of participants and personnel } \\
\text { (performance bias) } \\
\text { All outcomes }\end{array}$ & Unclear risk & No details provided \\
\hline $\begin{array}{l}\text { Incomplete outcome data (attrition bias) } \\
\text { All outcomes }\end{array}$ & Low risk & $\begin{array}{l}70 \text { entered. } 2 \text { and } 3 \text { patients died in the in- } \\
\text { tervention and control groups respectively } \\
\text { during the whole course of the project im- } \\
\text { plementation }\end{array}$ \\
\hline Selective reporting (reporting bias) & Unclear risk & $\begin{array}{l}\text { Protocol not published and does not state } \\
\text { primary outcomes }\end{array}$ \\
\hline Sample size & High risk & Fewer than 50 participants per trial arm \\
\hline
\end{tabular}

Barton 2007

Methods

Randomised, cross-over, controlled, single-centre trial (phase III)

Participants

Entered trial: 150 postmenopausal US female survivors of breast cancer. To be eligible all participants needed to report a decrease in sexual desire. This was defined as a score $<8$ on a 0 to 10 scale with 10 being the highest interest. To derive this they used the combined desire/interest (3 questions) and desire/frequency (2 questions) subscales of the Changes of Sexual Functioning Questionnaire (CSFQ). Eligible patients had to have a sexual partner. 131 were analysed. Mean age was 52.3 years. $80 \%$ of participants had been treated with chemotherapy

Interventions

Pharmacological

Topical cream intervention

Aim: whether transdermal testosterone would increase sexual desire in female cancer survivors

Interventionist: no details

Intervention: daily $10.4 \mathrm{mg}$ testosterone cream (Vanicream 2\% testosterone) in $1 / 8$ teaspoon

Comparison: placebo Vanicream

1 dose maximum per day

Intervention duration: 4 weeks

Time since cancer treatment: No details

Time length of intervention: 4 weeks of each of the trial arm treatments

Outcomes

1. The primary outcome was sexual desire, which was measured using combined subscales of desire/interest and desire/frequency of the CSFQ

Other scales were:

2. Derogatis Interview for Sexual Functioning/Self-Report Scale

3. Profile of Mood States

4. SF-36

Analysis at 4 and 8 weeks

Notes

Interventions for sexual dysfunction following treatments for cancer in women (Review)

Copyright $\Subset 2016$ The Cochrane Collaboration. Published by John Wiley \& Sons, Ltd. 
Barton 2007 (Continued)

\section{Risk of bias}

\begin{tabular}{|c|c|c|}
\hline Bias & Authors' judgement & Support for judgement \\
\hline $\begin{array}{l}\text { Random sequence generation (selection } \\
\text { bias) }\end{array}$ & Low risk & Central office, computer-generated \\
\hline Allocation concealment (selection bias) & Low risk & Done by the central office \\
\hline $\begin{array}{l}\text { Blinding of participants and personnel } \\
\text { (performance bias) } \\
\text { All outcomes }\end{array}$ & Low risk & Patients and all personnel were blinded \\
\hline $\begin{array}{l}\text { Incomplete outcome data (attrition bias) } \\
\text { All outcomes }\end{array}$ & Low risk & $\begin{array}{l}18 / 150 \text { patients lost to follow-up; reasons } \\
\text { provided }\end{array}$ \\
\hline Selective reporting (reporting bias) & Low risk & $\begin{array}{l}\text { Clearly provides results for all primary out- } \\
\text { comes }\end{array}$ \\
\hline Sample size & Unclear risk & $\begin{array}{l}\text { Sample of } 150 ; 50 \text { to } 199 \text { per treatment } \\
\text { arm }\end{array}$ \\
\hline
\end{tabular}

Baucom 2009

Methods

Participants
Randomised, parallel, controlled pilot trial

Early-stage female breast cancer. Sample 14 US couples. An aim of the intervention was to improve sexual function. Baseline sexual functioning using the sexual drive and relationship subscale of Derogatis Inventory of Sexual Functioning was below mid-score (16), suggesting a level of SD. Cancer treatment involved surgery $(n=11)$, chemotherapy $(n=3)$ and radiation $(n=1)$. Median age was 50 years, age range 30 to 80 years

Interventions

Psychotherapeutic
Directed to patient and partner. The intervention is based on a cognitive behavioural approach that has demonstrated considerable efficacy in alleviating and preventing relationship distress

Aim: to pilot a couple-based intervention programme for breast cancer that teaches couples how to minimise negative effects and maximise positive functioning during this difficult time

Interventionist: clinical psychology therapists trained in couple therapy and in the effects of cancer on relationship functioning

Intervention content: couple-based relationship enhancement

6 sessions of 75 minutes each. The sessions included (1) approaching breast cancer as a couple, (2) medical education regarding breast cancer, (3) communication skills for decision-making and sharing thoughts regarding cancer issues, (4) promoting healthy sexual adaptation and body image, (5) maintaining positives in life and (5) findings benefits and meaning in life. The content of each session could vary but the format was similar; they began with an update of the women's treatment for breast cancer and then 
Baucom 2009 (Continued)

reviewed homework assignments. The material provided per session was individualised to the couple. The session closed with the therapist providing a summary of the session and assigning the next homework session

Comparison: usual care. Couples received a list of community resources for additional support. They did not receive cancer education or any form of psychological intervention Duration of intervention: 6 weeks held bi-weekly

Time since cancer treatment: cancer treatment ongoing

Outcomes

No primary outcome declared

1. Quality of Marriage Index (QMI)

2. Derogatis Inventory of Sexual Functioning (DISF-SR)

3. Brief Symptom Inventory (BSI-18)

4. Post-traumatic Growth Inventory (PGI)

5. Functional Assessment of Cancer Therapy (FACT-B)

6. Self Image Scale (SIS)

7. Brief Fatigue Inventory (BFI)

1-year follow-up

Notes

Risk of bias

\begin{tabular}{|c|c|c|}
\hline Bias & Authors' judgement & Support for judgement \\
\hline $\begin{array}{l}\text { Random sequence generation (selection } \\
\text { bias) }\end{array}$ & Low risk & $\begin{array}{l}\text { Computer-based random number genera- } \\
\text { tor }\end{array}$ \\
\hline Allocation concealment (selection bias) & Low risk & $\begin{array}{l}\text { Couples and the assessor were blind to sub- } \\
\text { sequent treatment assignment }\end{array}$ \\
\hline $\begin{array}{l}\text { Blinding of participants and personnel } \\
\text { (performance bias) } \\
\text { All outcomes }\end{array}$ & Unclear risk & No details provided \\
\hline $\begin{array}{l}\text { Incomplete outcome data (attrition bias) } \\
\text { All outcomes }\end{array}$ & Low risk & $\begin{array}{l}\text { One couple in the intervention group } \\
\text { dropped out because they felt the interven- } \\
\text { tion did not meet their needs as the woman } \\
\text { required additional treatments for cancer } \\
\text { and one couple were lost in the control } \\
\text { group as the woman died }\end{array}$ \\
\hline Selective reporting (reporting bias) & Low risk & Results for all outcomes provided \\
\hline Sample size & High risk & Fewer than 50 participants per trial arm \\
\hline
\end{tabular}

Interventions for sexual dysfunction following treatments for cancer in women (Review) 
Methods

Participants

Outcomes
Randomised, controlled, parallel, single-centre feasibility trial

27 Canadian, sexually-distressed (as measured by scoring at least 24 on the Female Sexual Distress Revised Scale, which is higher than the recommended cutoff of 11 so as they identified women whose distress was "above and beyond what might ordinarily occur for women with gynaecologic cancer") female gynaecologic cancer patients subsequent to cancer treatment entered the trial. The women had received surgical, medical and/ or radiation treatment for gynaecological cancer. They were currently disease-free for a minimum of 3 months. Mean age in the intervention group was 39.9 years and in the wait-list control 44.6 years. Age range was 28 to 59 years. Over $70 \%$ were Caucasian

Interventions

Psychotherapeutic intervention

Aim: feasibility study examining the participation rates and preliminary outcomes for an online support group designed specifically for women who are sexually distressed subsequent to gynaecologic cancer treatment

Interventionist: psychologists co-ordinated the discussion forum

Intervention 1: 'GyneGals', hosted on 2 websites with weekly discussion topics. One website hosted the discussion forum, which allowed women access to an online group. The support group was a closed group only accessible to members and the research team. The other website housed the psycho-educational material, which was only accessible by members and the research team. The 2 websites were linked. In week 10 of the intervention, a 90-minute text-based chat session was offered in which the participants could interact in real time with a gynaecologic oncologist and radiation oncologist as well as the moderators

Comparison group: wait-list control, whenever the user wanted to (at least once a week)

Duration of intervention: 12 weeks

Time since cancer treatment: required to be disease-free for a minimum of 3 months and no more than 5 years post-diagnosis

The primary outcome was feasibility of the trial and intervention

The secondary outcomes were:

1. Female Sexual Distress Scale - revised, 13-item

2. HADS

3. Illness Intrusiveness Ratings Scale

4. GyneGals exit questionnaire to assess participant's satisfaction with intervention

Follow-up at 4 and 8 months

Notes

Risk of bias

Bias Authors' judgement

Support for judgement

Random sequence generation (selection Unclear risk No details provided bias)

Allocation concealment (selection bias)

Unclear risk

No details provided

Interventions for sexual dysfunction following treatments for cancer in women (Review) 


\begin{tabular}{l|l|l}
$\begin{array}{l}\text { Blinding of participants and personnel } \\
\text { (performance bias) } \\
\text { All outcomes }\end{array}$ & Unclear risk & No details provided \\
\hline $\begin{array}{l}\text { Incomplete outcome data (attrition bias) } \\
\text { All outcomes }\end{array}$ & Low risk & $23 / 27$ completed the study \\
\hline Selective reporting (reporting bias) & Unclear risk & No details provided \\
\hline Sample size & High risk & Fewer than 50 participants per trial arm \\
\hline
\end{tabular}

\section{Lee 2011}

Methods

Participants
Randomised, controlled, parallel, single-centre trial

98 women entered the trial with a history of primary breast cancer managed by chemotherapy or hormonal therapy, experienced menopause for a period of at least 12 months before the study, and at baseline in both trial arms on average there was a high degree of vulvovaginal dryness with pain (with a score of 10 indicating the highest score; in the intervention group the score was over 8.20 and in the placebo group 7.92) and dyspareunia (with a score of 10 indicating the highest score; in both the intervention and placebo groups it was over 8). Excluded were natural menopause, medical disease or other complications, other malignancies, a hysterectomy or oophorectomy, use of medication for uro-gynaecologic problems, unexplained vaginal bleeding and previous use of systemic or local sex hormones

Mean age in the intervention group was 45 years and in the control group 44 . At baseline in both trial arms participants (or most) reported painful intercourse. Over half of the participants were treated with chemotherapy plus hormonal therapy; the others were treated either by chemotherapy only or hormonal therapy only

Interventions

Intervention: $\mathrm{pH}$-balanced gel; the gel contained lactic acid to maintain the vaginal $\mathrm{pH}$ at about 4

Comparison: placebo gel (pH 7.2)

Both gels were applied via a vaginal applicator 3 times per week at bedtime

Time length of intervention: 12 weeks

Time since cancer treatment: not reported

Outcomes

Vaginal dryness and dyspareunia measured by visual analogue scale, vaginal health index and vaginal $\mathrm{pH}$

Notes

Risk of bias

Bias

Authors' judgement

Support for judgement

Interventions for sexual dysfunction following treatments for cancer in women (Review) 


\section{Lee 2011 (Continued)}

\begin{tabular}{|c|c|c|}
\hline $\begin{array}{l}\text { Random sequence generation (selection } \\
\text { bias) }\end{array}$ & Low risk & $\begin{array}{l}\text { Random assignment was made from a con- } \\
\text { fidential list of permuted blocks of } 4 \text { by a } \\
\text { third party before the study }\end{array}$ \\
\hline
\end{tabular}

third party before the study

Allocation concealment (selection bias) Low risk

Random assignment was made from a confidential list of permuted blocks of 4 by a third party before the study

Blinding of participants and personnel Low risk (performance bias)

All outcomes

The same-sized vaginal gel tubes with or without lactic acid $(\mathrm{pH} 4.0$ and $\mathrm{pH} 7.2$, respectively) were packaged identically by the manufacturer and labelled with sequential numbers according to the randomisation code

Incomplete outcome data (attrition bias) Low risk $5 / 49$ lost to follow-up in the intervention All outcomes arm and 7/42 in the placebo arm

\begin{tabular}{lll}
\hline Selective reporting (reporting bias) & Low risk & Results for primary outcomes provided \\
\hline Sample size & High risk & Fewer than 50 participants per trial arm
\end{tabular}

Marcus 2010

Methods

Participants
Multi-centred, randomised, parallel, controlled trial

304 US female breast cancer patients post-treatment, which included chemotherapy, radiation therapy, surgery and tamoxifen, entered the trial. The most common cancer treatment was chemotherapy (226/306). Most participants were aged between 41 and 60 years. At baseline there was a level of SD as documented in a figure (degree of SD not stated). It was assessed using a scale of 25 items of which some of the items were developed specifically for this project

Interventions

Psycho-therapeutic

Aim: to determine whether a telephone counselling programme can improve psychosocial outcomes among breast cancer patients post-treatment

Interventionist: psychosocial oncology counsellor

Intervention content: telephone counselling programme augmented with additional print materials. Patients were given the choice to prioritise counselling on 1 of 6 themes of the materials: these were living with uncertainty, living with physical change, living with self change, sexuality after breast cancer, living in relationships and living with economic change. The aim was to enhance adaptation by normalising feelings of uncertainly and preparing survivors for unanticipated disruption across quality of life domains (physical, emotional, social, sexual and economic). The intervention also included printed material (stress management guide), relaxation tapes, written activities (including self monitoring) and feedback on progress at session 10

Comparison group: received a resource directory for breast cancer

Duration of intervention: 16 sessions of 45 minutes each over 1 year, first 9 provided at 
2 weekly time points

Time since cancer treatment: states "just" completed treatment for breast cancer

\begin{tabular}{|c|c|c|}
\hline Outcomes & \multicolumn{2}{|c|}{$\begin{array}{l}\text { Primary outcome: none declared } \\
\text { 1. Cancer-specific distress: Impact of Event Scale (IES) } \\
\text { 2. Depression: Center for Epidemiologic Studies Depression Scale (CES-D) } \\
\text { 3. Sexual Dysfunction using the Sexual Dysfunction Scale (not referenced) } \\
\text { 4. Personal growth from cancer experience: questions derived for survey } \\
\text { Assessment at 3, 6, } 12 \text { and } 18 \text { months }\end{array}$} \\
\hline Notes & - & \\
\hline \multicolumn{3}{|l|}{ Risk of bias } \\
\hline Bias & Authors' judgement & Support for judgement \\
\hline $\begin{array}{l}\text { Random sequence generation (selection } \\
\text { bias) }\end{array}$ & Unclear risk & No details on randomisation \\
\hline Allocation concealment (selection bias) & Unclear risk & No details provided \\
\hline $\begin{array}{l}\text { Blinding of participants and personnel } \\
\text { (performance bias) } \\
\text { All outcomes }\end{array}$ & Unclear risk & No details provided \\
\hline $\begin{array}{l}\text { Incomplete outcome data (attrition bias) } \\
\text { All outcomes }\end{array}$ & Low risk & $\begin{array}{l}\text { The response rates at each follow-up did } \\
\text { not differ by trial arm. } 243 / 304 \text { completed; } \\
\text { reasons not provided }\end{array}$ \\
\hline Selective reporting (reporting bias) & Unclear risk & No details provided \\
\hline Sample size & Unclear risk & 50 to 199 per treatment arm \\
\hline
\end{tabular}

Rowland 2009

Methods

Participants
Randomised, parallel, controlled trial involving 3 arms; 1) Intervention, 2) Intervention participants randomised to intervention but declined intervention but follow-up, 3) Control group

411 US women with breast cancer who had completed all cancer therapy except Tamoxifen entered the trial. 294 completed the trial. Mean age 57 years in the intervention group and 56 in the control group (range 35 to 86). Participants had either lumpectomy, mastectomy only or mastectomy and reconstruction. Around half had also received chemotherapy. Mean years since diagnosis: 3 years in the control group, 2.8 in the intervention group. Majority (over 80\%) Anglo-American. Majority (over 70\%) married. Minority (third) were educated to postgraduate level. Around half of the participants were employed. All who were invited had reported in an earlier study that they had problems with body image, sexuality and intimacy and/or communication with a partner. Degree 
Rowland 2009 (Continued)

of sexual problems were not further detailed

Interventions

Psychotherapeutic: the intervention was derived from the trialists' conceptual model of the development of SD in breast cancer survivors

Directed at the patient

Aim: hypothesis that women in the intervention arm would experience greater improvement in their emotional wellbeing as well as body image, comfort and satisfaction with sexual functioning and partner communication than women randomised to the control group

Interventionist: medical social workers

Intervention content: psychoeducational group programme derived from the trialists' conceptual model of the development of sexual dysfunction. The programme aimed to improve satisfaction with sexual functioning and intimate relationships by providing information, enhancing communication skills and reducing anxiety in intimate situations. To ensure quality control investigators review audiotapes of a subset of sessions Comparison group: received an educational pamphlet: 'Facing forward: a guide for cancer survivors'

Duration of intervention: 6 weekly 2-hour meetings

Time since cancer treatment: not stated

Outcomes

Primary outcome was the Mental Health Index from the Medical Outcomes Study

Secondary outcomes included Likert scale items to measure sexual outcomes

Outcomes assessed 4 months after treatment

Notes

$83 / 284(29 \%)$ randomised to the intervention group did not agree to take part in the intervention. The primary reasons were inconvenience in time or location of the sessions, the participant's perception that she was not distressed and did not need the intervention and being too busy

Risk of bias

\begin{tabular}{l|l|l}
\hline Bias & Authors' judgement & Support for judgement \\
\hline $\begin{array}{l}\text { Random sequence generation (selection } \\
\text { bias) }\end{array}$ & Unclear risk & No details provided \\
\hline $\begin{array}{l}\text { Allocation concealment (selection bias) } \\
\begin{array}{l}\text { Blinding of participants and personnel } \\
\text { (performance bias) } \\
\text { All outcomes }\end{array}\end{array}$ & Unclear risk & No details provided \\
\hline $\begin{array}{l}\text { Incomplete outcome data (attrition bias) } \\
\text { All outcomes }\end{array}$ & Low risk & No details provided \\
\hline $\begin{array}{l}\text { Selective reporting (reporting bias) } \\
\text { Sample size }\end{array}$ & Unclear risk & $95 / 411$ lost to follow-up; no reasons stated \\
\hline
\end{tabular}

Interventions for sexual dysfunction following treatments for cancer in women (Review)

Copyright $\Subset 2016$ The Cochrane Collaboration. Published by John Wiley \& Sons, Ltd. 
Methods

Participants

Randomised, parallel, controlled trial

300 African American women who were breast cancer survivors entered the trial. Participants at baseline had sexual dysfunction using the Female SFI: the mean score across the entire sample was 18.2 (the recommended score for indicating sexual dysfunction is less than 26.5). Treatments for cancer varied; most commonly it was surgery and/or chemotherapy or radiotherapy. Mean age 54 years. Time since cancer diagnosis 6.5 years

Psychotherapeutic

Directed at the patient

Aim: to assess the effectiveness of the peer counselling programme compared with brief telephone counselling and to examine the influence of socio-medical factors on reproductive problems and the outcome of the intervention

Interventionist: trained counsellors who were African American breast cancer survivors Intervention 1: Sisters Peer Counseling involving a 77 page workbook plus 3 sessions with a trained peer counsellor. Each 60- to 90-minute session focused on a chapter of the workbook. Each chapter began with a list of topics (such as how to overcome vaginal dryness) and the survivor rated the importance of each topic before the counselling session; this helped to tailor the focus of the discussion

Intervention 2: telephone counselling, which included being sent the workbook and being invited to call the counsellor using a prepaid telephone card for up to 30 minutes to discuss the workbook

Duration of treatment: 3 sessions over 6 weeks

Time since cancer treatment: not stated

Outcomes

Emotional distress, sexual function, relationship satisfaction, spirituality, menopause symptoms and knowledge. Outcomes assessed up to 1 year after start of the intervention

Notes

Risk of bias

Bias

Random sequence generation (selection Unclear risk bias)
Authors' judgement

Unclear risk

Unclear risk

Blinding of participa
(performance bias)

All outcomes

Incomplete outcome data (attrition bias) High risk

All outcomes
Unclear risk

\section{Support for judgement}

Minimisation techniques - a form of adaptive randomisation. They do not provide details on sequence generation

No details provided

No details provided

$189 / 300$

Selective reporting (reporting bias) 
Schover 2011 (Continued)

\begin{tabular}{l|l}
\hline Sample size & Unclear risk \\
\hline Schover $\mathbf{2 0 1 3}$ & Randomised, parallel, controlled trial \\
\hline Methods & $\begin{array}{l}58 \text { US survivors of localised breast or gynaecologic cancers entered the trial. The majority } \\
\text { (71\%) had received chemotherapy, } 7 \% \text { pelvic radiation and } 19 \% \text { were taking tamoxifen. }\end{array}$ \\
\hline Participants & $\begin{array}{l}\text { Mean age } 58 \text { years. Over } 59 \% \text { had at least } 4 \text { years college education, the majority were } \\
\text { white (79\%) and married }(81 \%) .81 \% \text { had breast cancer, the others gynaecologic. } 54 \% \\
\text { were at cancer stage I. Mean years since diagnosis 3.5. 48\% had a comorbid condition } \\
\text { including diabetes, depression and hypertension. All had some indication at baseline } \\
\text { of sexual dysfunction using the Female Sexual Function Index (FSFI) as indicated by a } \\
\text { score of less than } 26.5 \text {. Scores for this scale range from } 2 \text { to } 36, \text { with the lower the score } \\
\text { the poorer is sexual function }\end{array}$ \\
\hline
\end{tabular}

Interventions

Web-based intervention called Tendrils: sexual renewal for women after cancer Intervention directed at the patient

Aim: the efficacy of a trial of an Internet-based intervention for cancer-related female sexual dysfunction with the support of 3 counselling sessions compared to when the website is used as a self help site

Intervention: website with sections describing the sexual and fertility consequences of their cancer and treatment, an interactive vulva self portrait with pain and pleasure mapping, sex after menopause; management of vaginal dryness and pain; causes and treatment options for loss of desire or orgasm problems; resuming sex. It also involved videos of women cancer survivors and vignettes played by actors illustrating common problems and coping strategies. A therapist manual provided guidance and content checklists during 3 counselling sessions. These were provided by 2 masters level mental health professionals. The counsellors guided women through the website and discussed behavioural homework

Comparison: self help, which involved access to the website but no provision of a counsellor

Duration of intervention: 12 weeks

Time since cancer treatment: unclear

Outcomes

The primary outcome was the FSFI. Other outcomes were the Menopausal Sexual Internet Questionnaire, the Brief Symptom Inventory, Global Severity Index and the Quality of Life in Adult Cancer Survivors

Outcomes were assessed at end of treatment and at 3- and 6-month follow-up

Notes

\section{Risk of bias}

Bias

Random sequence generation (selection Unclear risk bias)
Authors' judgement

Support for judgement

Randomisation stated, no details provided

Interventions for sexual dysfunction following treatments for cancer in women (Review) 
Schover 2013 (Continued)

\begin{tabular}{l|ll}
\hline Allocation concealment (selection bias) & Unclear risk & No details provided \\
\hline $\begin{array}{l}\text { Blinding of participants and personnel } \\
\text { (performance bias) } \\
\text { All outcomes }\end{array}$ & Unclear risk & No details provided \\
\hline $\begin{array}{l}\text { Incomplete outcome data (attrition bias) } \\
\text { All outcomes }\end{array}$ & Unclear risk & No details provided \\
\hline Selective reporting (reporting bias) & Unclear risk & No details provided \\
\hline Sample size & High risk & Fewer than 50 participants per trial arm \\
\hline
\end{tabular}

Svensk 2009

Methods

Participants

Interventions

Outcomes

Notes

Risk of bias
Randomised, controlled, parallel trial

42 Swedish women with breast cancer who were undergoing radiotherapy entered the trial. Median age in the intervention group was 59.5 years and in the control group 55 years. Participants had a reduced level of sexual function and enjoyment at the first assessment following breast cancer treatments. This was indicated by the lower baseline scores for the EORTC QLQ-BR23 subscale on sexual functioning at baseline in both trial arms

Intervention: art therapy involving 5 individual sessions for 1 hour a week. The aim was to offer time and space for expression and reflection, to give support in the process of restoring body image and to reduce stress. Sessions were based on a phenomenological method of art therapy

Comparison: no details

Intervention length: 5 weeks

Time since cancer treatment: ongoing

\begin{tabular}{l} 
Sutcomes \\
$\begin{array}{l}\text { Sexual functioning measured using the EORTC Quality of Life Questionnaire, version } \\
\text { 1.0. It includes } 23 \text { items to assess as well as sexual functioning and enjoyment, disease } \\
\text { symptoms, side effects, body image and future perspectives } \\
\text { Quality of life using (1) the Swedish version of the WHO instrument WHOQOL- } \\
\text { BREF. This involves } 26 \text { items in } 4 \text { domains: physical, psychological, social relationships } \\
\text { and environment, and the (2) the European Organization for Research and Treatment } \\
\text { of Cancer Instrument } \\
\text { Outcomes measured before randomisation and start of radiotherapy, } 2 \text { months later and } \\
6 \text { months later }\end{array}$ \\
\hline Notes
\end{tabular}

Bias

Authors' judgement

Support for judgement 
Svensk 2009 (Continued)

\begin{tabular}{l|l|l}
\hline $\begin{array}{l}\text { Random sequence generation (selection } \\
\text { bias) }\end{array}$ & Low risk & $\begin{array}{l}\text { "computer generated". Stratification was done } \\
\text { according to whether the patient had received } \\
\text { adjuvant chemotherapy before radiotherapy } \\
\text { treatment or not }\end{array}$ \\
\hline $\begin{array}{l}\text { Allocation concealment (selection bias) } \\
\text { (plinding of participants and personnel } \\
\text { All outcomes }\end{array}$ & Low risk & $\begin{array}{l}\text { The randomisation was computer-generated at } \\
\text { the Regional Centre of Oncology at Umea } \\
\text { University }\end{array}$ \\
\hline $\begin{array}{l}\text { Incomplete outcome data (attrition bias) } \\
\text { All outcomes }\end{array}$ & Low risk & $\begin{array}{l}\text { Participants could not be blinded because of the } \\
\text { nature of the intervention; does not state that } \\
\text { the analyst or other personnel were blinded }\end{array}$ \\
\hline $\begin{array}{l}\text { Selective reporting (reporting bias) } \\
\text { Sample size }\end{array}$ & Unclear risk & 42/42 completed the study \\
\hline
\end{tabular}

Yang 2012

Methods

Participants

Interventions
Randomised, parallel, controlled pilot trial

34 South Korean women with gynaecological cancer who had radical hysterectomy entered and 24 completed trial. Study included because at the start of the intervention in both trial arms the overall mean on sexual function using the sexual function score of the Pelvic Floor Questionnaire indicated sexual dysfunction. Total scores in scale range from 0 to 20.8 items on the scale cover sufficient lubrication, vaginismus, coital incontinence, vaginal laxity, dyspareunia and sexual bother. A zero score means no problem in any of the items. In the intervention group the mean score was 6.02 and in the intervention group 4.62. Mean age 52 years

Exercise intervention

Intervention directed at patient

Aim: to investigate the effectiveness of this pelvic floor rehabilitation programme on pelvic floor function and quality of life in gynaecological cancer survivors

Interventionist: physiotherapist

Intervention content: intensive pelvic floor muscle training incorporated with core exercise. The exercise is with biofeedback via a vaginal silicon pressure sensor. There was also per session a 30-minute counselling session, which involved life-style advice, evaluation and encouragement. In the first week patients learnt about the anatomy and function of the pelvic floor muscles

Comparison group received usual health care

Duration of intervention: weekly for 4 weeks of 45 exercises of 30 minutes duration

Time since cancer treatment: does not specify but less than 5 years 
Yang 2012 (Continued)

\begin{tabular}{|c|c|c|}
\hline Outcomes & \multicolumn{2}{|c|}{$\begin{array}{l}\text { Primary outcome not stated } \\
\text { (1) Pelvic floor dysfunction questionnaire } \\
\text { (2) Pelvic floor muscle strength } \\
\text { (3) Motor evoked potential (MEP) of the sacral nerve } \\
\text { (4) Patient-reported health-related quality of life (HRQOL) measured using the Euro- } \\
\text { pean Organization for } \\
\text { Research and Treatment of Cancer (EORTC) quality of life questionnaire QLQ-C30 } \\
\text { (a } 30 \text {-item multidimensional questionnaire on global health/quality of life) and the } \\
\text { EORTC QLQ-CX-24 (a specific cervical cancer module of patients' experience, body } \\
\text { image and sexuality) } \\
\text { Outcomes were assessed at } 4 \text { weeks }\end{array}$} \\
\hline Notes & - & \\
\hline \multicolumn{3}{|l|}{ Risk of bias } \\
\hline Bias & Authors' judgement & Support for judgement \\
\hline $\begin{array}{l}\text { Random sequence generation (selection } \\
\text { bias) }\end{array}$ & Low risk & $\begin{array}{l}\text { Computerised, stratified block randomisa- } \\
\text { tion }\end{array}$ \\
\hline Allocation concealment (selection bias) & Unclear risk & No details provided \\
\hline $\begin{array}{l}\text { Blinding of participants and personnel } \\
\text { (performance bias) } \\
\text { All outcomes }\end{array}$ & Unclear risk & $\begin{array}{l}\text { Blinding of participants not possible be- } \\
\text { cause of the nature of the intervention. To } \\
\text { avoid knowledge of an individual's train- } \\
\text { ing progression and thereby potentially in- } \\
\text { fluencing the process of measurement the } \\
\text { training sessions and strength measure- } \\
\text { ments were administered by different peo- } \\
\text { ple. Outcome evaluators were blinded to } \\
\text { group allocation }\end{array}$ \\
\hline $\begin{array}{l}\text { Incomplete outcome data (attrition bias) } \\
\text { All outcomes }\end{array}$ & Low risk & Similar in both arms and reasons provided \\
\hline Selective reporting (reporting bias) & Unclear risk & No details provided \\
\hline Sample size & High risk & Fewer than 50 participants per trial arm \\
\hline
\end{tabular}

CSFQ: Changes of Sexual Functioning Questionnaire

EORTC: the European Organization for Research and Treatment of Cancer Quality of Life Questionnaire

FSFI: Female Sexual Function Index

HADS: Hospital Anxiety and Depression Scale

SD: sexual dysfunction

WHOQOL-BREF: World Health Organization quality of life instrument

Interventions for sexual dysfunction following treatments for cancer in women (Review) 
Characteristics of excluded studies [ordered by study ID]

\begin{tabular}{|c|c|}
\hline Study & Reason for exclusion \\
\hline Badger 2005 & SD not mentioned \\
\hline Barber 2002 & Article includes sexual functioning, but cancer patients were not included \\
\hline Barrett-Connor 1996 & It is unlikely that these "healthy menopausal women" are cancer patients \\
\hline Berman 2003 & No cancer patients \\
\hline Boesen 2011 & No documented evidence that at the start of the intervention the participants had SD \\
\hline Brotto 2012 & $\begin{array}{l}\text { Around half of the participants were not randomised and there was no separate analysis for those who were } \\
\text { randomised }\end{array}$ \\
\hline Burstein 1999 & This is not a RCT and alternative medicine was not an intervention for SD \\
\hline Chow 2014 & Does not differentiate whether the SD was before or after the cancer treatment \\
\hline Christensen 1983 & No baseline of SD provided \\
\hline Davis 2004 & $\begin{array}{l}\text { Exploratory study of psychosocial needs of women with breast cancer. Not an intervention for SD following } \\
\text { treatments for cancer }\end{array}$ \\
\hline Decruze 1999 & Not a RCT \\
\hline Dennerstein 1979 & No cancer patients \\
\hline Doorenbos 2006 & No SD outcome \\
\hline Floter 2002 & No cancer patients \\
\hline Ganz 2000 & $\begin{array}{l}\text { Subjects were peri or postmenopausal (they had to have been amenorrhoeic for at least } 6 \text { months). The cause } \\
\text { of sexual dysfunction was not studied in this sample and some women may have had problems that preceded } \\
\text { the cancer diagnosis or could have been attributed to treatment }\end{array}$ \\
\hline Given 2004 & No SD outcome \\
\hline Goetsch 2014 & No outcomes on sexual function \\
\hline Hasenbring 1999 & No SD outcome \\
\hline Huang 2013 & Patients with cancer were excluded \\
\hline Izuo 1967 & No sexual function outcomes \\
\hline Jefferies 2006 & No established baseline report of SD \\
\hline
\end{tabular}

Interventions for sexual dysfunction following treatments for cancer in women (Review)

Copyright @ 2016 The Cochrane Collaboration. Published by John Wiley \& Sons, Ltd. 
(Continued)

\begin{tabular}{|c|c|}
\hline Jones 2006 & No sexual function outcomes \\
\hline Jung Hoon 2006 & No sexual function outcomes \\
\hline Juraskova 2013 & No comparative arm \\
\hline Kylstra 1999 & Not a treatment for SD \\
\hline Lengacher 2009 & No sexual function outcomes \\
\hline Lepore 2015 & No outcomes on sexual function \\
\hline Loprinzi 2011 & No sexual outcomes \\
\hline Marsden 2001 & $\begin{array}{l}\text { Subjects are postmenopausal. The cause of sexual dysfunction was not studied in this sample and some } \\
\text { women may have had problems that preceded the cancer diagnosis or could have been attributed to treatment }\end{array}$ \\
\hline Moore 1999 & No cancer patients \\
\hline Morales 2004 & Tamoxifen: not a treatment for SD \\
\hline Mulhall 2006 & Discussion paper \\
\hline Munarriz 2002 & No cancer patients \\
\hline Munstedt 1998 & Not evaluating treatment for SD \\
\hline Narvaez 2008 & Less than $50 \%$ reported sexual problems at baseline \\
\hline Nho 2013 & Not a RCT \\
\hline Nieman 2003 & No cancer patients \\
\hline Nikander 2003 & No sexual outcome measures \\
\hline Northouse 2002 & SD not specifically mentioned \\
\hline Northouse 2013 & Does not measure sexual function outcomes \\
\hline Park 2015 & Not a randomised trial \\
\hline Pietrzak 2007 & Not a treatment for SD \\
\hline Pitkin 1971 & Intervention was a preventative treatment \\
\hline Ponzone 2005 & Discussion article \\
\hline Rawlins 1999 & Discussion article \\
\hline
\end{tabular}


(Continued)

\begin{tabular}{|c|c|}
\hline Reese 2014 & $\begin{array}{l}6 \text { relevant participants; it is not clear whether for any one the sexual concerns started after treatment or prior } \\
\text { to treatment for cancer }\end{array}$ \\
\hline Robinson 1999 & No established baseline report of SD \\
\hline Schover 2006 & Does not provide outcomes per trial arm \\
\hline Schroder 2005 & Not a RCT \\
\hline Scott 2004 & Participants on average had poor sexual functioning prior to cancer treatment \\
\hline Seidman 2000 & No cancer patients \\
\hline Serewel 1990 & No cancer patients. \\
\hline Shabani 2014 & Does not measure sexual outcomes \\
\hline Sherwin 1984 & Not about treatments for SD following treatment for cancer \\
\hline Sherwin 1985 & No cancer patients \\
\hline Shifren $2000 \mathrm{a}$ & No cancer patients \\
\hline Suckling 2006 & Discussion paper \\
\hline Sweeney 2002 & Not an intervention for SD \\
\hline Theobald 2002 & No SD outcomes \\
\hline Thompson 2003 & SD is under " other symptoms" with other non-SD symptoms, t herefore data are not evaluable \\
\hline van der Meulen 2014 & No sexual function outcomes \\
\hline Vos 2006 & No SD outcomes \\
\hline Warkentin 2006 & Not a RCT \\
\hline Watts 1995 & No cancer patients \\
\hline Wei 2005 & $\begin{array}{l}\text { This is a poor quality report of a RCT of psychotherapy for } 1 \text { week before and } 1 \text { week after an (unspecified) } \\
\text { operation for cervical cancer. The baseline level of "sexual functioning" amongst participants is not reported, } \\
\text { either before or after the operation. } \\
\text { It is unclear who the male participants were and who answered the questionnaire } \\
\text { The sexual outcome "sexual satisfaction" is self reported using what appears to be a single question } \\
\text { The figures given are not explained (so it is not clear whether they are means or medians, for example) } \\
\text { The randomisation procedure is not well explained }\end{array}$ \\
\hline Wenzel 1999 & An assessment for SD and not a treatment \\
\hline
\end{tabular}


(Continued)

Wenzel 2015

Although SD measure d it is part of a global score (with no reported subscale) on gynaecological problems

Wu 2014

Does not measure sexual dysfunction

RCT: randomised controlled trial

SD: sexual dysfunction

Characteristics of studies awaiting assessment [ordered by study ID]

Esplen 2014

\begin{tabular}{ll}
\hline Methods & RCT \\
\hline Participants & Breast cancer survivors \\
\hline Interventions & Group therapy and guided imagery \\
\hline Outcomes & Sexual functioning \\
\hline Notes & Conference abstract of a study that has been completed - probably fits eligibility criteria - await full published version \\
\hline
\end{tabular}

Goetsch 2015

\begin{tabular}{ll}
\hline Methods & RCT \\
\hline Participants & Breast cancer survivors \\
\hline Interventions & Analgesic liquid \\
\hline Outcomes & Penetration pain and sexual distress \\
\hline Notes & Conference abstract of study that has been completed - probably fits eligibility criteria - await full published version
\end{tabular}

Gremore 2014

\begin{tabular}{ll}
\hline Methods & RCT \\
\hline Participants & Patients with head and neck cancer and their partners \\
\hline Interventions & Couple-based psychosocial intervention \\
\hline
\end{tabular}

Outcomes Not clear 


\section{Gremore 2014 (Continued)}

Notes Study in progress - unclear if eligible

Hickey 2015

\begin{tabular}{ll}
\hline Methods & RCT \\
\hline Participants & Women with breast cancer \\
\hline Interventions & Lubricant for vaginal dryness \\
\hline Outcomes & Sexual discomfort \\
\hline Notes & Publication only of a conference abstract with preliminary findings
\end{tabular}

\section{Jensen 2014}

\begin{tabular}{ll}
\hline Methods & RCT \\
\hline Participants & Patient undoing a radical cystectomy \\
\hline Interventions & Home-based exercises \\
\hline Outcomes & Quality of life measures \\
\hline Notes & Study in progress - unclear if eligible \\
\hline Paterson 2015 & \\
\hline Methods & RCT \\
\hline Participants & Breast cancer survivors \\
\hline Interventions & Mindfulness-based stress reduction programme \\
\hline Outcomes & Sexual distress and body image disturbances \\
\hline Notes & Conference abstract of a study that is in progress - unclear if fits eligibility criteria \\
\hline
\end{tabular}

Willems 2015

\begin{tabular}{ll}
\hline Methods & RCT \\
\hline Participants & Cancer survivors \\
\hline Interventions & Web-based tailored intervention on psychosocial and lifestyle support \\
\hline $\begin{array}{l}\text { Interventions for sexual dysfunction following treatments for cancer in women (Review) } \\
\text { Copyright } \odot 2016\end{array}$
\end{tabular}


Willems 2015

(Continued)

\begin{tabular}{ll} 
Outcomes & Not stated \\
\hline Notes & Conference abstract of a study that is in progress - unclear if fits eligibility criteria
\end{tabular}

RCT: randomised controlled trial

Characteristics of ongoing studies [ordered by study ID]

Davis 2015

\begin{tabular}{ll}
\hline Trial name or title & - \\
\hline Methods & RCT \\
\hline Participants & Women with breast cancer being treated with an aromatase inhibitor \\
\hline Interventions & $300 \mu$ g intravaginal testosterone therapy \\
\hline Outcomes & Sexual dysfunction \\
\hline Starting date & - \\
\hline Contact information & - \\
\hline Notes & -
\end{tabular}

\section{DuHamel 2013}

\begin{tabular}{ll} 
Trial name or title & Cancer Survivorship Intervention-Sexual Health (CSI-SH) \\
\hline Methods & Pilot RCT \\
\hline Participants & Female rectal and anal cancer survivors \\
\hline Interventions & $\begin{array}{l}\text { 4 intervention sessions focused on different topics including education about the impact of treatment and } \\
\text { specific strategies for sexual health. The first 3 sessions were followed by booster telephone sessions to review } \\
\text { the strategies }\end{array}$ \\
\hline Outcomes & $\begin{array}{l}\text { Assessments were at baseline and approximately } 4 \text { and } 8 \text { months post-baseline with measures of quality of life } \\
\text { (EORTC-QLQ-C30), Sexual Functioning (FSFI) and psychological wellbeing (e.g. Impact of Events Scale- } \\
\text { Revised: IES-R) }\end{array}$ \\
\hline Starting date & Not reported \\
\hline Contact information & duhamelk@mskcc.org
\end{tabular}


DuHamel 2013 (Continued)

Notes

Gessler 2015

Trial name or title Developing a Stepped Approach to improving sexual Function aFteR treatment fOr gyNaecological cance (SAFFRON)

\begin{tabular}{ll}
\hline Methods & RCT \\
\hline Participants & Women treated for gynaecological cancer \\
\hline Interventions & $\begin{array}{l}\text { The stepped care intervention will be developed over the first } 6 \text { months of the project. It will involve psycho- } \\
\text { logical therapies }\end{array}$ \\
\hline Outcomes & Sexual function \\
\hline Starting date & January 2014 \\
\hline Contact information & s.gessler@ucl.ac.uk \\
\hline Notes & - \\
\hline
\end{tabular}

Hummel 2015

\begin{tabular}{ll}
\hline Trial name or title & $\begin{array}{l}\text { KIS Study: a study evaluating the effectiveness of an internet-based therapy program for sexuality and intimacy } \\
\text { problems in women treated for breast cancer }\end{array}$ \\
\hline Methods & RCT \\
\hline Participants & Breast cancer survivors \\
\hline Interventions & Behavioural: internet-based cognitive behavioural therapy \\
\hline Outcomes & Sexuality problems \\
\hline Starting date & December 2012 \\
\hline Contact information & 1.hummel@nki.nl \\
\hline Notes & ClinicalTrials.gov Identifier: NCT02091765 \\
\hline
\end{tabular}




\section{NCT00459134 2015}

Trial name or title L-Arginine supplements in treating women who are cancer survivors

\begin{tabular}{ll}
\hline Methods & RCT \\
\hline Participants & Cancer survivors with sexual dysfunction \\
\hline Interventions & L-Arginine supplements \\
\hline Outcomes & Sexual function \\
\hline Starting date & 2007; study is reported to have been completed but no publication of results identified \\
\hline Contact information & Not provided \\
\hline Notes & -
\end{tabular}

\section{NCT02091765 2015}

Trial name or title KIS Study: a study evaluating the effectiveness of an Internet-based therapy program for sexuality and intimacy problems in women treated for breast cancer. ID NCT02091765

\begin{tabular}{ll}
\hline Methods & RCT \\
\hline Participants & Breast cancer survivors with intimacy problems \\
\hline Interventions & Internet-based cognitive behavioural therapy \\
\hline Outcomes & Sexuality problems \\
\hline Starting date & 2014 \\
\hline Contact information & Neil K Aaronson n.aaronson@nki.nl \\
\hline Notes & -
\end{tabular}

\section{Schofield 2013}

\begin{tabular}{ll}
\hline Trial name or title & The PeNTAGOn study (peer and nurse support trial to assist women in gynaecological oncology) \\
\hline Methods & RCT \\
\hline Participants & Women in gynaecological oncology receiving curative radiotherapy \\
\hline Interventions & A nurse- and peer-led support programme
\end{tabular}

Outcomes Primary outcome: psychological distress. Secondary outcomes: patient quality of life, symptom distress, unmet supportive care needs, preparation for treatment, psychosexual functioning and vaginal stenosis 
Schofield 2013 (Continued)

\begin{tabular}{ll} 
Starting date & Not reported \\
\hline Contact information & Penelope.schofield@petermac.org \\
\hline Notes & - \\
\hline
\end{tabular}

RCT: randomised controlled trial 


\section{DATAANDANALYSES}

This review has no analyses.

\section{ADDITIONAL TABLES}

Table 1. Barton 2007 scores for sexual functioning

\begin{tabular}{llll}
\hline Measure & Arm & Mean score $(\mathbf{9 5 \%}$ CI) Week 4* & Mean score (95\% CI) Week 8** \\
\hline $\begin{array}{l}\text { Changes in Sexual } \\
\text { Functioning Questionnaire }\end{array}$ & $\begin{array}{l}\text { Rx/placebo } \\
\text { Placebo/Rx }\end{array}$ & $\begin{array}{l}5.69(4.13 \text { to } 10.63) \\
3.40(2.08 \text { to } 6.75)\end{array}$ & $\begin{array}{l}6.87(6.42 \text { to } 11.38) \\
8.17(7.36 \text { to } 13.82)\end{array}$ \\
\hline $\begin{array}{l}\text { Changes in Sexual } \\
\begin{array}{l}\text { Functioning Questionnaire, } \\
\text { Pleasure subscale }\end{array}\end{array}$ & $\begin{array}{l}\text { Rx/placebo } \\
\text { Placebo/Rx }\end{array}$ & $\begin{array}{l}9.38(7.00 \text { to } 11.23) \\
4.71(0.43 \text { to } 8.98)\end{array}$ & $\begin{array}{l}9.33(6.84 \text { to } 16.49) \\
11.04(9.03 \text { to } 18.59)\end{array}$ \\
\hline $\begin{array}{l}\text { Profile of Mood States } \\
\text { Rx/placebo }\end{array}$ & Placebo/Rx & $-0.55(-3.77$ to 2.67$)$ & $1.07(-1.89$ to 4.03$)$ \\
\hline $\begin{array}{l}\text { Profile of Mood States, } \\
\text { Vitality subscale }\end{array}$ & $\begin{array}{l}\text { Rx/placebo } \\
\text { Placebo/Rx }\end{array}$ & $\begin{array}{l}0.56(-2.58 \text { to } 3.71) \\
2.76(-0.52 \text { to } 6.04)\end{array}$ & $\begin{array}{l}1.82(-1.74 \text { to } 8.07) \\
4.68(2.01 \text { to } 7.34)\end{array}$ \\
\hline
\end{tabular}

CI: confidence interval

$\mathrm{Rx}$ : intervention

${ }^{*}$ Pre-cross-over; ${ }^{* *}$ Post-cross-over

Table 2. Aktas 2014 follow-up subscale scores for sexual function

\begin{tabular}{|c|c|c|}
\hline Measure* & Mean score at follow-up in intervention group & Mean score at follow-up in control group \\
\hline Sexual non-communication & $5.14(\mathrm{SD} 2.07)$ & $6.94(\mathrm{SD} 1.28)$ \\
\hline Anorgasmia & $8.83(\mathrm{SD} 1.79)$ & $11.26(\mathrm{SD} 1.42)$ \\
\hline Avoidance & $6.34(\mathrm{SD} 3.13)$ & $9.60(\mathrm{SD} 2.94)$ \\
\hline Non-sensuality & $7.43(\mathrm{SD} 3.09)$ & $10.20(\mathrm{SD} 2.90)$ \\
\hline Infrequency of sexual contact & $6.03(\mathrm{SD} 1.58)$ & $6.43($ SD 1.77) \\
\hline Sexual dissatisfaction & $7.0(\mathrm{SD} 2.82)$ & $9.63(\mathrm{SD} 2.45)$ \\
\hline Vaginismus & $9.26(\mathrm{SD} 3.01)$ & $12.17(\mathrm{SD} 3.31)$ \\
\hline
\end{tabular}


Table 3. Baucom 2009 follow-up scores for sexual functioning

\begin{tabular}{|c|c|c|}
\hline Measure & $\begin{array}{l}\text { Mean score (SD) at follow-up in interven- } \\
\text { tion group }\end{array}$ & $\begin{array}{l}\text { Mean score (SD) at follow-up in control } \\
\text { group }\end{array}$ \\
\hline Sexual drive and relationship & $13.00(3.11)$ & $9.80(5.93)$ \\
\hline Relationship satisfaction & $39.71(3.45)$ & $40.20(5.07)$ \\
\hline Brief Symptom Inventory & $6.71(5.77)$ & $15.80(20.91)$ \\
\hline Post-traumatic Growth Inventory & $62.00(29.10)$ & $66.20(35.73)$ \\
\hline Functional Well-being FACT-B & $3.22(0.34)$ & $2.89(0.91)$ \\
\hline Self-image Scale - self acceptance & $21.29(4.75)$ & $19.20(9.09)$ \\
\hline Self-image Scale - partner acceptance & $21.96(2.27)$ & $21.50(4.79)$ \\
\hline Brief Fatigue Inventory & $2.98(0.96)$ & $3.22(2.25)$ \\
\hline Usual pain & $2.29(1.50)$ & $2.40(1.67)$ \\
\hline Rotterdam Symptom Inventory & $18.71(2.36)$ & $23.80(9.81)$ \\
\hline
\end{tabular}

Table 4. Classen 2013 follow-up subscale scores for sexual function

\begin{tabular}{|c|c|c|}
\hline Measure & $\begin{array}{l}\text { Mean change from baseline score at fol- } \\
\text { low-up in intervention group }\end{array}$ & $\begin{array}{l}\text { Mean change from baseline score at fol- } \\
\text { low-up in control group }\end{array}$ \\
\hline Sexual function intention-to-treat* & $2.54(\mathrm{SD} 9.59)$ & $0.26(\mathrm{SD} 3.19)$ \\
\hline Sexual function actively used* & $3.82(\mathrm{SD} 9.43)$ & $0.26(\mathrm{SD} 3.19)$ \\
\hline $\begin{array}{l}\text { Anxiety and depression }{ }^{* *} \text { intention-to- } \\
\text { treat }\end{array}$ & $0.63(\mathrm{SD} 4.39)$ & $0.50(\mathrm{SD} 2.91)$ \\
\hline Anxiety and depression ${ }^{* *}$ actively used & $1.73(\mathrm{SD} 3.93)$ & $0.50(\mathrm{SD} 2.91)$ \\
\hline Intimacy ${ }^{* * *}$ intention-to-treat & $0.19(\mathrm{SD} 1.33)$ & $-0.17(\mathrm{SD} 1.21)$ \\
\hline Relationship ${ }^{* * *}$ intention-to-treat & $-0.04(\mathrm{SD} 0.68)$ & $-0.01(\mathrm{SD} 0.82)$ \\
\hline Instrumental ${ }^{* * *}$ intention-to-treat & $-0.22(\mathrm{SD} 0.85)$ & $-0.10(\mathrm{SD} 1.26)$ \\
\hline Intimacy $^{* * *}$ & $0.75(\mathrm{SD} 1.01)$ & $-0.17(\mathrm{SD} 1.21)$ \\
\hline
\end{tabular}

Copyright $\odot 2016$ The Cochrane Collaboration. Published by John Wiley \& Sons, Ltd. 
Table 4. Classen 2013 follow-up subscale scores for sexual function (Continued)

\begin{tabular}{|c|c|c|}
\hline Relationship*** & $-0.15(\mathrm{SD} 0.50)$ & $-0.01(\mathrm{SD} 0.82)$ \\
\hline Instrumental ${ }^{* *}$ & $*_{-0.21}(\mathrm{SD} 0.71)$ & $-0.10($ SD 1.26) \\
\hline
\end{tabular}

Table 5. Rowland 2009 follow-up subscale scores for sexual and psychological function

\begin{tabular}{|c|c|c|}
\hline Measure & $\begin{array}{l}\text { Mean baseline (SD) and change score }(S D) \\
\text { at follow-up in intervention group }\end{array}$ & $\begin{array}{l}\text { Mean baseline (SD) and change score (SD) } \\
\text { at follow-up in control group }\end{array}$ \\
\hline Satisfaction with variety of sex & $4.0(1.1), 0.1(1.2)$ & $4.0(1.0),-0.03(1.0)$ \\
\hline Satisfaction with sexual relationship & $4.8(1.1), 0.0(1.5)$ & $4.7(1.4),-0.3(1.3)^{*}$ \\
\hline Pain with sex & $3.8(2.0), 0.7(1.9)$ & $4.1(1.9),-0.1(1.7)$ \\
\hline Pain interfering with pleasure & $4.4(1.7), 0.3(1.4)$ & $4.4(1.7), 0.0(1.1)$ \\
\hline Improved comfort with sexuality* & $3.3(0.6)$ & $3.1(0.6)$ \\
\hline Comfort about being touched & $4.7(1.6), 0.1(1.4)$ & $4.6(1.6),-0.1(1.2)$ \\
\hline Comfort undressing & $4.7(1.7), 0.2(1.9)$ & $5.0(1.4),-0.2(1.8)$ \\
\hline Comfort being nude & $5.3(1.4), 0.3(1.3)$ & $5.2(1.4),-0.1(1.6)$ \\
\hline Impact of cancer on sex & $2.6(1.0), 0.1(0.8)$ & $2.4(1.0), 0.2(0.9)$ \\
\hline Impact on relationship & $50.9(5.7), 1.1(4.0)$ & $51.0(5.6),-1.3(4.6)$ \\
\hline Improved communication* & $3.5(0.7)$ & $3.2(0.7)$ \\
\hline Mental health & $80.8(11.6),-0.7(10.4)$ & $82.6(9.2),-3.8(9.4)$ \\
\hline
\end{tabular}

* Measured at follow-up only

SD: standard deviation 
Table 6. Svensk 2009 follow-up scores

\begin{tabular}{|c|c|c|}
\hline Measure & $\begin{array}{l}\text { Mean score (SD) at follow-up in interven- } \\
\text { tion group }\end{array}$ & $\begin{array}{l}\text { Mean score (SD) at follow-up in control } \\
\text { group }\end{array}$ \\
\hline Sexual function at 2 months & $38.60(24.88)$ & $30.16(28.20)$ \\
\hline Sexual function at 6 months & $34.21(24.52)$ & $28.33(26.55)$ \\
\hline Sexual enjoyment at 2 months & $56.25(26.44)$ & $53.85(25.60)$ \\
\hline Sexual enjoyment at 6 months & $69.05(24.34)$ & $72.22(27.83)$ \\
\hline Overall quality of life at 2 months & $78.75(14.68)$ & $66.67(22.82)$ \\
\hline Overall quality of life at 6 months & $85.00(12.57)$ & $67.50(20.03)$ \\
\hline Physical health at 2 months & $68.75(13.51)$ & $61.39(19.71)$ \\
\hline Physical health at 6 months & $74.82(13.33)$ & $63.93(19.80)$ \\
\hline Psychological health at 2 months & $70.83(15.29)$ & $63.69(15.87)$ \\
\hline Psychological health at 6 months & $73.96(10.28)$ & $69.38(13.13)$ \\
\hline Social relationships at 2 months & $74.58(14.43)$ & $69.44(15.66)$ \\
\hline Social relationships at 6 months & $77.50(12.99)$ & $71.67(16.31)$ \\
\hline Body image at 2 months & $81.67(24.57)$ & $80.95(20.77)$ \\
\hline Body image at 6 months & $91.25(12.82)$ & $83.33(27.64)$ \\
\hline Adverse effects at 2 months & $14.76(11.13)$ & $20.33(12.23)$ \\
\hline Adverse effects at 6 months & $10.24(7.61)$ & $14.97(12.71)$ \\
\hline Breast symptoms at 2 months & $20.42(16.10)$ & $21.03(14.58)$ \\
\hline Breast symptoms at 6 months & $17.08(11.30)$ & $20.63(17.80)$ \\
\hline Arm symptoms at 2 months & $16.11(21.77)$ & $26.46(29.71)$ \\
\hline Arm symptoms at 6 months & $15.56(20.52)$ & $18.52(17.33)$ \\
\hline Upset by hair loss at 2 months & $11.11(19.25)$ & $50.00(23.57)$ \\
\hline Upset by hair loss at 6 months & $25.00(16.67)$ & $50.00(70.71)$ \\
\hline
\end{tabular}


SD: standard deviation

\section{A P P E N D I C ES}

\section{Appendix I. Search strategies}

\section{Electronic database search terms as used in 2015 update}

The search terms used reflected the three components to our research question:

- interventions for SD;

- SD variants;

- treatments for cancer.

The search terms are for both men and women; this is because initially we planned to include interventions for both sexes in one review. The findings were only split when it became apparent that the number of trials would prevent timely completion of a review covering both interventions for men and for women.

\section{CENTRAL (The Cochrane Library)}

\#1 MeSH descriptor: [Alprostadil] explode all trees \#2 MeSH descriptor: [Papaverine] explode all trees \#3 MeSH descriptor: [Phentolamine] explode all trees \#4 MeSH descriptor: [Yohimbine] explode all trees \#5 MeSH descriptor: [Apomorphine] explode all trees \#6 MeSH descriptor: [Potassium Channels] explode all trees

\#7 (alprostadil or androgel or Apomorphine or britaject or aromatase inhibitors or agonist of melancortin receptor or Adcirca or alpha adrenoceptor agonist or alpha-2 adrenoceptor agonist or androgel or arginine or botox or botulinum toxin or bromocriptine or cialis or dopaminergic agents or caverject or clomipramine or cyproheptadine or clonidine or delquamine or edex or hormone therapy or Isoxsuprine or intracavernosal vasodilators or levitra or Lignocaine or l-arginine or lodenfil or Methitest or methyl testosterone or midodrin or mianserin or moclobemide or mirtazapine or mianserin or moclobemide or ortho-gynest or ovestin or papaverine or papaverine-phentolamine or phentolamine or parlodel or phentolamine or potassium channel openers or progestational agents or premarin or prempro or prostins or Prostaglandins or prostaglandin E1 or pentoxifylline or potassium channels or Phosphodiesterase Type 5 or PDE5i or penile suppository or reboxetine or sildenafil or tadalafil or tampovagan or topical or topical cream or vagifem or vaginal cream or vaginal lubricant or vaginal or viagra or vasomax or Viagel or vardenafil or vasodilator or virilon or vasoactive or staxyn or topical estrogen cream or trental or vasodilan or viridal or yohimbine or android or androgen therapy or testosterone or testosterone cream or testosterone gel or testred):ti,ab,kw (Word variations have been searched)

\#8 MeSH descriptor: [Testosterone] explode all trees

\#9 MeSH descriptor: [Penile Implantation] explode all trees

\#10 MeSH descriptor: [Penile Prosthesis] explode all trees

\#11 MeSH descriptor: [Prosthesis Implantation] explode all trees

\#12 (testosterone replacement or testosterone or venous constriction rings or vacuum device* or vacuum erect* or penile implant*

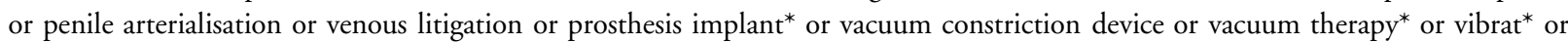
vibrostimulation or electroejaculation or prolong ring*):ti,ab,kw (Word variations have been searched)

\#13 MeSH descriptor: [Aromatase Inhibitors] explode all trees

\#14 (vaginal dilator* or arginine or android or methyl testosterone or testosterone cream or vaginal lubricant or vaginal estradiol ring or vaginal estradiol ring or vaginal estrogen ring or vaginal oestrogen ring or topical estrogen cream or vaginal cream or estrogen replacement of ERT or estrogen replacement or aromatase inhibitors):ti,ab,kw (Word variations have been searched)

Interventions for sexual dysfunction following treatments for cancer in women (Review)

Copyright @ 2016 The Cochrane Collaboration. Published by John Wiley \& Sons, Ltd. 
\#15 MeSH descriptor: [Estriol] explode all trees

\#16 MeSH descriptor: [Estrogens, Conjugated (USP)] explode all trees

\#17 MeSH descriptor: [Vaginal Creams, Foams, and Jellies] explode all trees

\#18 MeSH descriptor: [Ginkgo biloba] explode all trees

\#19 MeSH descriptor: [Pausinystalia] explode all trees

\#20 MeSH descriptor: [Turnera] explode all trees

\#21 MeSH descriptor: [Panax] explode all trees

\#22 MeSH descriptor: [Hypericum] explode all trees

\#23 MeSH descriptor: [Patient Education as Topic] explode all trees

\#24 MeSH descriptor: [Psychological Techniques] explode all trees

\#25 MeSH descriptor: [Psychotherapy] explode all trees

\#26 MeSH descriptor: [Counseling] explode all trees

\#27 MeSH descriptor: [Sex Counseling] explode all trees

\#28 MeSH descriptor: [Cognitive Therapy] explode all trees

\#29 (psychological intervention* or psycholog* or behavior* or behaviour* or cognitive behav* therapy or cognitive therap* or psychotherap* or counsel* or sex therap* or patient educat* or behav* therapy or CBT or couple therap* or couple intervention or couplebased or intimacy enhancing or mindfulness or patient education or psychological techniques or psychosexual or psychotherapy or psycho-somatic or Rational emotive therap* or restoring intimacy or relaxation or relaxation therap* or relaxation training or psychosocial or Sensual, body image or sex-counsel* or sexual communication or sexual rehabilitation or sexuality or self-esteem or self concept or stress or psycho-education or sexual life reframing or coping skills or motivational counselling or anxiety management training or marital therap* or group therap* or focal therap* or psychodynamic therap* or supportive therap* or psychoanalyses or interpersonal therap* or individual therap* or problem solving or emotional support or hypnosis or bibliotherap* or sexual skills therap* or systematic desensitization or hypnotherapy* or radical emotive therap* or psychodynamic or psychoeducational):ti,ab,kw (Word variations have been searched)

\#30 MeSH descriptor: [Phosphodiesterase 5 Inhibitors] explode all trees

\#31 MeSH descriptor: [Vasodilator Agents] explode all trees

\#32 (Phosphodiesterase Type 5 or PDE5i or adcirca or cialis or levitra or Viagra or vardenafil or sildenafil or tadalafil):ti,ab,kw (Word variations have been searched)

\#33 MeSH descriptor: [Aromatase Inhibitors] explode all trees

\#34 MeSH descriptor: [Apomorphine] explode all trees

\#35 (estriol or femprox):ti,ab,kw (Word variations have been searched)

\#36 conjugated estrogens:ti,ab,kw (Word variations have been searched)

\#37 estrogen ring:ti,ab,kw (Word variations have been searched)

\#38 estrogen therapy:ti,ab,kw (Word variations have been searched)

\#39 estrogen replacement:ti,ab,kw (Word variations have been searched)

\#40 estradiol ring:ti,ab,kw (Word variations have been searched)

\#41 vaginal oestrogen ring:ti,ab,kw (Word variations have been searched)

\#42 estrogen cream:ti,ab,kw (Word variations have been searched)

\#43 topical oestrogens:ti,ab,kw (Word variations have been searched)

\#44 (oestrogen or epimestrol):ti,ab,kw (Word variations have been searched)

\#45 (estradiol or oestrogenic steroids):ti,ab,kw (Word variations have been searched)

\#46 (estrone or ethinyl estradiol or mestranol or quinestrol):ti,ab,kw (Word variations have been searched)

\#47 (oestradiol or Dienestrol or estriol or estetrol):ti,ab,kw (Word variations have been searched)

\#48 “selective oestrogen receptor modulator":ti,ab,kw (Word variations have been searched)

\#49 (clomiph or raloxifene or tamoxifen or toremife or clomid or clomifene or clomifert or serophene or raloxifene or keoxifene): ti,ab,kw (Word variations have been searched)

\#50 (evista or dimethylamine or novaldex or tomaxithen or soltamox or zitazonium or menerba):ti,ab,kw (Word variations have been searched)

\#51 (femarelle or toremifene or serm or bazedoxifene):ti,ab,kw (Word variations have been searched)

\#52 ly-139481:ti,ab,kw (Word variations have been searched)

\#53 ly-156758:ti,ab,kw (Word variations have been searched)

\#54 MF-101:ti,ab,kw (Word variations have been searched)

\#55 DT56a:ti,ab,kw (Word variations have been searched)

Interventions for sexual dysfunction following treatments for cancer in women (Review)

Copyright $\Subset 2016$ The Cochrane Collaboration. Published by John Wiley \& Sons, Ltd. 
\#56 LY-117018:ti,ab,kw (Word variations have been searched)

\#57 (arginine or acupuncture or DHEA or dehydroepiandrosterone or damiana or gingko or gingko bilboa or Hypericum or Panax or pausinystalia or Turnera or turner diffusa or yohimbine or l-arginine, or pycnogeno, or viacreme or viagel or sensual or ginseng or st john's wort or complimentary medicine* or alternative medicine* or alternative therap* or alternative remed* or complimentary therap* or complimentary remed*):ti,ab,kw (Word variations have been searched)

\#58 (dilation or dilators or eros therap* or eros clitoral vacuum device or vaginal dilators or vibrator or vibrostimulation or mechanical stretching of tissues or cock ring or electroejaculation or magnetic stimulation or penile implantation or penile prosthesis or penile implant or penile arterialisation or penile vibratory stimulation or prosthesis implant* or prolong ring or muse or venous constriction ring* or venous litigation or vacuum device* or vacuum constriction device* or vacuum therapy or vacuum pump or penile injection): ti,ab,kw (Word variations have been searched)

\#59 (kegel exercise* or lubricant* or lubrication or pelvic floor biofeedback or yoga or cream* or foam* or jellies or muscle relaxation or vaginal exercise or physical exercise or olive oil or physiotherapy or weight lifting or physical training or pelvic floor muscle control or self touch or penile rehabilitation or erectile rehabilitation orphysiotherap* or cavernous nerve regeneration, or sonic hedgehog or glial growth factor 2 or GGF2 or magnetic stimulation or cavernous nerve stimulation or low-intensity extracorporeal shockwave therapy or nerve stimulation):ti,ab,kw (Word variations have been searched)

\#60 (alpha adrenoceptor agonist* or alpha adrenoceptor antagonist or midodrin or vasodilan or isoxsuprine or pentoxifylline or trental or delquamine or pseudoephedrine or desipramine or cyproheptadine or lignocaine):ti,ab,kw (Word variations have been searched) \#61 MeSH descriptor: [Complementary Therapies] explode all trees

$\# 62$ (\#1 or \#2 or \#3 or \#4 or \#5 or \#6 or \#7 or \#8 or \#9 or \#10 or \#11 or \#12 or \#13 or \#14 or \#15 or \#16 or \#17 or \#18 or \#19 or \# 20 or \#21 or \#22 or \#23 or \#24 or \#25 or \#26 or \#27 or \#28 or \#29 or \#30 or \#31 or \#32 or \#33 or \#34 or \#35 or \#36 or \#37 or \#38 or \#39 or \#40 or \#41 or \#42 or \#43 or \#44 or \#45 or \#46 or \#47 or \#48 or \#49 or \#50 or \#51 or \#52 or \#53 or \#54 or \#55 or \#56 or $\# 57$ or \#58 or \#59 or \#60 or \#61)

\#63 MeSH descriptor: [Sexual Dysfunctions, Psychological] explode all trees

\#64 MeSH descriptor: [Sexual Dysfunction, Physiological] explode all trees

\#65 MeSH descriptor: [Erectile Dysfunction] explode all trees

\#66 MeSH descriptor: [Lubrication] explode all trees

\#67 MeSH descriptor: [Coitus] explode all trees

\#68 MeSH descriptor: [Copulation] explode all trees

\#69 ((sex* near/3 (dysfunct* or satisf* or problem* or symptom* or arousal* or activit*)) or orgasm or libido or lubricat* or impotence or dyspareunia or hypoactive sexual desire disorder or sexual aversion or coitus or coition):ti,ab,kw (Word variations have been searched) \#70 (sexual intercourse or erectile dysfunction or erect* or sexual attraction or copulation or intimacy or procreat* or relations or sex or sex act or sexual congress or sexual relation or arousal or penile erection or vaginal dryness or sexual pain or (pain* near/3 intercourse) or (sex* near/3 pain*) or vaginismus or (sexual* near/2 wellbeing) or (sexual* near/2 well being) or sexual function* or (pain next (urogential or vulval or vaginal or perineal or penile or testicular or ileostomy or colostomy or urostomy))):ti,ab,kw (Word variations have been searched)

\#71 (ejaculation dysfunction or premature ejaculation or early ejaculation or delayed ejaculation or retarded ejaculation or anejaculation or painful ejaculation or retrograde ejaculation or anterograde ejaculation or inhibited ejaculation or erectile difficulty or erectile dysfunction or loss of libido or lack of libido):ti,ab,kw (Word variations have been searched)

$\# 72 \# 63$ or $\# 64$ or \#65 or \#66 or \#67 or \#68 or \#69 or \#70 or \#71

\#73 MeSH descriptor: [Neoplasms] explode all trees

\#74 MeSH descriptor: [Brachytherapy] explode all trees

\#75 MeSH descriptor: [Radiotherapy, Conformal] explode all trees

\#76 MeSH descriptor: [Radiotherapy, Adjuvant] explode all trees

\#77 MeSH descriptor: [Chemotherapy, Adjuvant] explode all trees

\#78 MeSH descriptor: [Mastectomy] explode all trees

\#79 MeSH descriptor: [Prostatectomy] explode all trees

\#80 (irradiat* or radiotherap* or chemotherap* or mastectom* or breast conserv* or prostatectom* or brachytherp or radiation or prostectomy or oncology or excisional surgey or hysterectomy or radical surgery or vulvar surgery or cryotherpy or androgen suppression or androgen deprivation or abdominoerineal resection or AP resection or APR or anterior resection or extralevator abdominoperineal excision or ELAP or colostomy or mutilating surgery or vulval reconstruction or vaginal reconstruction or penile reconstruction or breast reconstruction or breast implants):ti,ab,kw (Word variations have been searched)

\#81 (neoplasm* or cancer* or carcinoma* or neoplasia* or adenocarcinoma* or tumor or malignan* or tumour*):ti,ab,kw (Word variations have been searched)

Interventions for sexual dysfunction following treatments for cancer in women (Review)

Copyright (c) 2016 The Cochrane Collaboration. Published by John Wiley \& Sons, Ltd. 
\#82 (chemotherap* or mastectomy or breast conserv*or oophorectomy or hormone therapy or hormone treatment):ti,ab,kw (Word variations have been searched)

$\# 83 \# 73$ or $\# 74$ or $\# 75$ or $\# 76$ or $\# 77$ or $\# 78$ or $\# 79$ or $\# 80$ or $\# 81$ or $\# 82$

$\# 84$ \#62 and \#72 and \#83

\section{MEDLINE (OVID)}

1. exp Alprostadil/

2. exp Papaverine/

3. exp Phentolamine/

4. exp Yohimbine/

5. exp Apomorphine/

6. exp Potassium Channels/

7. (alprostadil or androgel or Apomorphine or britaject or aromatase inhibitors or agonist of melancortin receptor or Adcirca or alpha adrenoceptor agonist or alpha-2 adrenoceptor agonist or androgel or arginine or botox or botulinum toxin or bromocriptine or cialis or dopaminergic agents or caverject or clomipramine or cyproheptadine or clonidine or delquamine or edex or hormone therapy or Isoxsuprine or intracavernosal vasodilators or levitra or Lignocaine or 1-arginine or lodenfil or Methitest or methyl testosterone or midodrin or mianserin or moclobemide or mirtazapine or mianserin or moclobemide or ortho-gynest or ovestin or papaverine or papaverine-phentolamine or phentolamine or parlodel or phentolamine or potassium channel openers or progestational agents or premarin or prempro or prostins or Prostaglandins or prostaglandin E1 or pentoxifylline or potassium channels or Phosphodiesterase Type 5 or PDE5i or penile suppository or reboxetine or sildenafil or tadalafil or tampovagan or topical or topical cream or vagifem or vaginal cream or vaginal lubricant or vaginal or viagra or vasomax or Viagel or vardenafil or vasodilator or virilon or vasoactive or staxyn or topical estrogen cream or trental or vasodilan or viridal or yohimbine or android or androgen therapy or testosterone or testosterone cream or testosterone gel or testred).tw.

8. exp Testosterone/

9. exp Penile Implantation/

10. exp Penile Prosthesis/

11. exp Prosthesis Implantation/

12. (testosterone replacement or testosterone or venous constriction rings or vacuum device* or vacuum erect* or penile implant* or penile arterialisation or venous litigation or prosthesis implant* or vacuum constriction device or vacuum therapy* or vibrat* or vibrostimulation or electroejaculation or prolong ring*).tw.

13. exp Aromatase Inhibitors/

14. (vaginal dilator* or arginine or android or methyl testosterone or testosterone cream or vaginal lubricant or vaginal estradiol ring or vaginal estradiol ring or vaginal estrogen ring or vaginal oestrogen ring or topical estrogen cream or vaginal cream or estrogen replacement of ERT or estrogen replacement or aromatase inhibitors).tw.

15. exp Estriol/

16. exp "Estrogens, Conjugated (USP)"/

17. exp "Vaginal Creams, Foams, and Jellies"/

18. exp Ginkgo biloba/

19. exp Pausinystalia/

20. exp Turnera/

21. exp Panax/

22. exp Hypericum/

23. exp Patient Education as Topic/

24. exp Psychological Techniques/

25. exp Psychotherapy/

26. exp Counseling/

27. exp Sex Counseling/

28. exp Cognitive Therapy/

29. (psychological intervention* or psycholog* or behavior* or behaviour* or cognitive behav* therapy or cognitive therap* or psychotherap* or counsel* or sex therap* or patient educat* or behav* therapy or CBT or couple therap* or couple intervention or couplebased or intimacy enhancing or mindfulness or patient education or psychological techniques or psychosexual or psychotherapy or psycho-somatic or Rational emotive therap* or restoring intimacy or relaxation or relaxation therap* or relaxation training or psycho-

Interventions for sexual dysfunction following treatments for cancer in women (Review) 
social or Sensual, body image or sex-counsel* or sexual communication or sexual rehabilitation or sexuality or self-esteem or self concept or stress or psycho-education or sexual life reframing or coping skills or motivational counselling or anxiety management training or marital therap* or group therap* or focal therap* or psychodynamic therap* or supportive therap* or psychoanalyses or interpersonal therap* or individual therap* or problem solving or emotional support or hypnosis or bibliotherap* or sexual skills therap* or systematic desensitization or hypnotherapy* or radical emotive therap* or psychodynamic or psychoeducational).tw.

30. exp Phosphodiesterase 5 Inhibitors/

31. exp Vasodilator Agents/

32. (Phosphodiesterase Type 5 or PDE5i or adcirca or cialis or levitra or Viagra or vardenafil or sildenafil or tadalafil).tw.

33. exp Aromatase Inhibitors/

34. exp Apomorphine/

35. (estriol or femprox).tw.

36. conjugated estrogens.tw.

37. estrogen ring.tw.

38. estrogen therapy.tw.

39. estrogen replacement.tw.

40. estradiol ring.tw.

41. vaginal oestrogen ring.tw.

42. estrogen cream.tw.

43. topical oestrogens.tw.

44. (oestrogen or epimestrol).tw.

45. (estradiol or oestrogenic steroids).tw.

46. (estrone or ethinyl estradiol or mestranol or quinestrol).tw.

47. (oestradiol or Dienestrol or estriol or estetrol).tw.

48. selective oestrogen receptor modulators.tw.

49. (clomiph or raloxifene or tamoxifen or toremife or clomid or clomifene or clomifert or serophene or raloxifene or keoxifene).tw.

50. (evista or dimethylamine or novaldex or tomaxithen or soltamox or zitazonium or menerba).tw.

51. (femarelle or toremifene or serm or bazedoxifene).tw.

52. ly-139481.mp.

53. ly-156758.mp.

54. MF-101.mp.

55. DT56a.mp.

56. LY-117018.mp.

57. (arginine or acupuncture or DHEA or dehydroepiandrosterone or damiana or gingko or gingko bilboa or Hypericum or Panax or pausinystalia or Turnera or turner diffusa or yohimbine or l-arginine, or pycnogeno, or viacreme or viagel or sensual or ginseng or st john's wort or complimentary medicine* or alternative medicine* or alternative therap* or alternative remed* or complimentary therap* or complimentary remed*).tw.

58. (dilation or dilators or eros therap* or eros clitoral vacuum device or vaginal dilators or vibrator or vibrostimulation or mechanical stretching of tissues or cock ring or electroejaculation or magnetic stimulation or penile implantation or penile prosthesis or penile implant or penile arterialisation or penile vibratory stimulation or prosthesis implant* or prolong ring or muse or venous constriction ring* or venous litigation or vacuum device* or vacuum constriction device* or vacuum therapy or vacuum pump or penile injection).tw. 59. (kegel exercise* or lubricant* or lubrication or pelvic floor biofeedback or yoga or cream* or foam* or jellies or muscle relaxation or vaginal exercise or physical exercise or olive oil or physiotherapy or weight lifting or physical training or pelvic floor muscle control or self touch or penile rehabilitation or erectile rehabilitation orphysiotherap* or cavernous nerve regeneration, or sonic hedgehog or glial growth factor 2 or GGF2 or magnetic stimulation or cavernous nerve stimulation or low-intensity extracorporeal shockwave therapy or nerve stimulation).tw.

60. (alpha adrenoceptor agonist* or alpha adrenoceptor antagonist or midodrin or vasodilan or isoxsuprine or pentoxifylline or trental or delquamine or pseudoephedrine or desipramine or cyproheptadine or lignocaine).tw.

61. exp Complementary Therapies/

62. or/1-61

63. exp Sexual Dysfunctions, Psychological/ or exp Sexual Dysfunction, Physiological/

64. exp Erectile Dysfunction/

65. exp Lubrication/

66. exp Coitus/

Interventions for sexual dysfunction following treatments for cancer in women (Review)

Copyright @ 2016 The Cochrane Collaboration. Published by John Wiley \& Sons, Ltd. 
67. exp Copulation/

68. ((sex* adj3 (dysfunct* or satisf* or problem* or symptom* or arousal* or activit*)) or orgasm or libido or lubricat* or impotence or dyspareunia or hypoactive sexual desire disorder or sexual aversion or coitus or coition).tw.

69. (sexual intercourse or erectile dysfunction or erect* or sexual attraction or copulation or intimacy or procreat* or relations or sex or sex act or sexual congress or sexual relation or arousal or penile erection or vaginal dryness or sexual pain or (pain* adj3 intercourse) or (sex* adj3 pain*) or vaginismus or (sexual* adj2 wellbeing) or (sexual* adj2 well being) or sexual function* or (pain adj (urogential or vulval or vaginal or perineal or penile or testicular or ileostomy or colostomy or urostomy))).tw.

70. (ejaculation dysfunction or premature ejaculation or early ejaculation or delayed ejaculation or retarded ejaculation or anejaculation or painful ejaculation or retrograde ejaculation or anterograde ejaculation or inhibited ejaculation or erectile difficulty or erectile dysfunction or loss of libido or lack of libido).tw.

71. or/63-70

72. exp Neoplasms/

73. exp Brachytherapy/

74. exp Radiotherapy, Conformal/

75. exp Radiotherapy, Adjuvant/

76. exp Chemotherapy, Adjuvant/

77. exp Mastectomy/

78. exp Prostatectomy/

79. (irradiat* or radiotherap* or chemotherap* or mastectom* or breast conserv* or prostatectom* or brachytherp or radiation or prostectomy or oncology or excisional surgey or hysterectomy or radical surgery or vulvar surgery or cryotherpy or androgen suppression or androgen deprivation or abdominoerineal resection or AP resection or APR or anterior resection or extralevator abdominoperineal excision or ELAP or colostomy or mutilating surgery or vulval reconstruction or vaginal reconstruction or penile reconstruction or breast reconstruction or breast implants).tw.

80. (neoplasm* or cancer* or carcinoma* or neoplasia* or adenocarcinoma* or tumor or malignan* or tumour*).tw.

81. (chemotherap* or mastectomy or breast conserv*or oophorectomy or hormone therapy or hormone treatment).tw.

82. or/72-81

83. 62 and 71 and 82

84. randomized controlled trial.pt.

85. controlled clinical trial.pt.

86. randomized.ab.

87. placebo.ab.

88. drug therapy.fs.

89. randomly.ab.

90. trial.ab.

91. or/84-90

92. exp animals/ not humans.sh.

93. 91 not 92

94.83 and 93

\section{EMBASE (OVID)}

1. exp Alprostadil/

2. exp Papaverine/

3. exp Phentolamine/

4. exp Yohimbine/

5. exp Apomorphine/

6. exp Potassium Channels/

7. (alprostadil or androgel or Apomorphine or britaject or aromatase inhibitors or agonist of melancortin receptor or Adcirca or alpha adrenoceptor agonist or alpha-2 adrenoceptor agonist or androgel or arginine or botox or botulinum toxin or bromocriptine or cialis or dopaminergic agents or caverject or clomipramine or cyproheptadine or clonidine or delquamine or edex or hormone therapy or Isoxsuprine or intracavernosal vasodilators or levitra or Lignocaine or 1-arginine or lodenfil or Methitest or methyl testosterone or midodrin or mianserin or moclobemide or mirtazapine or mianserin or moclobemide or ortho-gynest or ovestin or papaverine or papaverine-phentolamine or phentolamine or parlodel or phentolamine or potassium channel openers or progestational agents or

Interventions for sexual dysfunction following treatments for cancer in women (Review)

Copyright (c) 2016 The Cochrane Collaboration. Published by John Wiley \& Sons, Ltd. 
premarin or prempro or prostins or Prostaglandins or prostaglandin E1 or pentoxifylline or potassium channels or Phosphodiesterase Type 5 or PDE5i or penile suppository or reboxetine or sildenafil or tadalafil or tampovagan or topical or topical cream or vagifem or vaginal cream or vaginal lubricant or vaginal or viagra or vasomax or Viagel or vardenafil or vasodilator or virilon or vasoactive or staxyn or topical estrogen cream or trental or vasodilan or viridal or yohimbine or android or androgen therapy or testosterone or testosterone cream or testosterone gel or testred).tw.

8. exp Testosterone/

9. exp Penile Implantation/

10. exp Penile Prosthesis/

11. exp Prosthesis Implantation/

12. (testosterone replacement or testosterone or venous constriction rings or vacuum device* or vacuum erect* or penile implant* or penile arterialisation or venous litigation or prosthesis implant* or vacuum constriction device or vacuum therapy* or vibrat* or vibrostimulation or electroejaculation or prolong ring*).tw.

13. exp Aromatase Inhibitors/

14. (vaginal dilator* or arginine or android or methyl testosterone or testosterone cream or vaginal lubricant or vaginal estradiol ring or vaginal estradiol ring or vaginal estrogen ring or vaginal oestrogen ring or topical estrogen cream or vaginal cream or estrogen replacement of ERT or estrogen replacement or aromatase inhibitors).tw.

15. exp Estriol/

16. exp "Estrogens, Conjugated (USP)"/

17. exp "Vaginal Creams, Foams, and Jellies"/

18. exp Ginkgo biloba/

19. exp Pausinystalia/

20. exp Turnera/

21. exp Panax/

22. exp Hypericum/

23. exp Patient Education as Topic/

24. exp Psychological Techniques/

25. exp Psychotherapy/

26. exp Counseling/

27. exp Sex Counseling/

28. exp Cognitive Therapy/

29. (psychological intervention* or psycholog* or behavior* or behaviour* or cognitive behav* therapy or cognitive therap* or psychotherap* or counsel* or sex therap* or patient educat* or behav* therapy or CBT or couple therap* or couple intervention or couplebased or intimacy enhancing or mindfulness or patient education or psychological techniques or psychosexual or psychotherapy or psycho-somatic or Rational emotive therap* or restoring intimacy or relaxation or relaxation therap* or relaxation training or psychosocial or Sensual, body image or sex-counsel* or sexual communication or sexual rehabilitation or sexuality or self-esteem or self concept or stress or psycho-education or sexual life reframing or coping skills or motivational counselling or anxiety management training or marital therap* or group therap* or focal therap* or psychodynamic therap* or supportive therap* or psychoanalyses or interpersonal therap* or individual therap* or problem solving or emotional support or hypnosis or bibliotherap* or sexual skills therap* or systematic desensitization or hypnotherapy* or radical emotive therap* or psychodynamic or psychoeducational).tw.

30. exp Phosphodiesterase 5 Inhibitors/

31. exp Vasodilator Agents/

32. (Phosphodiesterase Type 5 or PDE5i or adcirca or cialis or levitra or Viagra or vardenafil or sildenafil or tadalafil).tw.

33. exp Aromatase Inhibitors/

34. exp Apomorphine/

35. (estriol or femprox).tw.

36. conjugated estrogens.tw.

37. estrogen ring.tw.

38. estrogen therapy.tw.

39. estrogen replacement.tw.

40. estradiol ring.tw.

41. vaginal oestrogen ring.tw.

42. estrogen cream.tw.

43. topical oestrogens.tw.

Interventions for sexual dysfunction following treatments for cancer in women (Review)

Copyright $\odot 2016$ The Cochrane Collaboration. Published by John Wiley \& Sons, Ltd. 
44. (oestrogen or epimestrol).tw.

45. (estradiol or oestrogenic steroids).tw.

46. (estrone or ethinyl estradiol or mestranol or quinestrol).tw.

47. (oestradiol or Dienestrol or estriol or estetrol).tw.

48. selective oestrogen receptor modulators.tw.

49. (clomiph or raloxifene or tamoxifen or toremife or clomid or clomifene or clomifert or serophene or raloxifene or keoxifene).tw.

50. (evista or dimethylamine or novaldex or tomaxithen or soltamox or zitazonium or menerba).tw.

51. (femarelle or toremifene or serm or bazedoxifene).tw.

52. ly-139481.mp.

53. ly-156758.mp.

54. MF-101.mp.

55. DT56a.mp.

56. LY-117018.mp.

57. (arginine or acupuncture or DHEA or dehydroepiandrosterone or damiana or gingko or gingko bilboa or Hypericum or Panax or pausinystalia or Turnera or turner diffusa or yohimbine or l-arginine, or pycnogeno, or viacreme or viagel or sensual or ginseng or st john's wort or complimentary medicine* or alternative medicine* or alternative therap* or alternative remed* or complimentary therap* or complimentary remed*).tw.

58. (dilation or dilators or eros therap* or eros clitoral vacuum device or vaginal dilators or vibrator or vibrostimulation or mechanical stretching of tissues or cock ring or electroejaculation or magnetic stimulation or penile implantation or penile prosthesis or penile implant or penile arterialisation or penile vibratory stimulation or prosthesis implant* or prolong ring or muse or venous constriction ring* ${ }^{*}$ or venous litigation or vacuum device* or vacuum constriction device* or vacuum therapy or vacuum pump or penile injection).tw. 59. (kegel exercise* or lubricant* or lubrication or pelvic floor biofeedback or yoga or cream* or foam* or jellies or muscle relaxation or vaginal exercise or physical exercise or olive oil or physiotherapy or weight lifting or physical training or pelvic floor muscle control or self touch or penile rehabilitation or erectile rehabilitation orphysiotherap* or cavernous nerve regeneration, or sonic hedgehog or glial growth factor 2 or GGF2 or magnetic stimulation or cavernous nerve stimulation or low-intensity extracorporeal shockwave therapy or nerve stimulation).tw.

60. (alpha adrenoceptor agonist* or alpha adrenoceptor antagonist or midodrin or vasodilan or isoxsuprine or pentoxifylline or trental or delquamine or pseudoephedrine or desipramine or cyproheptadine or lignocaine).tw.

61. exp Complementary Therapies/

62. or/1-61

63. exp Sexual Dysfunctions, Psychological/ or exp Sexual Dysfunction, Physiological/

64. exp Erectile Dysfunction/

65. exp Lubrication/

66. $\exp$ Coitus/

67. exp Copulation/

68. ((sex* adj3 (dysfunct* or satisf* or problem* or symptom* or arousal* or activit*)) or orgasm or libido or lubricat* or impotence or dyspareunia or hypoactive sexual desire disorder or sexual aversion or coitus or coition).tw.

69. (sexual intercourse or erectile dysfunction or erect* or sexual attraction or copulation or intimacy or procreat* or relations or sex or sex act or sexual congress or sexual relation or arousal or penile erection or vaginal dryness or sexual pain or (pain* adj 3 intercourse) or (sex* adj3 pain*) or vaginismus or (sexual* adj2 wellbeing) or (sexual* adj2 well being) or sexual function* or (pain adj (urogential or vulval or vaginal or perineal or penile or testicular or ileostomy or colostomy or urostomy))).tw.

70. (ejaculation dysfunction or premature ejaculation or early ejaculation or delayed ejaculation or retarded ejaculation or anejaculation or painful ejaculation or retrograde ejaculation or anterograde ejaculation or inhibited ejaculation or erectile difficulty or erectile dysfunction or loss of libido or lack of libido).tw.

71. or/63-70

72. $\exp$ Neoplasms/

73. exp Brachytherapy/

74. exp Radiotherapy, Conformal/

75. exp Radiotherapy, Adjuvant/

76. exp Chemotherapy, Adjuvant/

77. exp Mastectomy/

78. exp Prostatectomy/

Interventions for sexual dysfunction following treatments for cancer in women (Review)

Copyright @ 2016 The Cochrane Collaboration. Published by John Wiley \& Sons, Ltd. 
79. (irradiat* or radiotherap* or chemotherap* or mastectom* or breast conserv* or prostatectom* or brachytherp or radiation or prostectomy or oncology or excisional surgey or hysterectomy or radical surgery or vulvar surgery or cryotherpy or androgen suppression or androgen deprivation or abdominoerineal resection or AP resection or APR or anterior resection or extralevator abdominoperineal excision or ELAP or colostomy or mutilating surgery or vulval reconstruction or vaginal reconstruction or penile reconstruction or breast reconstruction or breast implants).tw.

80. (neoplasm* or cancer* or carcinoma* or neoplasia* or adenocarcinoma* or tumor or malignan* or tumour*).tw.

81. (chemotherap* or mastectomy or breast conserv*or oophorectomy or hormone therapy or hormone treatment).tw.

82. or/72-81

83.62 and 71 and 82

84. random\$.tw.

85. factorial\$.tw.

86. crossover\$.tw.

87. cross over\$.tw.

88. cross-over\$.tw.

89. placebo\$.tw.

90. (doubl\$ adj blind $\$$ ).tw.

91. (singl\$ adj blind $\$$ ).tw.

92. assign $\$ . t w$.

93. allocat\$.tw.

94. volunteer\$.tw.

95. Crossover Procedure/

96. double-blind procedure.tw.

97. Randomized Controlled Trial/

98. Single Blind Procedure/

99. or/84-98

100. (animal/ or nonhuman/) not human/

101. 99 not 100

102. 83 and 101

\section{PsycINFO (OVID)}

1. exp Papaverine/

2. exp Yohimbine/

3. exp Apomorphine/

4. (alprostadil or androgel or Apomorphine or britaject or aromatase inhibitors or agonist of melancortin receptor or Adcirca or alpha adrenoceptor agonist or alpha-2 adrenoceptor agonist or androgel or arginine or botox or botulinum toxin or bromocriptine or cialis or dopaminergic agents or caverject or clomipramine or cyproheptadine or clonidine or delquamine or edex or hormone therapy or Isoxsuprine or intracavernosal vasodilators or levitra or Lignocaine or l-arginine or lodenfil or Methitest or methyl testosterone or midodrin or mianserin or moclobemide or mirtazapine or mianserin or moclobemide or ortho-gynest or ovestin or papaverine or papaverine-phentolamine or phentolamine or parlodel or phentolamine or potassium channel openers or progestational agents or premarin or prempro or prostins or Prostaglandins or prostaglandin E1 or pentoxifylline or potassium channels or Phosphodiesterase Type 5 or PDE5i or penile suppository or reboxetine or sildenafil or tadalafil or tampovagan or topical or topical cream or vagifem or vaginal cream or vaginal lubricant or vaginal or viagra or vasomax or Viagel or vardenafil or vasodilator or virilon or vasoactive or staxyn or topical estrogen cream or trental or vasodilan or viridal or yohimbine or android or androgen therapy or testosterone or testosterone cream or testosterone gel or testred).tw.

5. exp Testosterone/

6. (testosterone replacement or testosterone or venous constriction rings or vacuum device* or vacuum erect* or penile implant* or penile arterialisation or venous litigation or prosthesis implant* or vacuum constriction device or vacuum therapy* or vibrat* or $^{*}$ vibrostimulation or electroejaculation or prolong ring*).tw.

7. (vaginal dilator* or arginine or android or methyl testosterone or testosterone cream or vaginal lubricant or vaginal estradiol ring or vaginal estradiol ring or vaginal estrogen ring or vaginal oestrogen ring or topical estrogen cream or vaginal cream or estrogen replacement of ERT or estrogen replacement or aromatase inhibitors).tw.

8. exp Hypericum/

Interventions for sexual dysfunction following treatments for cancer in women (Review)

Copyright @ 2016 The Cochrane Collaboration. Published by John Wiley \& Sons, Ltd. 
9. exp Psychotherapy/

10. exp Counseling/

11. exp Cognitive Therapy/

12. (psychological intervention* or psycholog* or behavior* or behaviour* or cognitive behav* therapy or cognitive therap* or psychotherap* or counsel* or sex therap* or patient educat* or behav* therapy or CBT or couple therap* or couple intervention or couplebased or intimacy enhancing or mindfulness or patient education or psychological techniques or psychosexual or psychotherapy or psycho-somatic or Rational emotive therap* or restoring intimacy or relaxation or relaxation therap* or relaxation training or psychosocial or Sensual, body image or sex-counsel* or sexual communication or sexual rehabilitation or sexuality or self-esteem or self concept or stress or psycho-education or sexual life reframing or coping skills or motivational counselling or anxiety management training or marital therap* or group therap* or focal therap* or psychodynamic therap* or supportive therap* or psychoanalyses or interpersonal therap* or individual therap* or problem solving or emotional support or hypnosis or bibliotherap* or sexual skills therap* or systematic desensitization or hypnotherapy* or radical emotive therap* or psychodynamic or psychoeducational).tw.

13. (Phosphodiesterase Type 5 or PDE5i or adcirca or cialis or levitra or Viagra or vardenafil or sildenafil or tadalafil).tw.

14. exp Aromatase Inhibitors/

15. exp Apomorphine/

16. (estriol or femprox).tw.

17. conjugated estrogens.tw.

18. estrogen ring.tw.

19. estrogen therapy.tw.

20. estrogen replacement.tw.

21. vaginal oestrogen ring.tw.

22. estrogen cream.tw.

23. topical oestrogens.tw.

24. (oestrogen or epimestrol).tw.

25. (estradiol or oestrogenic steroids).tw.

26. (estrone or ethinyl estradiol or mestranol or quinestrol).tw.

27. (oestradiol or Dienestrol or estriol or estetrol).tw.

28. selective oestrogen receptor modulators.tw.

29. (clomiph or raloxifene or tamoxifen or toremife or clomid or clomifene or clomifert or serophene or raloxifene or keoxifene).tw.

30. (evista or dimethylamine or novaldex or tomaxithen or soltamox or zitazonium or menerba).tw.

31. (femarelle or toremifene or serm or bazedoxifene).tw.

32. ly-139481.mp.

33. ly-156758.mp.

34. MF-101.mp.

35. DT56a.mp.

36. LY-117018.mp.

37. (arginine or acupuncture or DHEA or dehydroepiandrosterone or damiana or gingko or gingko bilboa or Hypericum or Panax or pausinystalia or Turnera or turner diffusa or yohimbine or l-arginine, or pycnogeno, or viacreme or viagel or sensual or ginseng or st john's wort or complimentary medicine* or alternative medicine* or alternative therap* or alternative remed* or complimentary therap* or complimentary remed*).tw.

38. (dilation or dilators or eros therap* or eros clitoral vacuum device or vaginal dilators or vibrator or vibrostimulation or mechanical stretching of tissues or cock ring or electroejaculation or magnetic stimulation or penile implantation or penile prosthesis or penile implant or penile arterialisation or penile vibratory stimulation or prosthesis implant* or prolong ring or muse or venous constriction ring* or venous litigation or vacuum device* or vacuum constriction device* or vacuum therapy or vacuum pump or penile injection).tw. 39. (kegel exercise* or lubricant* or lubrication or pelvic floor biofeedback or yoga or cream* or foam* or jellies or muscle relaxation or vaginal exercise or physical exercise or olive oil or physiotherapy or weight lifting or physical training or pelvic floor muscle control or self touch or penile rehabilitation or erectile rehabilitation orphysiotherap* or cavernous nerve regeneration, or sonic hedgehog or glial growth factor 2 or GGF2 or magnetic stimulation or cavernous nerve stimulation or low-intensity extracorporeal shockwave therapy or nerve stimulation).tw.

40. (alpha adrenoceptor agonist* or alpha adrenoceptor antagonist or midodrin or vasodilan or isoxsuprine or pentoxifylline or trental or delquamine or pseudoephedrine or desipramine or cyproheptadine or lignocaine).tw.

41. exp Alternative Medicine/

42. exp Sexual Function Disturbances/

Interventions for sexual dysfunction following treatments for cancer in women (Review)

Copyright @ 2016 The Cochrane Collaboration. Published by John Wiley \& Sons, Ltd. 
43. exp Erectile Dysfunction/

44. exp Coitus/

45. exp Copulation/

46. ((sex* adj3 (dysfunct* or satisf* or problem* or symptom* or arousal* or activit*)) or orgasm or libido or lubricat* or impotence or dyspareunia or hypoactive sexual desire disorder or sexual aversion or coitus or coition).tw.

47. (sexual intercourse or erectile dysfunction or erect* or sexual attraction or copulation or intimacy or procreat* or relations or sex or sex act or sexual congress or sexual relation or arousal or penile erection or vaginal dryness or sexual pain or (pain* adj3 intercourse) or (sex* adj3 pain*) or vaginismus or (sexual* adj2 wellbeing) or (sexual* adj2 well being) or sexual function* or (pain adj (urogential or vulval or vaginal or perineal or penile or testicular or ileostomy or colostomy or urostomy))).tw.

48. (ejaculation dysfunction or premature ejaculation or early ejaculation or delayed ejaculation or retarded ejaculation or anejaculation or painful ejaculation or retrograde ejaculation or anterograde ejaculation or inhibited ejaculation or erectile difficulty or erectile dysfunction or loss of libido or lack of libido).tw.

49. exp Neoplasms/

50. exp Brachytherapy/

51. exp Radiation Therapy/

52. exp Chemotherapy/

53. exp Mastectomy/

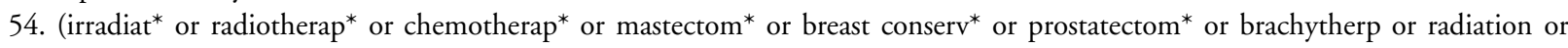
prostectomy or oncology or excisional surgey or hysterectomy or radical surgery or vulvar surgery or cryotherpy or androgen suppression or androgen deprivation or abdominoerineal resection or AP resection or APR or anterior resection or extralevator abdominoperineal excision or ELAP or colostomy or mutilating surgery or vulval reconstruction or vaginal reconstruction or penile reconstruction or breast reconstruction or breast implants).tw.

55. (neoplasm* or cancer* or carcinoma* or neoplasia* or adenocarcinoma* or tumor or malignan* or tumour*).tw.

56. (chemotherap* or mastectomy or breast conserv*or oophorectomy or hormone therapy or hormone treatment).tw.

57. clinical trials/

58. (randomis ${ }^{*}$ or randomiz ${ }^{*}$ ).tw.

59. (random $\$$ adj3 (allocat\$ or assign\$)).tw.

60. ((clinic\$ or control\$) adj trial\$).tw.

61. ((singl $\$$ or doubl $\$$ or trebl $\$$ or tripl $\$$ ) adj3 (blind $\$$ or mask $\$)$ ).tw.

62. (crossover $\$$ or “cross over\$").tw.

63. random sampling/

64. Experiment Controls/

65. Placebo/

66. placebo\$.tw.

67. exp program evaluation/

68. treatment effectiveness evaluation/

69. ((effectiveness or evaluat $\$$ ) adj3 (stud $\$$ or research $\$)$ ).tw.

70. or/57-69

71. or $/ 1-41$

72. or $/ 42-48$

73. or $/ 49-56$

74.70 and 71 and 72 and 73

\section{AMED (OVID)}

(No RCT filter added)

1. (alprostadil or androgel or Apomorphine or britaject or aromatase inhibitors or agonist of melancortin receptor or Adcirca or alpha adrenoceptor agonist or alpha-2 adrenoceptor agonist or androgel or arginine or botox or botulinum toxin or bromocriptine or cialis or dopaminergic agents or caverject or clomipramine or cyproheptadine or clonidine or delquamine or edex or hormone therapy or Isoxsuprine or intracavernosal vasodilators or levitra or Lignocaine or l-arginine or lodenfil or Methitest or methyl testosterone or midodrin or mianserin or moclobemide or mirtazapine or mianserin or moclobemide or ortho-gynest or ovestin or papaverine or papaverine-phentolamine or phentolamine or parlodel or phentolamine or potassium channel openers or progestational agents or premarin or prempro or prostins or Prostaglandins or prostaglandin E1 or pentoxifylline or potassium channels or Phosphodiesterase

Interventions for sexual dysfunction following treatments for cancer in women (Review)

Copyright $\odot 2016$ The Cochrane Collaboration. Published by John Wiley \& Sons, Ltd. 
Type 5 or PDE5i or penile suppository or reboxetine or sildenafil or tadalafil or tampovagan or topical or topical cream or vagifem or vaginal cream or vaginal lubricant or vaginal or viagra or vasomax or Viagel or vardenafil or vasodilator or virilon or vasoactive or staxyn or topical estrogen cream or trental or vasodilan or viridal or yohimbine or android or androgen therapy or testosterone or testosterone cream or testosterone gel or testred).tw.

2. exp Testosterone/

3. (testosterone replacement or testosterone or venous constriction rings or vacuum device* or vacuum erect* or penile implant*

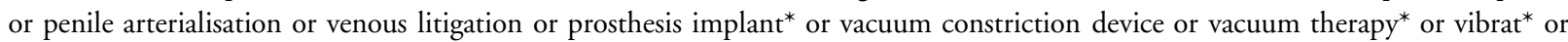
vibrostimulation or electroejaculation or prolong ring*).tw.

4. (vaginal dilator* or arginine or android or methyl testosterone or testosterone cream or vaginal lubricant or vaginal estradiol ring or vaginal estradiol ring or vaginal estrogen ring or vaginal oestrogen ring or topical estrogen cream or vaginal cream or estrogen replacement of ERT or estrogen replacement or aromatase inhibitors).tw.

5. exp Ginkgo biloba/

6. exp Panax/

7. exp Hypericum/

8. exp Psychotherapy/

9. exp Counseling/

10. exp Sex Counseling/

11. exp Cognitive Therapy/

12. (psychological intervention* or psycholog* or behavior* or behaviour* or cognitive behav* therapy or cognitive therap* or psychotherap* or counsel* or sex therap* or patient educat* or behav* therapy or CBT or couple therap* or couple intervention or couplebased or intimacy enhancing or mindfulness or patient education or psychological techniques or psychosexual or psychotherapy or psycho-somatic or Rational emotive therap* or restoring intimacy or relaxation or relaxation therap* or relaxation training or psychosocial or Sensual, body image or sex-counsel* or sexual communication or sexual rehabilitation or sexuality or self-esteem or self concept or stress or psycho-education or sexual life reframing or coping skills or motivational counselling or anxiety management training or marital therap* or group therap* or focal therap* or psychodynamic therap* or supportive therap* or psychoanalyses or interpersonal therap* or individual therap* or problem solving or emotional support or hypnosis or bibliotherap* or sexual skills therap* or systematic desensitization or hypnotherapy* or radical emotive therap* or psychodynamic or psychoeducational).tw.

13. exp Vasodilator Agents/

14. (Phosphodiesterase Type 5 or PDE5i or adcirca or cialis or levitra or Viagra or vardenafil or sildenafil or tadalafil).tw.

15. (estriol or femprox).tw.

16. conjugated estrogens.tw.

17. estrogen ring.tw.

18. estrogen therapy.tw.

19. estrogen replacement.tw.

20. estradiol ring.tw.

21. vaginal oestrogen ring.tw.

22. estrogen cream.tw.

23. topical oestrogens.tw.

24. (oestrogen or epimestrol).tw.

25. (estradiol or oestrogenic steroids).tw.

26. (estrone or ethinyl estradiol or mestranol or quinestrol).tw.

27. (oestradiol or Dienestrol or estriol or estetrol).tw.

28. selective oestrogen receptor modulators.tw.

29. (clomiph or raloxifene or tamoxifen or toremife or clomid or clomifene or clomifert or serophene or raloxifene or keoxifene).tw.

30. (evista or dimethylamine or novaldex or tomaxithen or soltamox or zitazonium or menerba).tw.

31. (femarelle or toremifene or serm or bazedoxifene).tw.

32. ly-139481.mp.

33. ly-156758.mp.

34. MF-101.mp.

35. DT56a.mp.

36. LY-117018.mp.

37. (arginine or acupuncture or DHEA or dehydroepiandrosterone or damiana or gingko or gingko bilboa or Hypericum or Panax or pausinystalia or Turnera or turner diffusa or yohimbine or l-arginine, or pycnogeno, or viacreme or viagel or sensual or ginseng

Interventions for sexual dysfunction following treatments for cancer in women (Review)

Copyright @ 2016 The Cochrane Collaboration. Published by John Wiley \& Sons, Ltd. 
or st john's wort or complimentary medicine* or alternative medicine* or alternative therap* or alternative remed* or complimentary therap* or complimentary remed*).tw.

38. (dilation or dilators or eros therap* or eros clitoral vacuum device or vaginal dilators or vibrator or vibrostimulation or mechanical stretching of tissues or cock ring or electroejaculation or magnetic stimulation or penile implantation or penile prosthesis or penile implant or penile arterialisation or penile vibratory stimulation or prosthesis implant* or prolong ring or muse or venous constriction ring* ${ }^{*}$ or venous litigation or vacuum device* or vacuum constriction device* or vacuum therapy or vacuum pump or penile injection).tw. 39. (kegel exercise* or lubricant* or lubrication or pelvic floor biofeedback or yoga or cream* or foam* or jellies or muscle relaxation or vaginal exercise or physical exercise or olive oil or physiotherapy or weight lifting or physical training or pelvic floor muscle control or self touch or penile rehabilitation or erectile rehabilitation orphysiotherap* or cavernous nerve regeneration, or sonic hedgehog or glial growth factor 2 or GGF2 or magnetic stimulation or cavernous nerve stimulation or low-intensity extracorporeal shockwave therapy or nerve stimulation).tw.

40. (alpha adrenoceptor agonist* or alpha adrenoceptor antagonist or midodrin or vasodilan or isoxsuprine or pentoxifylline or trental or delquamine or pseudoephedrine or desipramine or cyproheptadine or lignocaine).tw.

41. exp Complementary Therapies/

42. exp Sexual Dysfunctions, Psychological/ or exp Sexual Dysfunction, Physiological/

43. exp Erectile Dysfunction/

44. exp Lubrication/

45. exp Coitus/

46. exp Copulation/

47. ((sex* adj3 (dysfunct* or satisf* or problem* or symptom* or arousal* or activit*)) or orgasm or libido or lubricat* or impotence or dyspareunia or hypoactive sexual desire disorder or sexual aversion or coitus or coition).tw.

48. (sexual intercourse or erectile dysfunction or erect* or sexual attraction or copulation or intimacy or procreat* or relations or sex or sex act or sexual congress or sexual relation or arousal or penile erection or vaginal dryness or sexual pain or (pain* adj 3 intercourse) or (sex* adj3 pain*) or vaginismus or (sexual* adj2 wellbeing) or (sexual* adj2 well being) or sexual function* or (pain adj (urogential or vulval or vaginal or perineal or penile or testicular or ileostomy or colostomy or urostomy))).tw.

49. (ejaculation dysfunction or premature ejaculation or early ejaculation or delayed ejaculation or retarded ejaculation or anejaculation or painful ejaculation or retrograde ejaculation or anterograde ejaculation or inhibited ejaculation or erectile difficulty or erectile dysfunction or loss of libido or lack of libido).tw.

50. or/42-49

51. exp Neoplasms/

52. exp Brachytherapy/

53. exp Radiotherapy/

54. exp Mastectomy/

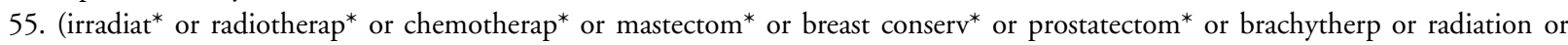
prostectomy or oncology or excisional surgey or hysterectomy or radical surgery or vulvar surgery or cryotherpy or androgen suppression or androgen deprivation or abdominoerineal resection or AP resection or APR or anterior resection or extralevator abdominoperineal excision or ELAP or colostomy or mutilating surgery or vulval reconstruction or vaginal reconstruction or penile reconstruction or breast reconstruction or breast implants).tw.

56. (neoplasm* or cancer* or carcinoma* or neoplasia* or adenocarcinoma* or tumor or malignan* or tumour*).tw.

57. (chemotherap* or mastectomy or breast conserv*or oophorectomy or hormone therapy or hormone treatment).tw.

58. or/ $1-41$

59. or $/ 51-57$

60.50 and 58 and 59

\section{CINAHL (EBSCO)}

S91 S81 AND S90

S90 S82 OR S83 OR S84 OR S85 OR S86 OR S87 OR S88 OR S89

S89 (allocat* random*)

S88 (MH "Quantitative Studies")

S87 (MH "Placebos")

S86 placebo*

S85 (random* allocat*)

Interventions for sexual dysfunction following treatments for cancer in women (Review)

Copyright @ 2016 The Cochrane Collaboration. Published by John Wiley \& Sons, Ltd. 
S84 (MH "Random Assignment")

S83 (Randomi?ed control* trial*) $^{*}$

S82 (singl* blind*) or (doubl* blind*) or (tripl* blind*) or (trebl* blind*) or (trebl* mask* ${ }^{*}$ ) or (tripl* mask* ${ }^{*}$ ) or (doubl* mask ${ }^{*}$ ) or (singl* mask $^{*}$ )

S81 S60 AND S68 AND S79

S80 S60 AND S68 AND S79

S79 S69 OR S70 OR S71 OR S72 OR S73 OR S74 OR S75 OR S76 OR S77 OR S78

Search modes - Boolean/Phrase

Interface - EBSCOhost Research

Databases

S78 (neoplasm* or cancer* or carcinoma* or neoplasia* or adenocarcinoma* or tumor or malignan* or tumour*)

S77 (chemotherap* or mastectomy or breast conserv*or oophorectomy or hormone therapy or hormone treatment)

S76 (irradiat* or radiotherap* or chemotherap* or mastectom* or breast conserv* or prostatectom* or brachytherp or radiation or prostectomy

or oncology or excisional surgey or hysterectomy or radical surgery or vulvar surgery or cryotherpy or androgen suppression or androgen deprivation or abdominoerineal resection or AP resection or APR or anterior resection or extralevator abdominoperineal excision or ELAP or

colostomy or mutilating surgery or vulval reconstruction or vaginal reconstruction or penile reconstruction or breast reconstruction or breast

implants)

S75 (MH "Prostatectomy+")

S74 (MH "Mastectomy+")

S73 (MH "Chemotherapy, Adjuvant")

S72 (MH "Radiotherapy, Adjuvant")

S71 (MH "Radiotherapy, Conformal")

S70 (MH "Brachytherapy")

S69 (MH "Neoplasms+")

S68 S61 OR S62 OR S63 OR S64 OR S65 OR S66 OR S67

S67 (ejaculation dysfunction or premature ejaculation or early ejaculation or delayed ejaculation or retarded ejaculation or anejaculation or

painful ejaculation or retrograde ejaculation or anterograde ejaculation or inhibited ejaculation or erectile difficulty or erectile dysfunction or loss of libido or lack of libido)

S66 (pain N1 (urogential or vulval or vaginal or perineal or penile or testicular or ileostomy or colostomy or urostomy))

S65 ((pain* N3 intercourse) or (sex* N3 pain*) or vaginismus or (sexual* N2 wellbeing) or (sexual* N2 well being) or( sexual function*))

S64 ((sex* N3 (dysfunct* or satisf* or problem* or symptom* or arousal ${ }^{*}$ or activit $\left.{ }^{*}\right)$ ) or orgasm or libido or lubricat* ${ }^{*}$ or impotence or dyspareunia or hypoactive sexual desire disorder or sexual aversion or coitus or coition)

S63 (MH "Coitus")

S62 (MH "Impotence")

S61 (MH "Psychosexual Disorders+")

S60 S1 OR S2 OR S3 OR S4 OR S5 OR S6 OR S7 OR S8 OR S9 OR S10 OR S11 OR S12 OR S13 OR S14 OR S15 OR S16 OR

S17 OR S18 OR S19 OR S20 OR S21 OR

S22 OR S23 OR S24 OR S25 OR S26 OR S 27 OR S28 OR S29 OR S 30 OR S 31 OR S32 OR S 33 OR S 34 OR S 35 OR S 36 OR S37 OR S38 OR S39 OR S40 OR S41 OR S42

OR S43 OR S44 OR S45 OR S46 OR S47 OR S48 OR S49 OR S50 OR S51 OR S52 OR S53 OR S54 OR S55 OR S56 OR S57

OR S58 OR

S59 (MH “Alternative Therapies+")

S58 (alpha adrenoceptor agonist* or alpha adrenoceptor antagonist or midodrin or vasodilan or isoxsuprine or pentoxifylline or trental or

delquamine or pseudoephedrine or desipramine or cyproheptadine or lignocaine)

S57 (kegel exercise* or lubricant* or lubrication or pelvic floor biofeedback or yoga or cream* or foam* or jellies or muscle relaxation or vaginal exercise or physical exercise or olive oil or physiotherapy or weight lifting or physical training or pelvic floor muscle control or self

Interventions for sexual dysfunction following treatments for cancer in women (Review) 
touch or penile rehabilitation or erectile rehabilitation orphysiotherap* or cavernous nerve regeneration, or sonic hedgehog or glial growth

factor 2 or GGF2 or magnetic stimulation or cavernous nerve stimulation or low-intensity extracorporeal shockwave therapy or nerve stimulation)

S56 (dilation or dilators or eros therap* or eros clitoral vacuum device or vaginal dilators or vibrator or vibrostimulation or mechanical stretching of tissues or cock ring or electroejaculation or magnetic stimulation or penile implantation or penile prosthesis or penile implant or

penile arterialisation or penile vibratory stimulation or prosthesis implant* or prolong ring or muse or venous constriction ring* or venous

litigation or vacuum device* or vacuum constriction device* or vacuum therapy or vacuum pump or penile injection)

S55 (arginine or acupuncture or DHEA or dehydroepiandrosterone or damiana or gingko or gingko bilboa or Hypericum or Panax or pausinystalia

or Turnera or turner diffusa or yohimbine or l-arginine, or pycnogeno, or viacreme or viagel or sensual or ginseng or st john's wort or complimentary medicine* or alternative medicine* or alternative therap* or alternative remed* or complimentary therap* or complimentary remed*)

S54 "LY-117018”

S53 "DT56a"

S52 "MF-101"

S51 "ly-156758"

S50 "ly-139481"

S49 (femarelle or toremifene or serm or bazedoxifene)

S48 (evista or dimethylamine or novaldex or tomaxithen or soltamox or zitazonium or menerba)

S47 (clomiph or raloxifene or tamoxifen or toremife or clomid or clomifene or clomifert or serophene or raloxifene or keoxifene)

S46 "selective oestrogen receptor modulators"

S45 (oestradiol or Dienestrol or estriol or estetrol)

S44 (estrone or ethinyl estradiol or mestranol or quinestrol)

S43 (estradiol or oestrogenic steroids)

S42 (oestrogen or epimestrol)

S41 topical oestrogens

S40 estrogen cream

S39 vaginal oestrogen ring

S38 vaginal oestrogen ring

S37 estradiol ring

S36 estrogen replacement

S35 estrogen therapy

S34 estrogen ring

S33 conjugated estrogens

S32 (estriol or femprox)

S31 (MH “Apomorphine")

S30 (MH "Aromatase Inhibitors+")

S29 (Phosphodiesterase Type 5 or PDE5i or adcirca or cialis or levitra or Viagra or vardenafil or sildenafil or tadalafil)

S28 Vasodilator Agents

S27 (MH "Phosphodiesterase Inhibitors+")

S26 (psychological intervention* or psycholog* or behavior* or behaviour* or cognitive behav* therapy or cognitive therap* or psychotherap*

or counsel* or sex therap* or patient educat* or behav* therapy or CBT or couple therap* or couple intervention or couple-based or intimacy

enhancing or mindfulness or patient education or psychological techniques or psychosexual or psychotherapy or psycho-somatic or Rational emotive

therap* ${ }^{*}$ restoring intimacy or relaxation or relaxation therap* ${ }^{*}$ or relaxation training or psycho-social or Sensual, body image or sexcounsel*

or sexual communication or sexual rehabilitation or sexuality or self-esteem or self concept or stress or psycho-education or sexual life

Interventions for sexual dysfunction following treatments for cancer in women (Review) 
reframing or coping skills or motivational counselling or anxiety management training or marital therap* or group therap* or focal therap* or

psychodynamic therap* or supportive therap* or psychoanalyses or interpersonal therap* or individual therap* or problem solving or emotional

support or hypnosis or bibliotherap* or sexual skills therap* or systematic desensitization or hypnotherapy* or radical emotive therap* or

psychodynamic or psychoeducational)

S25 (MH "Cognitive Therapy")

S24 (MH "Sexual Counseling”)

S23 (MH "Counseling+")

S22 (MH "Psychotherapy+")

S21 (MH "Psychological Techniques+")

S20 (MH "Patient Education+")

S19 (MH “St. John's Wort”)

S18 (MH "Ginseng”)

S17 (MH "Ginkgo Biloba")

S16 (MH "Vaginal Creams, Foams and Jellies")

S15 (MH "Estrogens, Conjugated")

S14 (MH "Estriol")

S13 (vaginal dilator* or arginine or android or methyl testosterone or testosterone cream or vaginal lubricant or vaginal estradiol ring or

vaginal estradiol ring or vaginal estrogen ring or vaginal oestrogen ring or topical estrogen cream or vaginal cream or estrogen replacement of

ERT or estrogen replacement or aromatase inhibitors)

S12 (MH “Aromatase Inhibitors+")

S11 (testosterone replacement or testosterone or venous constriction rings or vacuum device* or vacuum erect* or penile implant* or penile

arterialisation or venous litigation or prosthesis implant* or vacuum constriction device or vacuum therapy* or vibrat* or vibrostimulation or

electroejaculation or prolong ring*)

S10 (MH "Prostheses and Implants+")

S9 (MH "Penile Prosthesis")

S8 (MH "Testosterone+")

S7 (alprostadil or androgel or Apomorphine or britaject or aromatase inhibitors or agonist of melancortin receptor or Adcirca or alpha adrenoceptor agonist or alpha-2 adrenoceptor agonist or androgel or arginine or botox or botulinum toxin or bromocriptine or cialis or

dopaminergic agents or caverject or clomipramine or cyproheptadine or clonidine or delquamine or edex or hormone therapy or Isoxsuprine or

intracavernosal vasodilators or levitra or Lignocaine or l-arginine or lodenfil or Methitest or methyl testosterone or midodrin or mianserin or

moclobemide or mirtazapine or mianserin or moclobemide or ortho-gynest or ovestin or papaverine or papaverine-phentolamine or phentolamine or

parlodel or phentolamine or potassium channel openers or progestational agents or premarin or prempro or prostins or Prostaglandins or

prostaglandin E1 or pentoxifylline or potassium channels or Phosphodiesterase Type 5 or PDE5i or penile suppository or reboxetine or sildenafil

or tadalafil or tampovagan or topical or topical cream or vagifem or vaginal cream or vaginal lubricant or vaginal or viagra or vasomax or Viagel

or vardenafil or vasodilator or virilon or vasoactive or staxyn or topical estrogen cream or trental or vasodilan or viridal or yohimbine or android or androgen therapy or testosterone or testosterone cream or testosterone gel or testred)

S6 (MH "Apomorphine")

S5 (MH "Yohimbine")

S4 (MH "Yohimbine")

Interventions for sexual dysfunction following treatments for cancer in women (Review)

Copyright $\Subset 2016$ The Cochrane Collaboration. Published by John Wiley \& Sons, Ltd. 
S3 (MH "Yohimbine")

S2 (MH "Phentolamine")

S1 (MH "Papaverine")

\section{WHAT'S NEW}

Last assessed as up-to-date: 8 September 2015.

\begin{tabular}{|c|c|c|}
\hline Date & Event & Description \\
\hline 5 May 2015 & New search has been performed & $\begin{array}{l}\text { We have updated this review to include the results of a } \\
\text { new search and added 'Risk of bias' tables }\end{array}$ \\
\hline 20 February 2015 & New citation required and conclusions have changed & $\begin{array}{l}\text { We have split the original review on interventions for } \\
\text { sexual dysfunction following treatments for cancer into } \\
\text { two reviews; the findings on interventions for sexual } \\
\text { dysfunction for men following cancer treatments will } \\
\text { now be reported in a separate review. We changed the } \\
\text { inclusion criteria to only include interventions specifi- } \\
\text { cally developed to treat sexual dysfunction; this led to } \\
\text { the exclusion of a study previously included because it } \\
\text { was a preventative study. We have added } 11 \text { new trials } \\
\text { and the conclusions have changed in the light of this } \\
\text { new evidence }\end{array}$ \\
\hline
\end{tabular}

\section{H I S T O R Y}

Protocol first published: Issue 4, 2005

Review first published: Issue 4, 2007

\begin{tabular}{|c|c|c|}
\hline Date & Event & Description \\
\hline 8 February 2011 & Amended & Contact details updated. \\
\hline 24 September 2010 & Amended & Contact details updated. \\
\hline 9 November 2009 & Amended & Contact details updated. \\
\hline 13 May 2009 & Amended & Contact details updated. \\
\hline 30 October 2008 & Amended & Converted to new review format. \\
\hline
\end{tabular}




\section{CONTRIBUTIONSOFAUTHORS}

In the 2015 update: BC carried out the searching and screening, reviewed documents, assessed quality and extracted data, analysed data and first drafted the review. LJ advised on methods, screened, checked data extraction and commented on the draft. Input was given to the protocol and final review. VV advised on statistics, checked the analysis and commented on the draft. AT contributed to the original idea, advised on methods and commented on the draft. MK contributed to the original idea, advised on methods and contributed to the draft. All authors read the final draft. BC is responsible for further updates.

\section{DECLARATIONSOF INTEREST}

$\mathrm{BC}$ has no relevant conflicts of interest to declare. VV has no relevant conflicts of interest to declare. AT has no relevant conflicts of interest to declare. MK and LJ are grant holders on a ongoing funded NIHR pilot randomised trial of a stepped care intervention for women with sexual dysfunction after treatment for gynaecological cancer.

\section{SOURCES OF SUPPORT}

\section{Internal sources}

- Marie Curie Cancer Care supported the review authors BC, LJ and VV, UK.

\section{External sources}

- No sources of support supplied

\section{DIFFERENCESBETWEEN PROTOCOLANDREVIEW}

This review is an update of an earlier review that included interventions for sexual dysfunction following treatments for cancer in both women and men (Miles 2007). This review only includes interventions for treating sexual dysfunction following treatments for cancer in women. All sections have been revised to reflect the patient group. The inclusion criteria for sexual dysfunction have been amended, to make it clear what is eligible. More detail is also provided on outcomes of interest.

\section{INDEX TERMS}

\section{Medical Subject Headings (MeSH)}

Administration, Intravaginal; Erectile Dysfunction [therapy]; Neoplasms [ ${ }^{*}$ therapy]; Phosphodiesterase Inhibitors [therapeutic use]; Prostatic Neoplasms [therapy]; Psychotherapy; Randomized Controlled Trials as Topic; Sexual Dysfunction, Physiological [etiology; *therapy]; Sexual Dysfunctions, Psychological [*therapy]; Uterine Cervical Neoplasms [therapy]; Vacuum; Vaginal Creams, Foams, and Jellies [administration $\&$ dosage] 


\section{MeSH check words}

Adult; Female; Humans; Male

Copyright $\odot 2016$ The Cochrane Collaboration. Published by John Wiley \& Sons, Ltd. 